\title{
Location Corrections through Differential Networks (LOCD-IN)
}

A thesis presented to

the faculty of

the Russ College of Engineering and Technology of Ohio University

In partial fulfillment

of the requirements for the degree

Master of Science

Russell V. Gilabert

December 2018

(c) 2018 Russell V. Gilabert. All Rights Reserved. 
This thesis titled

Location Corrections through Differential Networks (LOCD-IN)

by

\section{RUSSELL V. GILABERT}

has been approved for

the School of Electrical Engineering and Computer Science and the Russ College of Engineering and Technology by

Maarten Uijt de Haag

Edmund K. Cheng Professor of Electrical Engineering and Computer Science

Dennis Irwin

Dean, Russ College of Engineering and Technology 


\begin{abstract}
GILABERT, RUSSELL V., M.S., December 2018, Electrical Engineering $\underline{\text { Location Corrections through Differential Networks (LOCD-IN) }}$

Director of Thesis: Maarten Uijt de Haag

Many mobile devices (phones, tablets, smartwatches, etc.) have incorporated embedded GNSS receivers into their designs allowing for wide-spread on-demand positioning. These receivers are typically less capable than dedicated receivers and can have an error of $8-20 \mathrm{~m}$. However, future application, such as UAS package delivery, will require higher accuracy positioning. Recently, the raw GPS measurements from these receivers have been made accessible to developers on select mobile devices. This allows GPS augmentation techniques usually reserved for expensive precision-grade receivers to be applied to these low cost embedded receivers. This thesis will explore the effects of various GPS augmentation techniques on these receivers.
\end{abstract}




\section{ACKNOWLEDGMENTS}

I would like to thank my academic advisor, Maarten Uijt de Haag, for providing guidance and opportunities in both my academic and professional careers. I would also like to thank my office mates, Akshay Bharadwaj, Joel Huff, and Adam Shultz as well as the rest of the Avionics Engineering Center at Ohio University. I could not have asked for a better advisor or educational experience.

Next, I would like to thank Evan Dill and the Safety-Critical Avionics Systems Branch at NASA Langley Research Center for their constant support. I have learned an incredible amount and have made countless connections during my time there.

Lastly, I would like to thank Kyle Edgerton, Grayson Honan, Nathan Lowe, Robert Smyth, and Seth Young for their contributions to this work.

Thank you. 
TABLE OF CONTENTS

Page

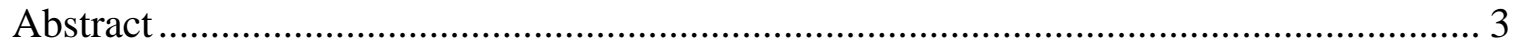

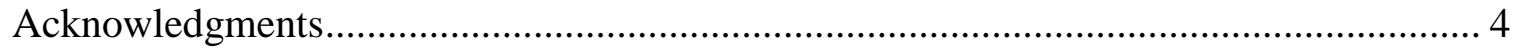

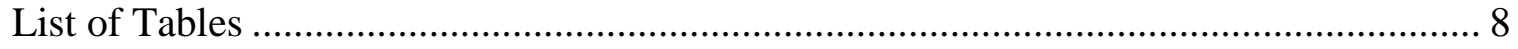

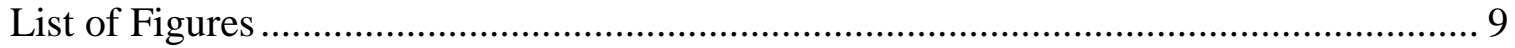

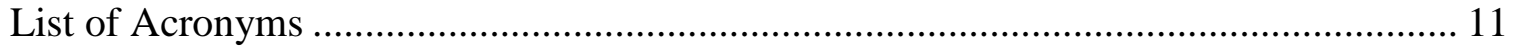

Chapter 1: Introduction ......................................................................................... 13

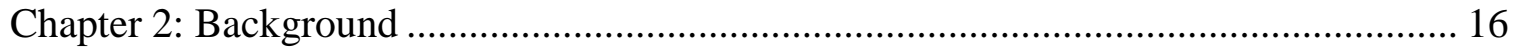

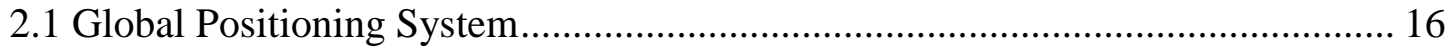

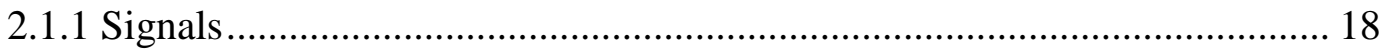

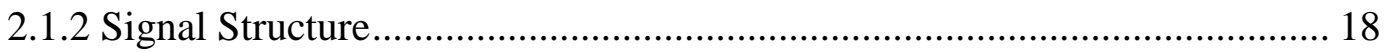

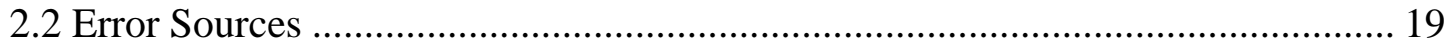

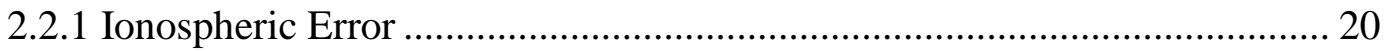

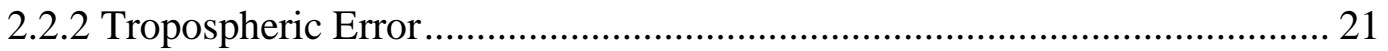

2.2.3 Clock and Ephemeris Errors .................................................................. 22

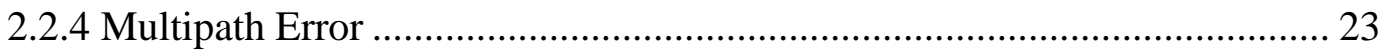

2.2.5 Spatial and Temporal Error Correlation …………................................... 23

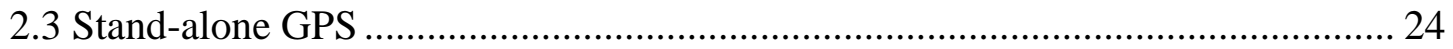

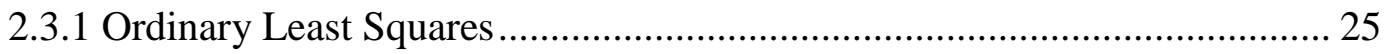

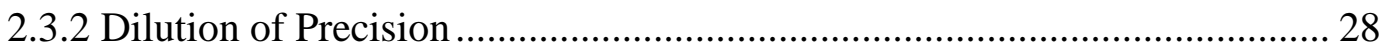

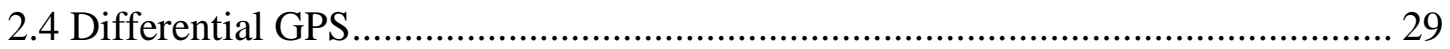

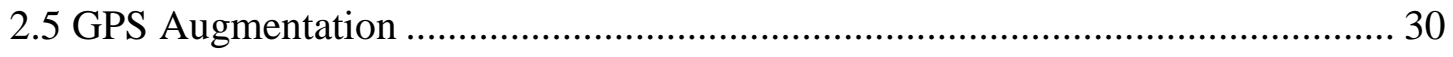

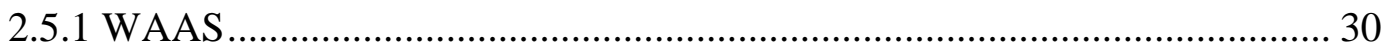

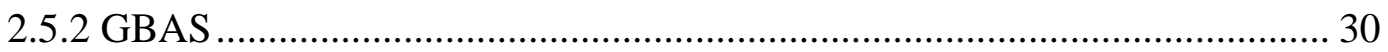

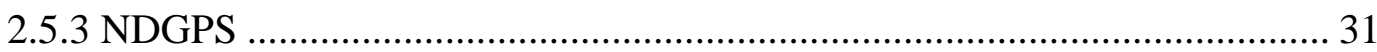

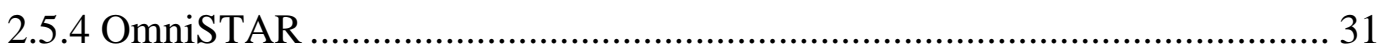

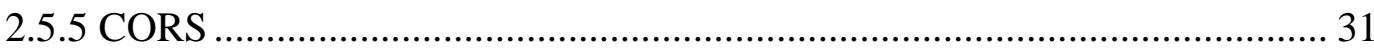

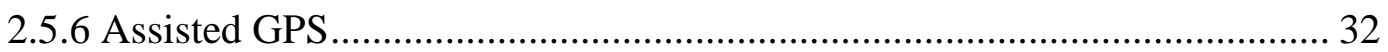

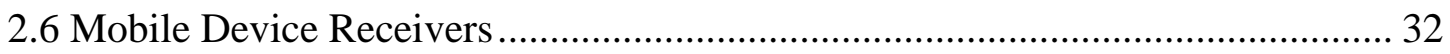

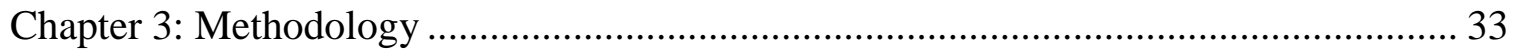

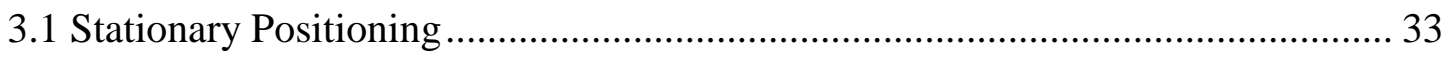


3.1.1 Base Station Correction Generation.......................................................... 34

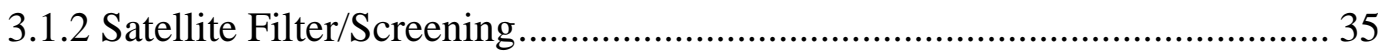

3.1.3 Base Station Correction Application …................................................... 35

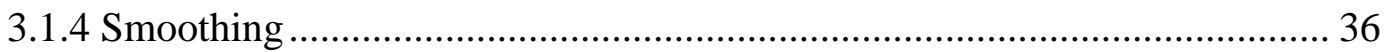

3.1.5 Code Minus Carrier Analysis.................................................................. 36

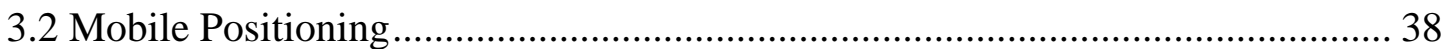

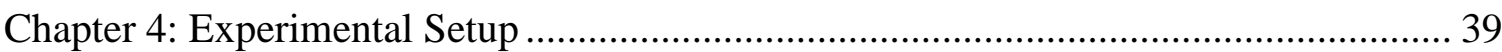

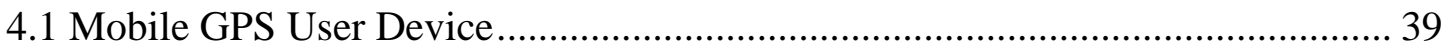

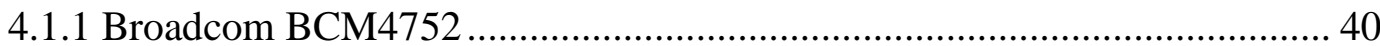

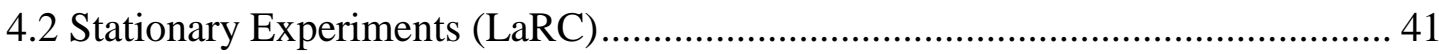

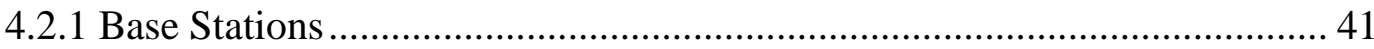

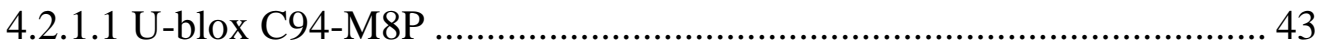

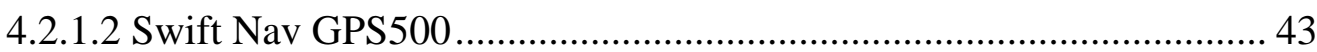

4.2.1.3 Raspberry Pi 3 B ..................................................................... 44

4.2.1.4 Ubiquity Nanostation LocoM5 ...................................................... 45

4.2.1.5 Ubiquity Rocket M5 ................................................................. 46

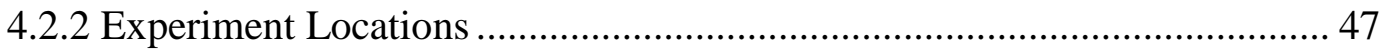

4.2.3 Experiment Procedure ......................................................................... 53

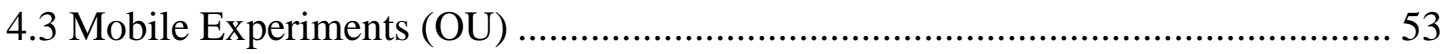

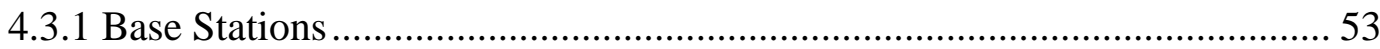

4.3.1.1 NovAtel GPS-702-GGL............................................................. 53

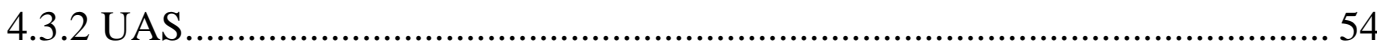

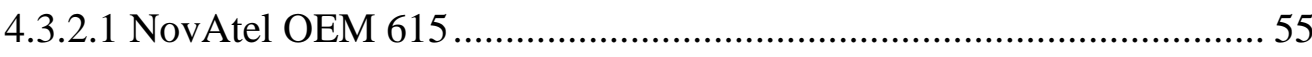

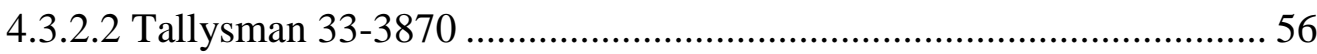

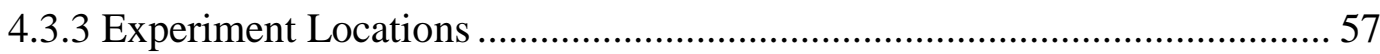

4.3.4 Experimental Procedure ..................................................................... 60

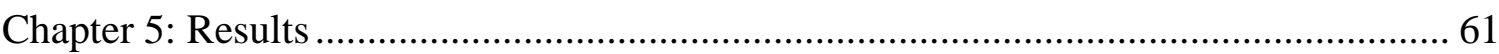

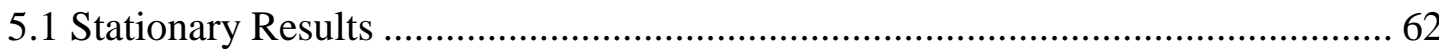

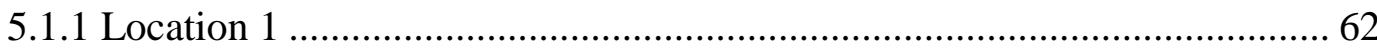

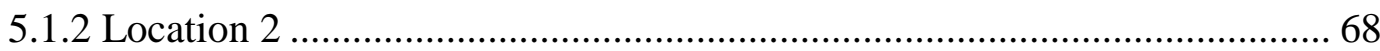

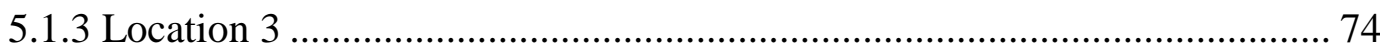

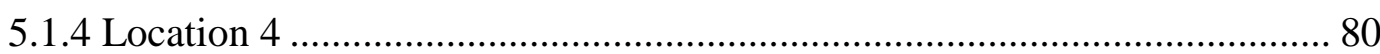

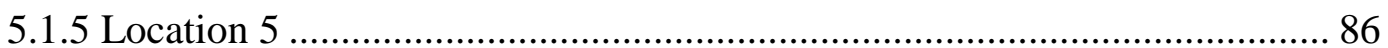




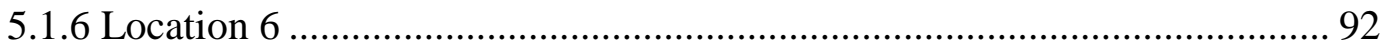

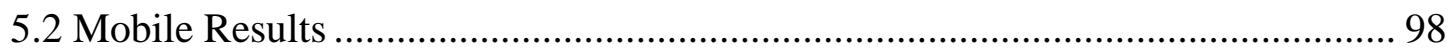

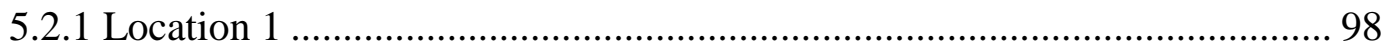

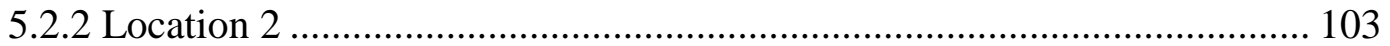

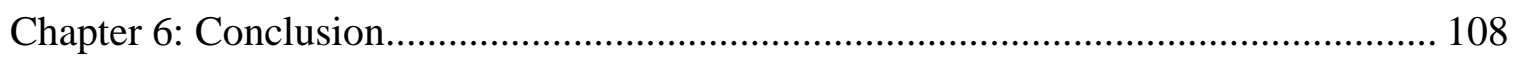

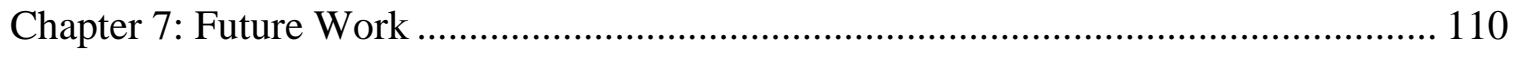

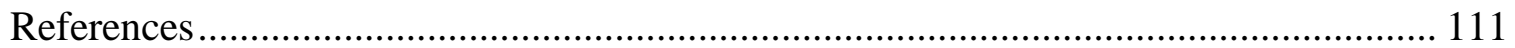




\section{LIST OF TABLES}

Page

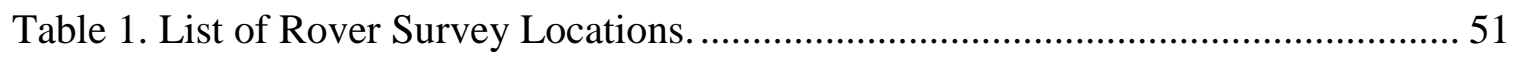

Table 2. List of Rover Survey Locations.................................................................... 59

Table 3. Average Lateral Error and Standard Deviation of Solutions for Location 1...... 64

Table 4. Base Station Correction Results for Location 1............................................... 66

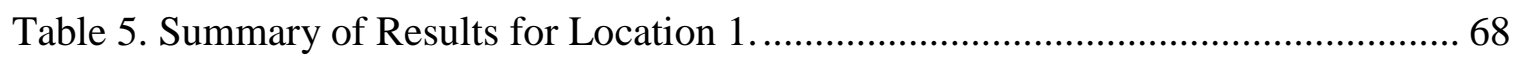

Table 6. Average Lateral Error and Standard Deviation of Solutions for Location 2...... 70

Table 7. Base Station Correction Results for Location 2............................................... 72

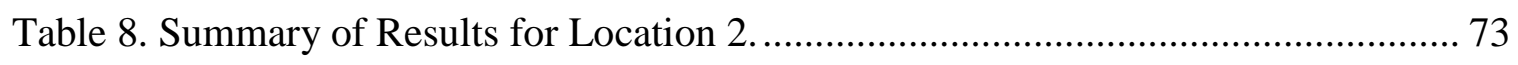

Table 9. Average Lateral Error and Standard Deviation of Solutions for Location 3...... 76

Table 10. Base Station Correction Results for Location 3............................................ 78

Table 11. Summary of Results for Location 3 ………........................................... 79

Table 12. Average Lateral Error and Standard Deviation of Solutions for Location 4.... 82

Table 13. Base Station Correction Results for Location 4.......................................... 84

Table 14. Summary of Results for Location 4........................................................ 86

Table 15. Average Lateral Error and Standard Deviation of Solutions for Location 5... 88

Table 16. Base Station Correction Results for Location 5........................................... 90

Table 17. Summary of Results for Location 5 ....................................................... 91

Table 18. Average Lateral Error and Standard Deviation of Solutions for Location 6... 94

Table 19. Base Station Correction Results for Location 6............................................. 96

Table 20. Summary of Results for Location 6........................................................... 98

Table 21. Average Lateral Error and Standard Deviation of Solutions for Location 1. 100

Table 22. Base Station Correction Results for Location 1........................................... 101

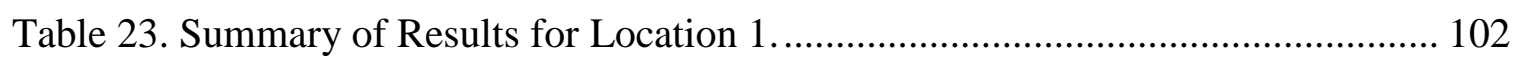

Table 24. Average Lateral Error and Standard Deviation of Solutions for Location 2. 105

Table 25. Base Station Correction Results for Location 2........................................... 106

Table 26. Summary of Results for Location 2 …………............................................ 107

Table 27. Average Lateral Error Improvements........................................................... 109 


\section{LIST OF FIGURES}

Page

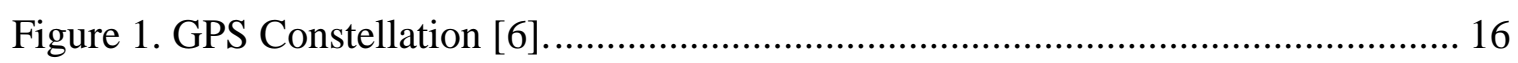

Figure 2. Graphic Depicting Spatially Correlated Errors. ……………............................ 24

Figure 3. Graphic Depicting Spatially Decorrelated Errors.............................................. 24

Figure 4. Block Diagram of Processing.................................................................... 34

Figure 5. Google Nexus 9 [17] .............................................................................. 40

Figure 6. Plot of Rover CMC Residuals. .................................................................. 41

Figure 7. Base Station Components...................................................................... 42

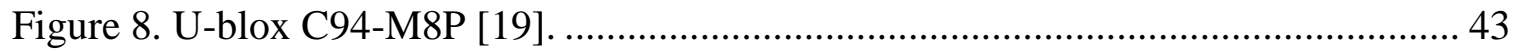

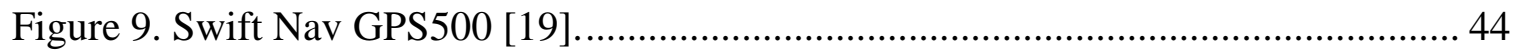

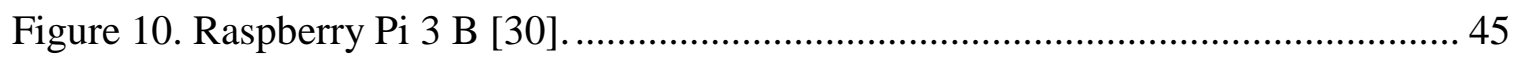

Figure 11. Ubiquity Nanostation LocoM5 [32] ....................................................... 46

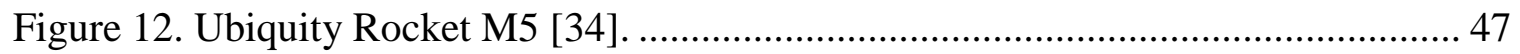

Figure 13. Map of Base Station and Rover Survey Locations......................................... 48

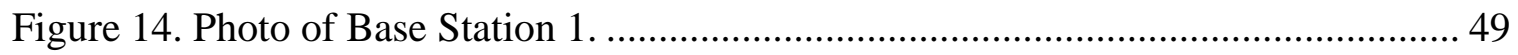

Figure 15. Photo of Base Station 2. ......................................................................... 49

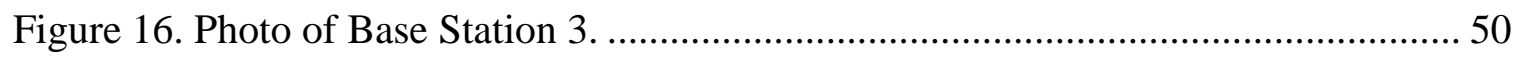

Figure 17. Photo of Location 4 (Urban) ................................................................... 51

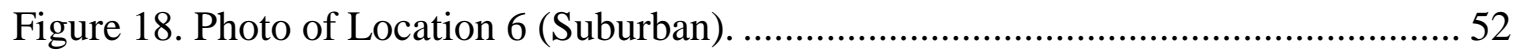

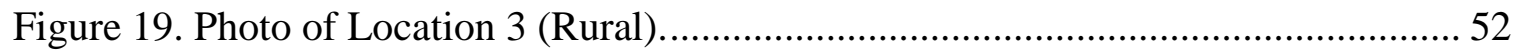

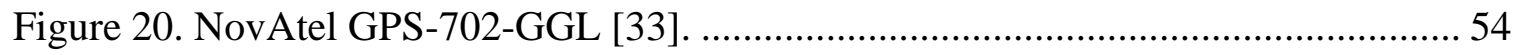

Figure 21. Photo of UAS Showing Android Tablet and GPS Antenna ............................. 55

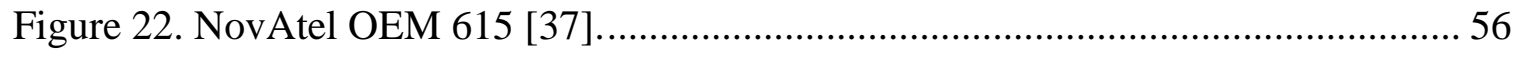

Figure 23. Tallysman 33-3870 [38]...................................................................... 56

Figure 24. Map of Base Station and Rover Survey Locations......................................... 57

Figure 25. Photo of Base Station Antenna................................................................ 58

Figure 26. Photo of Location 1 (Urban)................................................................... 59

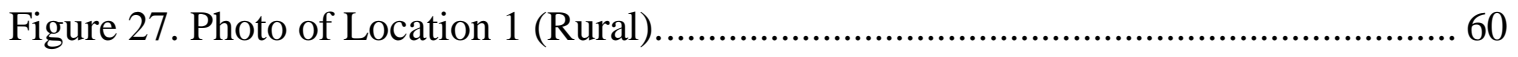

Figure 28. North and East DOP Values for Location 1................................................ 62

Figure 29. Graphs Depicting Solutions and Skyplots for Location 1.............................. 63

Figure 30. Solutions Produced Using Corrections for Location 1................................... 65 


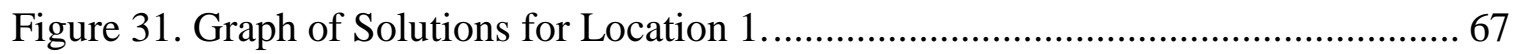

Figure 32. Graphs Depicting Solutions and Skyplots for Location 2............................ 69

Figure 33. Solutions Produced Using Corrections for Location 2.................................. 71

Figure 34. Graph of Solutions for Location 2...................................................... 73

Figure 35. Graphs Depicting Solutions and Skyplots for Location 3............................. 75

Figure 36. Solutions Produced Using Corrections for Location 3................................... 77

Figure 37. Graph of Solutions for Location 3......................................................... 79

Figure 38. Graphs Depicting Solutions and Skyplots for Location 4............................. 81

Figure 39. Solutions Produced Using Corrections for Location 4 ................................... 83

Figure 40. Graph of Solutions for Location 4.......................................................... 85

Figure 41. Graphs Depicting Solutions and Skyplots for Location 5 ............................. 87

Figure 42. Solutions Produced Using Corrections for Location 5................................... 89

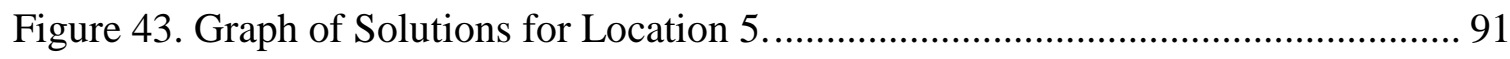

Figure 44. Graphs Depicting Solutions and Skyplots for Location 6............................. 93

Figure 45. Solutions Produced Using Corrections for Location 6................................... 95

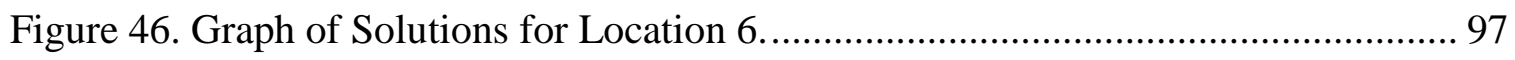

Figure 47. Graphs Depicting Solutions and Skyplots for Location 1............................. 99

Figure 48. Solutions Produced Using Corrections for Location 1................................. 100

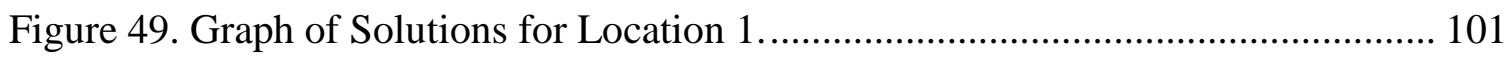

Figure 50. Graphs Depicting Solutions and Skyplots for Location 2.......................... 104

Figure 51. Solutions Produced Using Corrections Stations for Location 2................... 105

Figure 52. Graph of Solutions for Location 2 …………........................................ 106 


\section{LIST OF ACRONYMS}

\begin{tabular}{|c|c|}
\hline UAS & Unmanned Aircraft System \\
\hline GPS & Global Positioning System \\
\hline OS & Operating System \\
\hline DGPS & Differential GPS \\
\hline GNSS & Global Navigation Satellite System \\
\hline MEO & Medium Earth Orbit \\
\hline NDS & Nuclear Detonation Detection System \\
\hline RAP & Reserve Auxiliary Package \\
\hline DOP & Dilution of Precision \\
\hline RTCM & Radio Technical Commission for Maritime Services \\
\hline WAAS & Wide Area Augmentation System \\
\hline SBAS & Space-Based Augmentation System \\
\hline GBAS & Ground-Based Augmentation System \\
\hline LAAS & Local Area Augmentation System \\
\hline VHF & Very High Frequency \\
\hline CORS & Continuously Operating Reference Station \\
\hline NGS & National Geodetic Survey \\
\hline OPUS & Online Positioning User Service \\
\hline AGPS & Assisted GPS \\
\hline SWAP-C & Size, Weight, Power, and Cost \\
\hline LaRC & Langley Research Center \\
\hline
\end{tabular}


OU Ohio University

BLE Bluetooth Low Energy

CSRS Canadian Spatial Reference System 


\section{CHAPTER 1: INTRODUCTION}

In recent years, there has been a large increase in both the production and use of Unmanned Aircraft Systems (UAS) [1]. This growth has led to improvements to UAS design and technology and has created many new UAS applications. Proposed applications for UASs range from remote monitoring, search and rescue, to package delivery with each application requiring the UAS to be equipped with hardware and software tailored for the specific task. One popular application is the use of UAS to deliver packages with many large companies having stated plans to develop this technology [1].

For a UAS to deliver a package, it must know exactly where it must be delivered. The most convenient solution to this problem could be to have the recipient use their mobile phone's Global Positioning System (GPS) receiver to survey the desired location of package delivery. However, the accuracy of these receivers is relatively low [2]. In a study evaluating the performance of several mobile device GPS receivers, [2] found that the error associated with these systems can be as high as $16 \mathrm{~m}$ during typical operation. If unaided, the use of mobile phone GPS receivers for designation of a package delivery point could result in inaccurate survey of the recipient's desired delivery location. Upon arrival, the package may be left in an undesirable location due to this inaccuracy alone.

Typically, the GPS receiver inside of a mobile phone calculates a position and passes this directly to the phone's Operating System (OS) where it can be used by the desired application [3]. In this method the raw GPS data, particularly the code and carrier measurements, are not available for external processing. Recently, Android OS, a popular mobile device operating system for mobile devices, has implemented developer support 
for the raw GPS measurements produced by the onboard GPS receivers [3]. This allows developers to implement a variety of well-established GPS improvement techniques to these devices. For UAS package delivery, one particularly advantageous technique could be the use of Differential GPS (DGPS).

This technique compensates for the errors of one receiver using corrections from another, eliminating common errors between the two. This technique is typically implemented using expensive, high precision equipment. However, [4] shows that this technique can be applied to relatively inexpensive hardware and still have a significant impact. This technique could be particularly useful for reducing the error in low quality GPS receivers in mobile devices as a single base station can generate corrections appropriate for any number of rovers within an area where the errors correlate.

Currently, there is not an established method of accurately designating a location for UAS package delivery on a mass scale. However, recent improvements to both the hardware and software of mobile devices have allowed for the implementation of standard error mitigation techniques to mobile phone GPS receivers not previously possible. The use of a DGPS implementation may be a valid technique for improving the accuracy of mobile phone GPS receiver on a large scale allowing this to be a viable method for UAS package delivery location designation. This thesis will evaluate a set of experiments to assess the impact of DGPS as well as other techniques on a mobile GPS receiver.

The brief history of GPS will be discussed along with the current error sources, mitigation, and augmentation techniques in Chapter 2. In Chapter 3, the GPS augmentation methodology will be addressed in detail with the supporting mathematics. Next, the 
experimental setup will be described in Chapter 4 outlining the equipment used, the various test environments, and the test procedures. This Chapter is followed by the presentation and discussion of the results in Chapter 5. Lastly, the conclusion and finally the future work will be presented in Chapters 6 and 7.

Part of this work was presented at the ION/IEEE PLANS 2018 conference [5]. 


\section{CHAPTER 2: BACKGROUND}

This chapter addresses a brief overview of GPS for civilian applications and the various augmentation techniques that are employed to enhance its performance. Furthermore, the proliferation of small, low cost GPS receivers in mobile devices is addressed. It is shown that the success of these techniques can be applied to today's generation of low-cost GPS receivers found in many mobile devices allowing for additional applications of these devices.

\subsection{Global Positioning System}

The GPS is the first operational Global Navigation Satellite System (GNSS) and the successor of several United States navigation projects. The baseline configuration consists of 24 satellites each in a nearly circular Medium Earth Orbit (MEO) at an approximate altitude of $20,200 \mathrm{~km}$. The satellites are organized on 6 evenly spaced orbital planes with a 55-degree inclination angle. This configuration ensures that at least 4 satellites are visible at virtually any point on earth. The GPS constellation currently consists of 31 operational satellites with additional satellites deployed within the 6 existing planes [6]. The GPS constellation is depicted in Figure 1.

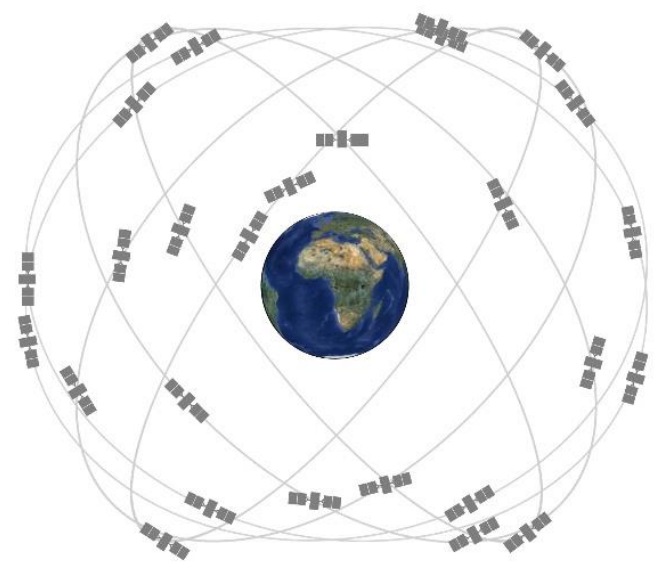

Figure 1. GPS Constellation [7]. 
At a high level, GPS receiver is able to determine a user's position on Earth using trilateration or multi-lateration when additional satellites are available. Assuming knowledge of the position of and distance to 3 satellites, 2 user position solutions can be determined, 1 on Earth, and another in space. In practice, determining the position of the user is somewhat more complicated.

While GPS satellites broadcasts multiple navigation signals for various users, the general concept is the same. Each satellite broadcasts its orbital parameters and encodes the precise transmission time on a signal. The receiver then takes measurements of the broadcast signals and computes the transit time of the signal and, thus, the distance to the satellite. However, while the satellites contain precise atomic clocks that are highly synchronized with one another, the clock of the user's GPS receiver is generally of much lesser quality and not synchronized with the GPS clocks. When measurements are made with reference to this biased receiver clock, the error and drift in the receiver clock results in a common bias in the distance from each observable satellite. These distance measurements are referred to as pseudoranges, $P R_{i}$, and the bias introduced by the receiver clock known as the receiver clock bias, $C_{b}$. The presence of this fourth unknown (3 position coordinates and the clock bias), requires a measurement to an additional satellite, i.e., a minimum of 4 satellite pseudoranges is required for a 3D position solution. The quality of pseudoranges, and subsequently the receiver's computed solution, is also affected by various errors sources including atmospheric, environmental, and systemic factors. These sources will be addressed later in this chapter. 


\subsubsection{Signals}

GPS satellites broadcast signals on several frequencies in the L-band. These are typically referred to as L1, L2, L3, L4, and L5. While the type of navigation signals and capability vary by satellite block generation, all satellites broadcast the Coarse/Acquisition, C/A, code on L1 and the encrypted $\mathrm{P}(\mathrm{Y})$ code on L1 and L2. As part of the GPS modernization program, additional civilian navigation signals are being added to the more recent GPS satellites including signals on L1, L2 and L5, referred to as L1C, L2C, and L5, respectively [6]. After completion of the GPS modernization program, 4 GPS signals will be available for civil users.

Military navigation messages are broadcast on $\mathrm{L} 1$ and $\mathrm{L} 2$ known as $\mathrm{P}(\mathrm{Y})$ and $\mathrm{M}$ codes. Signals are also broadcast on L3 and L4 by classified payloads. The signal on L3 is associated with the Nuclear Detonation Detection System (NDS) and the signal on L4 is associated with a payload known as the Reserve Auxiliary Package (RAP) [6].

Currently, the only fully operational civilian message is the L1 C/A code message, sometimes referred to as the legacy civil signal, with support for the newer signals, L1C, L2C, and L5 slowly increasing as newer satellites with these signal capabilities are launched [8]. Currently, many lower cost GPS receivers are only capable of using the L1 C/A code while more expensive hardware can utilize the remaining signals as well.

\subsubsection{Signal Structure}

While there are multiple signals broadcast at various frequencies in the L-Band, this section will only cover the L1 C/A signal structure as it is the only fully operational civilian GPS signal and is the only signal currently relevant to low SWAP-C embedded 
GPS receivers. The GPS satellites broadcast a pseudorandom BPSK signal (pseudorandom noise or PRN) on L1 C/A. The signal for each satellite is a unique sequence of 1023 bits referred to as chips. The chip width is about $300 \mathrm{~m}$ and has a chipping rate of $1.023 \mathrm{MHz}$. This signal is referred to as the course acquisition signal because its original purpose was to provide course alignment to the satellites before acquisition to the shorter, more precise $\mathrm{P}(\mathrm{Y})$ code. In order to produce a pseudorange measurement, a GPS receiver correlates a local copy of a satellite's PRN code, with the received signal to determine how long it took (time-of-arrival - time-of-transmission) for the signal to travel from the satellite to the user receiver. The pseudorange is then obtained by multiplying the time measurement by the speed of light [6].

The L1 C/A code is modulated on a $1575.42 \mathrm{MHz}$ carrier which, while not designed to be used for navigation, has been leveraged to provide more accurate receiver position solutions. The wavelength of this signal is $19 \mathrm{~cm}$ compared to the $300 \mathrm{~m}$ of one PRN code period. Accurate tracking of the carrier can be used to produce carrier-phase measurements, $\Phi_{i}$. However, due to the fact that the carrier-phase measurements measure the number of acquired Doppler cycles since acquisition of the signal, the carrier-phase measurement equals the range plus an unknown integer number of carrier-cycles $\left(N_{i} \lambda\right)$, also known as the carrier-phase ambiguity.

\subsection{Error Sources}

Both the pseudorange and carrier-phase measurements contain a variety of error sources. These error sources are described in models shown in Equations (1) and (2) 


$$
\begin{aligned}
& P R_{i}=R_{i}+\varepsilon_{\text {iono }}+\varepsilon_{\text {tropo }}+\varepsilon_{m p, p r}+\varepsilon_{\text {noise }, p r}+\varepsilon_{s v}+c \delta t_{u} \\
& \Phi_{i}=R_{i}+N_{i} \lambda-\varepsilon_{\text {iono }}+\varepsilon_{\text {tropo }}+\varepsilon_{m p, c p}+\varepsilon_{\text {noise }, c p}+\varepsilon_{s v}+c \delta t_{u}
\end{aligned}
$$

where $R_{i}$ is the true range from user receiver to satellite ' $i$ ',

$\varepsilon_{i o n o}$ is the error attributed to the signal delay in the ionosphere,

$\varepsilon_{\text {tropo }}$ is the error attributed to the signal delay in the troposphere,

$\varepsilon_{m p, p r}$ is the error attributed to multipath on the pseudorange,

$\varepsilon_{m p, c p}$ is the error attributed to multipath on the carrier phase,

$\varepsilon_{n o i s e, p r}$ is the error attributed to the receiver noise on the pseudorange,

$\varepsilon_{\text {noise,cp }}$ is the error attributed to the receiver noise on the carrier phase,

$\varepsilon_{s v}$ are the satellite clock and orbit errors,

$\delta t_{u}$ is the clock offset between the user clock and GPS time.

The following sub-sections will shortly discuss these error sources.

\subsubsection{Ionospheric Error}

The largest error source since Selective Availability was turned off, is the error introduced as the signal travels through the ionosphere. This area of the atmosphere contains ionized gases caused by sun's radiation that act to perturb the traveling signal. The intensity of the ionosphere fluctuates with solar activity and varies greatly between day and night. The pseudorange error introduced by the ionosphere can range from 2-10 meters in the zenith direction and higher at lower elevations resulting in an additive effect on the code, and an equal and opposite effect on the carrier as shown in Equations (1) and (2). In 
the case of a single frequency user, part of this error can be modeled and removed from the pseudorange measurements. However, in the case of a multi-frequency user, the error can be virtually eliminated. The broadcast model, sometimes referred to as the Klobuchar model, can be used to model and mitigate the receiver error at the user. It is described in Equation (3) and relies on parameters that are part of the ephemerides broadcast by the GPS satellites on L1 [6]

$$
\text { Ion }_{\text {L1 Delay }}=\left\{\begin{array}{cc}
A_{1}+A_{2} \cos \left(\frac{2 \pi\left(t-A_{3}\right)}{A_{4}}\right), & \text { if }\left|t-A_{3}\right|<A_{4} / 4 \\
A_{1} & \text { otherwise }
\end{array}\right.
$$

where $A_{1}$ is the night value of the zenith delay,

$A_{2}$ is the amplitude of the cosine function of the day value,

$A_{3}$ is the phase corresponding to the peak cosine function,

$A_{4}$ is the period of the cosine function.

\subsubsection{Tropospheric Error}

As the signal travels through the troposphere, the region of the atmosphere containing dry gases and water vapor below $16 \mathrm{~km}$, additional error is introduced. This occurs due to diffraction of the signal and results in additional delay. The overall pseudorange error introduced ranges from approximately 2.3-2.5 meters in the zenith direction and higher at lower elevations. This error can, in part, be removed by implementing various tropospheric models. One such model, the Saastamoinen model 
shown in Equations (4) and (5), models the wet and dry portions of the tropospheric delay separately [6]

$$
\begin{gathered}
\operatorname{Tr}_{\text {Dry L1 Delay }}=0.002277(1+0.0026 \cos 2 \phi+0.00028 H) P_{0} \\
\operatorname{Tr}_{\text {Wet L1 Delay }}=0.002277\left(\frac{1255}{T_{0}}+0.05\right) e_{0}
\end{gathered}
$$

where $T_{0}$ is the temperature,

$P_{0}$ is the total pressure,

$e_{0}$ is the partial pressure,

$\phi$ is the latitude,

$H$ is the orthometric height.

\subsubsection{Clock and Ephemeris Errors}

Additional errors can be introduced by the parameters uploaded from the ground segment. Over time, the orbits of the GPS satellites, as well as the clocks within them, begin to drift. While the effects of each drift are minimal, they can have a dramatic impact over time. To account for this, the ground segment uploads clock correction parameters as well as up to date orbital information to the satellites, which are broadcast to the user. The overall error associated with both the clock and ephemeris error is typically about $1.5 \mathrm{~m}$ for both types of error [6]. 


\subsubsection{Multipath Error}

Error introduced by multipath occurs when the receiver antenna receives both the line-of-sight signal from the satellite as well as reflected signals (specular) or diffracted signals (diffuse multipath). The line-of-sight signal and the distorted multipath signal are received by the antenna as a composite signal. The receiver processes this composite signal, which results in errors on both the code and carrier measurements. Multipath can occurs when a user is operating in an area with many reflective surfaces (buildings, bridges) and can range from about $1 \mathrm{~m}$, in areas with very few reflections, to as high as $50 \mathrm{~m}$, in highly reflective areas. A sure way to mitigate multipath error is to operate in an open environment away from reflective surfaces. However, in many cases this is unrealistic and other techniques are employed to mitigate multipath including utilization of antennas designed to suppress multipath. For example, the NovAtel GNSS-750 features a choke ring designed to reject multipath [9]. Additionally, many receiver manufacturers use narrow correlators as well as proprietary methods to further suppress multipath within the receiver [10].

\subsubsection{Spatial and Temporal Error Correlation}

The error sources on GPS signals can be divided into spatially and temporally correlated errors. Spatially correlated errors are correlated with location while temporally correlated errors are correlated with time. Spatially correlated errors include the satellite orbit, ionospheric, tropospheric and, to some extent, multipath errors. Temporally correlated errors include the ionospheric and tropospheric errors as well as the orbit and clock error as these slowly drift and are corrected over time. The spatial correlation of 
atmospheric errors is illustrated in Figures 2 and 3. When two receivers are within close proximity, the spatially correlated errors measured by the receiver are highly correlated as depicted in Figure 2. However, as the distance between the two receivers is increased, the spatially correlated errors decorrelate, as seen in Figure 3 for atmospheric errors.

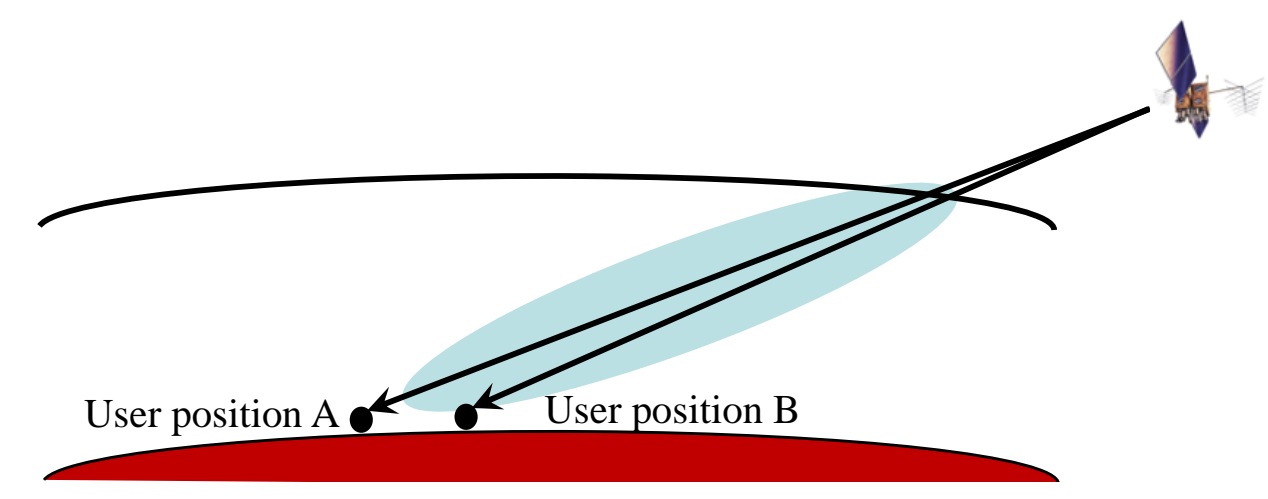

Figure 2. Graphic Depicting Spatially Correlated Errors.

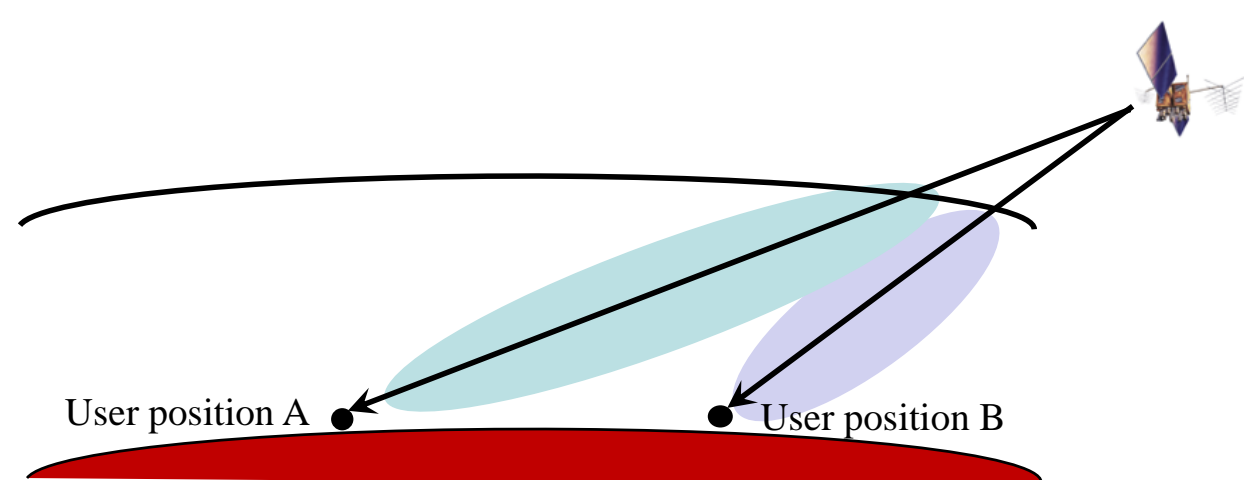

Figure 3. Graphic Depicting Spatially Decorrelated Errors.

\subsection{Stand-alone GPS}

A stand-alone GPS receiver may use various error models to reduce the errors on the pseudorange measurements from each satellite. A solution using these pseudoranges can be produced if the pseudorange measurements to at least 4 satellites are available. With these measurements, and the knowledge of the position of each of the satellites, the receiver 
is able to solve for the 3D coordinates of the user as well as the receiver clock bias [10] as shown in Equation (6)

$$
P R_{i}=\sqrt{\left(x_{i}-X\right)^{2}+\left(y_{i}-Y\right)^{2}+\left(z_{i}-Z\right)^{2}}+C_{b}
$$

where $P R_{i}$ is the pseudorange to satellite ' $i$ ',

$x_{i}, y_{i}, z_{i}$ are the ECEF coordinates of satellite ' $i$ ',

$X, Y, Z$ are the ECEF coordinates of the user,

$C_{b}$ is the receiver clock bias.

Solving for the four unknowns in Equation (6) requires at least 4 measurements and a system of $N \geq 4$ equations can be formed:

$$
\begin{aligned}
& P R_{1}=\sqrt{\left(x_{1}-X\right)^{2}+\left(y_{1}-Y\right)^{2}+\left(z_{1}-Z\right)^{2}}+C_{b} \\
& P R_{2}=\sqrt{\left(x_{2}-X\right)^{2}+\left(y_{2}-Y\right)^{2}+\left(z_{2}-Z\right)^{2}}+C_{b} \\
& \vdots \\
& P R_{N}=\sqrt{\left(x_{N}-X\right)^{2}+\left(y_{N}-Y\right)^{2}+\left(z_{N}-Z\right)^{2}}+C_{b}
\end{aligned}
$$

\subsubsection{Ordinary Least Squares}

An Ordinary Least Squares (OLS) method can be used to solve an over-determined system of equations. Such a method is useful in the case of solving a GPS position as measurements from more than 4 satellites are often visible. The OLS is an iterative process 
that computes a solution that best fits the measurements by minimizing that sum of squared residuals [6]. First, the pseudorange is estimated for each measurement using the ephemeris data and the user's estimated location as shown in Equation (8)

$$
\widehat{P R}_{i}=\sqrt{\left(x_{i}-\hat{X}\right)^{2}+\left(y_{i}-\hat{Y}\right)^{2}+\left(z_{i}-\hat{Z}\right)^{2}}+\hat{C}_{b}
$$

where $\widehat{P R}_{i}$ is the estimated pseudorange to satellite $i$,

$\hat{X}, \hat{Y}, \hat{Z}$ are the estimated ECEF coordinates of the user.

Next, the difference between the measured pseudorange and the estimated pseudorange to each satellite including the receiver clock bias is calculated for each measurement. As shown in Equation (9)

$$
\Delta P R_{i}=P R_{i}-\widehat{P R}_{i}
$$

where $\Delta P R_{i}$ is the difference between the estimated and measured pseudorange, $\hat{C}_{b}$ is the estimated receiver clock bias.

Since the satellites are far away from Earth and, thus, the user on Earth (i.e., $\sim 20,000 \mathrm{~km}$ ), the pseudorange difference in Equation (9), can be approximated by 


$$
\begin{aligned}
& \Delta P R_{i} \approx \frac{\partial P R_{i}}{\partial X} \Delta X+\frac{\partial P R_{i}}{\partial Y} \Delta Y+\frac{\partial P R_{i}}{\partial Z} \Delta Z+\frac{\partial P R_{i}}{\partial C_{b}} \Delta C_{b} \\
& \approx \frac{\hat{X}-x_{i}}{\widehat{P R}_{i}} \Delta X+\frac{\hat{Y}-y_{i}}{\widehat{P R}_{i}} \Delta Y+\frac{\hat{Z}-z_{i}}{\widehat{P R}_{i}} \Delta Z+\Delta C_{b}
\end{aligned}
$$

Using the following short notation:

$$
\begin{aligned}
g x_{i} & =\left(\hat{X}-x_{i}\right) / \hat{p}_{i} \\
g y_{i} & =\left(\hat{Y}-y_{i}\right) / \hat{p}_{i} \\
g z_{i} & =\left(\hat{Z}-z_{i}\right) / \hat{p}_{i}
\end{aligned}
$$

A matrix can be setup that can be used to estimate the residual position errors.

$$
\mathbf{G}=\left[\begin{array}{cccc}
g x_{1} & g y_{1} & g z_{1} & 1 \\
g x_{2} & g y_{2} & g z_{2} & 1 \\
\vdots & \vdots & \vdots & \vdots \\
g x_{N} & g y_{N} & g z_{N} & 1
\end{array}\right]
$$

The difference in the state is then computed as shown in Equation (13).

$$
\Delta \mathbf{x}=\left(\mathbf{G}^{T} \mathbf{G}\right)^{-1} \mathbf{G}^{T} \Delta \boldsymbol{P} \boldsymbol{R}
$$

Then these changes are added to the estimates as shown in Equation (14).

$$
\begin{gathered}
\hat{x}=\hat{x}+\Delta x_{1} \\
\hat{y}=\hat{y}+\Delta x_{2} \\
\hat{z}=\hat{z}+\Delta x_{3} \\
\hat{C}_{b}=\hat{C}_{b}+\Delta x_{4}
\end{gathered}
$$


This process is iterated until the solution converges.

\subsubsection{Dilution of Precision}

When computing the user solution, the geometry of the constellation as well as the environment of the receiver can greatly affect of the availability and accuracy of a solution. The constellation geometry and number of observable satellites also influences the solution accuracy. Poor satellite geometry, that is, geometry with a poor distribution of the satellites across the sky will result in a higher error on the user position. If several satellites were close together in the sky, their measurements would not provide more information about the user's position. The Dilution of Precision (DOP) introduced by the satellite geometry related the satellite range error to the user position error can be evaluated by looking at the various dilution of precision elements [10]. If evaluated in a local coordinate frame, the dilution matrix can be produced as shown in Equation (15).

$$
\mathbf{D}=\left(\mathbf{G}^{T} \mathbf{G}\right)^{-1}=\left[\begin{array}{llll}
d_{E E} & d_{E N} & d_{E U} & d_{E c b} \\
d_{N E} & d_{N N} & d_{N U} & d_{N c b} \\
d_{U E} & d_{U N} & d_{U U} & d_{U c b} \\
d_{c b E} & d_{c b N} & d_{c b U} & d_{c b c b}
\end{array}\right]
$$

The DOP of various dimensions can be produced using this matrix as shown in Equations (16), (17), and (18).

$$
\begin{gathered}
\text { Geometric DOP }(G D O P)=\sqrt{d_{E E}+d_{N N}+d_{N U}+d_{c b c}} \\
\text { Position DOP }(P D O P)=\sqrt{d_{E E}+d_{N N}+d_{N U}} \\
\text { Horizontal DOP }(H D O P)=\sqrt{d_{E E}+d_{N N}}
\end{gathered}
$$


With these parameters, the effective range error can be used to evaluate the effective error in each of these domains by multiplying the range error by the corresponding DOP.

\subsection{Differential GPS}

Outside of modeling, as is often done for in stand-alone GPS receivers, many errors can be corrected using differential GPS. In this technique, a precisely surveyed GPS reference receiver, usually referred to as the base station, makes pseudorange measurements of the observable satellites. The distance to the satellite is computed using its surveyed location and the broadcast ephemeris of the satellites. From this, corrections can be produced by taking the difference between the measured pseudorange and the calculated distance to the satellite. This difference term contains any specially correlated errors to the extent they do not decorrelate including the ionosphere, tropospheric, ephemeral, and satellite clock error. This can then be formed into corrections that can be applied to one or more GPS receivers, referred to as rovers, within proximity to the base stations. As the distance between the rover and base station increase, these errors become less correlated and the corrections less impactful.

Corrections from a reference station can be formatted in a variety of ways. They can be lumped into one large correction or separated by multitude of sources that make them up allowing the roving device to choose which corrections to utilize. The Radio Technical Commission for Maritime Services (RTCM) has created a few standards, such 
as RTCM 2.3 and RTCM 3.0, that allow for consistent formatting of corrections between receivers [10].

\subsection{GPS Augmentation}

There are several GPS augmentation systems currently in operation that are used to increase the reliability, accuracy, and integrity of the GPS system. Some, like the Wide Area Augmentation System (WAAS), are space based and are referred to as Space Based Augmentation Systems (SBAS) [12]. Others, like the Ground Based Augmentation System (GBAS), are ground based covering a smaller area and, typically, meant for applications that have stringent performance requirements such as precision approach and landing operations [13].

\subsubsection{WAAS}

WAAS works by providing corrections to receiver measurements through a network of ground stations and geo-stationary satellites. The ground stations are precisely surveyed, continuously monitor the GPS constellation, and produce corrections. These corrections are uplinked to geo-stationary satellites that rebroadcast the corrections in GPS frequencies making them widely available in the North America [14].

\subsubsection{GBAS}

GBAS, formerly known as Local Area Augmentation System (LAAS) within the United States, works in a similar manner. The system provides differential corrections as well as integrity monitoring of GPS. Precisely surveyed base stations generate corrections and broadcast them to the local vicinity, usually around an airport, over a Very High 
Frequency (VHF) radio link. These systems are generally used to increase the position accuracy of aircraft on approach at an airport [13].

\subsubsection{NDGPS}

The United States Coast Guard had built and operated a network of ground based DGPS stations, called the Nationwide Differential GPS (NDGPS) service, along the coasts of the United States to improve the accuracy and integrity of marine GPS receivers. However, these systems are currently being decommissioned and will be fully offline in a few years. According to the Coast Guard, the improvements to the accuracy and integrity of standalone GPS no longer warrant the use of an additional GPS augmentation system as defined by the mission requirements of NDGPS [15].

\subsubsection{OmniSTAR}

OmniSTAR is a service that provides GPS corrections to its users in real time by utilizing over 100 of its references sites. Its corrections are streamed either over its network of geostationary satellites or the internet. However, to utilize these corrections, a client must have a subscription to the service as well as an OmniSTAR compatible receiver.

\subsubsection{CORS}

Another source of corrections is from the Continuously Operating Reference Stations (CORS). These are a network of GPS reference stations managed by the National Geodetic Survey (NGS) that continuously monitor and produce raw measurements from their reference station for a variety of GNSS including GPS. As of August 2015, there were almost 2,000 stations within the network [17]. Additionally, CORS provides a post processing service called Online Positioning User Service (OPUS) that utilizes precise 
ephemeris data. However, the use of this service requires the collection of both L1 and L2 measurements for processes, making the service not accessible for hardware that doesn't support L2.

\subsubsection{Assisted GPS}

Assisted GPS (AGPS) AGPS is a technique that can be utilized by cellular enabled GPS receivers, such as cell phones, to aid in the calculation of receiver's position solution. AGPS data contains the location of the GPS satellites, the broadcast navigation message, the Doppler, and the GPS system time uncertainty. This information is transmitted over the cellular network and made available to the mobile device and is particularly beneficial in computing a solution when low power signals are received, such as while operating in a building or other environment that degrade signal reception. The primary benefit of this technique is the reduction in the amount of time required to compute a position solution $[10]$.

\subsection{Mobile Device Receivers}

Low cost GPS receivers have become common place in many of our mobile devices. These receivers are typically low Size, Weight, Power, and Cost (SWAP-C), and are generally lacking in accuracy when compared to high quality dedicated GPS receivers. While there have been some advancements in the capabilities of these receivers, they typically are only capable of receiving L1 C/A code signals. Recently, several newer generation Android smart phones and tablets allow developers access to the raw GPS measurements from the receiver [18]. This enables applications of GPS augmentation techniques to be applied to these low-cost receivers. 


\section{CHAPTER 3: METHODOLOGY}

This chapter will address the methodology used to process the collected data and compute a final position for each location tested. This process varies only slightly for the stationary and mobile experiments. This chapter is separated into two sections to describe these two methodologies.

\subsection{Stationary Positioning}

In the stationary experiments, each base station produces corrections that are applied to the measurements of the roving receiver. The solutions produced are compared against the known surveyed position as well as the location reported by the device chipset. A Code-Minus-Carrier (CMC) analysis is performed on the measurements for each of the base stations to determine the corrections with the least amount of error on them. This analysis informs which base station corrections should be applied to rover for each location. Lastly, a final solution for each location is produced by first smoothing the measurements using a Hatch filter and, then, applying corrections from the base stations that had previously been determined to have had the lowest error as determined by the CMC analysis. This process is shown at a high level in Figure 4 and is described in this chapter. 


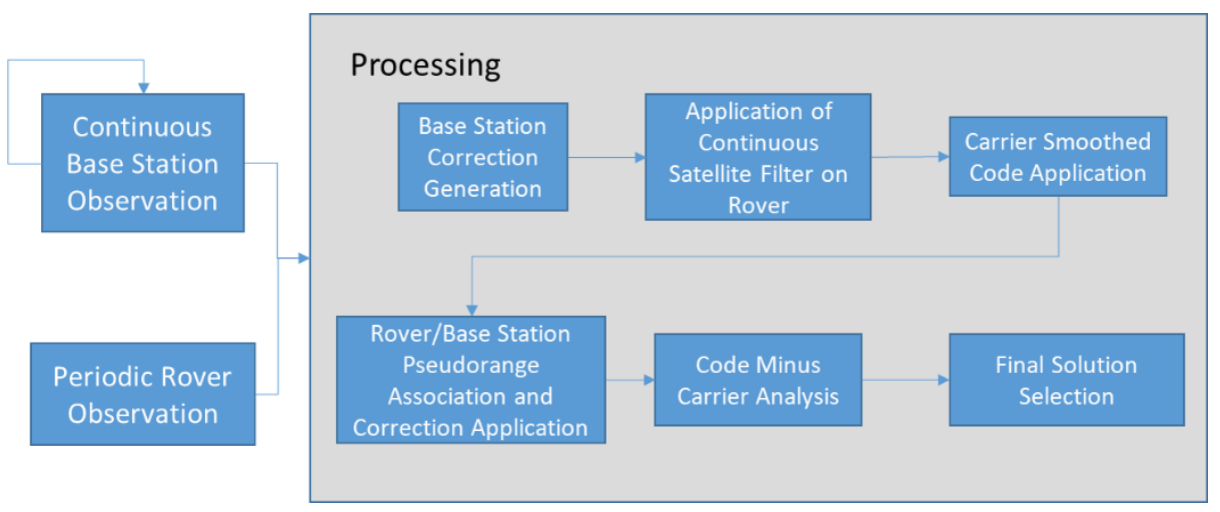

Figure 4. Block Diagram of Processing.

\subsubsection{Base Station Correction Generation}

Base station corrections are not generated in compliance with any standard but were instead created as the sum of errors on the pseudorange measurement. This is done by first calculating the true range to the satellite using the known survey coordinates and the satellite ephemeris. This value is then subtracted from the pseudorange value obtained from the base station receiver producing the following pseudorange corrections, as show in Equation (19)

$$
\Delta R=P R_{\text {meas }}-T R_{\text {calc }}
$$

where $\Delta R$ is the base station correction,

$P R_{\text {Meas }}$ is the pseudorange measurement of the base station,

$T R_{\text {calc }}$ is the calculated range based surveyed location of the base station antenna. 


\subsubsection{Satellite Filter/Screening}

During the data collection, it was found that the measurements from several satellites were not being tracked consistently resulted in a large error distribution as the measurements from those satellites would come in and out of the solution. To correct for this, if measurements from a satellite were dropped, all the measurements from that satellite were removed before the calculation of the solution. This was found to reduce the error and standard deviation for the tested scenarios. Other methods of measurement screening could also be utilized in a post processed or real time solution calculation such as screening of low power measurement or low elevation satellites measurements.

\subsubsection{Base Station Correction Application}

The pseudorange corrections from the base stations are applied to the rover's measurements before the OLS is performed. The corrections are subtracted from the rover's pseudorange measurements removing all common errors between the station and rover measurements as depicted in Equation (20)

$$
P R_{\text {cor }}=P R_{\text {meas }}-\Delta R
$$

where $P R_{\text {cor }}$ is equal to the corrected pseudorange measurement, $P R_{\text {Meas }}$ is the original pseudorange measurement of the tablet, $\Delta R$ is the generated base station correction. 


\subsubsection{Smoothing}

After application of the corrections, the corrected pseudoranges are smoothed using a Hatch filter, described in [19]. The equation describing this method is shown in Equation (21)

$$
P R_{s m}(k)=\frac{M_{f}-1}{M_{f}} *\left(P R_{s m}(k-1)+\Delta \Phi(k)\right)+\frac{1}{M_{f}} P R(k)
$$

where $P R_{s m}$ is the smoothed pseudorange measurement of index ' $k$ ',

$M_{f}$ is the filter time window (e.g., $M_{f}=100$ time epochs),

$\Delta \Phi$ is the change in carrier phase measurement,

$P R$ is the pseudorange measurement of the tablet.

The technique allows the noisy unambiguous pseudorange measurements to be smoothed by the much less noisy ambiguous carrier measurements. A smoothing time of 100 seconds was chosen as it is long enough to provide adequate error reduction while minimizing the potential ionospheric bias that can be produced by over smoothing. This can greatly reduce errors attributed to receiver noise and multipath from several meters to centimeters depending on the amount of error present.

\subsubsection{Code Minus Carrier Analysis}

A CMC analysis was performed to evaluate the multipath and receiver noise error on the pseudorange measurements on each of the base stations as these errors are significantly smaller on the carrier than on the pseudorange measurements. This multistep 
process, described in [20], isolates the receiver noise and multipath on a pseudorange measurement by comparing the difference between the pseudorange and carrier phase delta. First, the basic CMC value is produced by subtracting the carrier phase measurement from the pseudorange measurements shown in Equation (22)

$$
C M C_{\text {biased }}=P R_{\text {meas }}-\Phi
$$

where $C M C_{\text {biased }}$ is equal to the biased CMC,

$P R_{\text {Meas }}$ is the pseudorange measurement,

$\Phi$ is the carrier phase measurement.

A bias, caused by the carrier ambiguity integer is present in the CMC of Equation (22), but can be removed by subtracting the average CMC value from itself as shown in Equation (23)

$$
C M C_{\text {unbiased }}=C M C_{\text {biased }}-\overline{C M C}_{\text {biased }}
$$

where $C M C_{\text {biased }}$ is equal to the biased CMC, $\overline{C m C}_{\text {biased }}$ is equal to the average value of the biased CMC.

Lastly, the ionospheric error is removed from the CMC. This is done by taking a $2^{\text {nd }}$ order polynomial fit of the unbiased CMC and subtracting it as shown in Equation (24) 


$$
C M C_{\text {unbiased (iono-free) }}=C M C_{\text {unbiased }}-P F
$$

where $C M C_{\text {unbiased (iono-free) }}$ is the unbiased CMC with the ionosphere removed, $P F$ is a $2^{\text {nd }}$ order polynomial of the unbiased CMC.

To quantify the amount of error on the pseudorange measurements for each rover test location, the standard deviation of the CMC residuals was taken during the rover's observation period. These values were then summed together to obtain a metric to compare the error on the base stations between each other.

\subsection{Mobile Positioning}

The methodology for the mobile experiments is largely the same as that of the stationary experiments. The generation and application of corrections is still done but only for the single base station used. While a CMC analysis is performed on the base station, it is no longer used for base station selection but as an analytical tool to gain insight on the multipath error on the base station. This is primarily done to verify that little multipath error exists at the base station during the data collection at the rover and that corrections produced during this time are acceptable. 


\section{CHAPTER 4: EXPERIMENTAL SETUP}

This chapter describes the experimental setup used for this thesis. This primarily includes the base stations, the networking equipment and the rover device. The experimental setup involves 2 testing environments, 1 at the NASA Langley Research Center (LaRC) where the stationary experiments were performed, and another at Ohio University (OU) where the mobile experiments were performed. The configuration for these experiments is detailed in this chapter along with the environment and scenarios that were involved. The primary focus in the selection of hardware components was to develop a system capable of providing corrections while maintaining a relatively low cost.

\subsection{Mobile GPS User Device}

Throughout all the experiments in this thesis, the Nexus 9 tablet was used as the rover device. It was chosen for its ability to capture raw L1 C/A code and carrier measurements [21]. While limited relative to some dedicated GPS receivers, at the time of this experiment, the GPS receiver in this device, the Broadcom BCM4752 [22], had the largest feature set amongst the small set of commercially available android devices that support the logging of raw GPS measurements. This set includes the ability to log raw code and carrier phase measurements at a rate of $1 \mathrm{~Hz}$. 


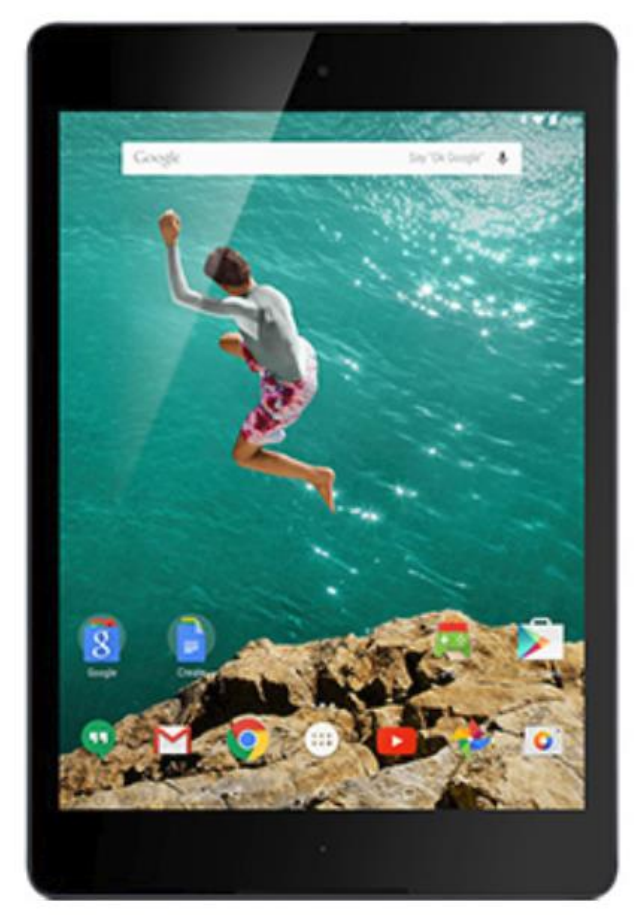

Figure 5. Google Nexus 9 [23].

\subsubsection{Broadcom BCM4752}

The receiver within the Nexus 9 tablet is the Broadcom BCM4752. This device is a multi-constellation receiver that supports GPS, GLONAAS, QZSS, and SBAS signals. The device utilizes Broadcom's sensor integration technology which integrates accelerometer, gyroscope, magnetometer, and altimeter sensors to aiding the receiver solution [24]. For these experiments, the device did not have a cellular connection and did not utilize AGPS.

Below in Figure 6 an example CMC plot is shown for measurements from the receiver within the tablet while operating in an open environment. The level of noise on these measurements is large relative to what would be expected on higher grade equipment 
with residuals fluctuating from $+/-40 \mathrm{~m}$ to $+/-100 \mathrm{~m}$ for the nosiest measurements. This high level of receiver noise results in $3 \mathrm{D}$ position solutions with a high standard deviation of error.

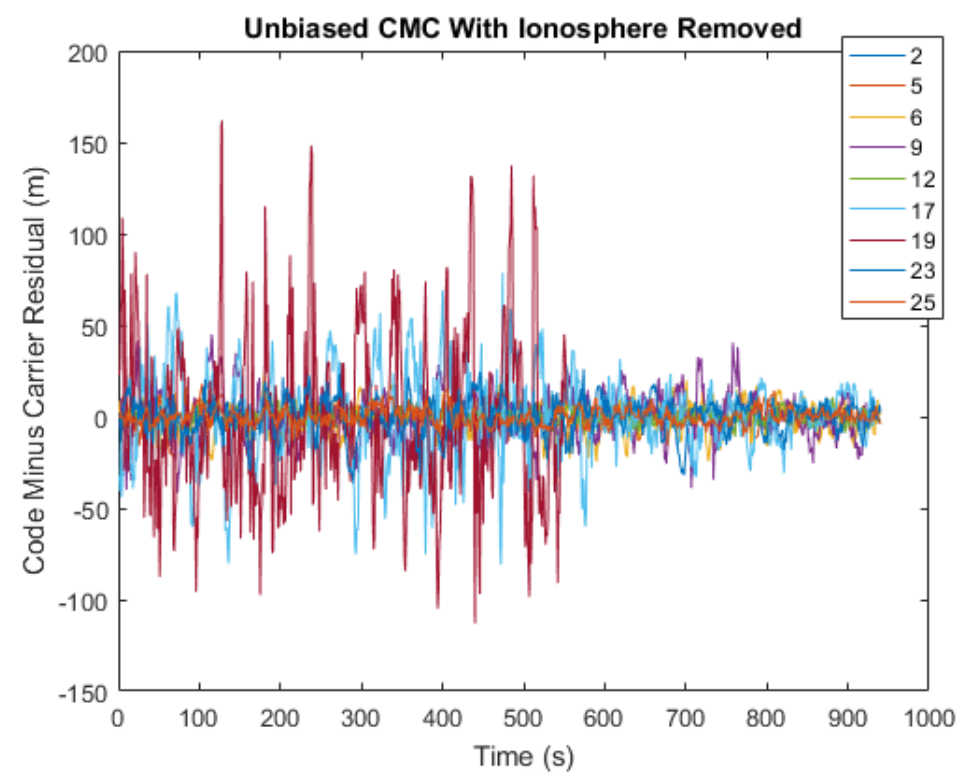

Figure 6. Plot of Rover CMC Residuals.

\subsection{Stationary Experiments (LaRC)}

\subsubsection{Base Stations}

A potential operational scenario could involve a large deployment of differential stations to cover a wide operational area while maintaining a short base-line between the base stations and the rovers. These stations were built using relatively low-cost components to evaluate feasibility of their use for this type of scenario.

For the stationary experiments three base stations were built and placed on the rooftops of three buildings on the LaRC campus. The center of each station's antenna was surveyed using a Trimble R10 GNSS receiver with Trimble NetR5 GNSS base stations. 
Raw GPS measurements from each station along with the known survey coordinates were used to produce pseudorange corrections, which were later applied to the rover. The system is shown in Figure 7 and its sub-systems are discussed in the following sub-sections.

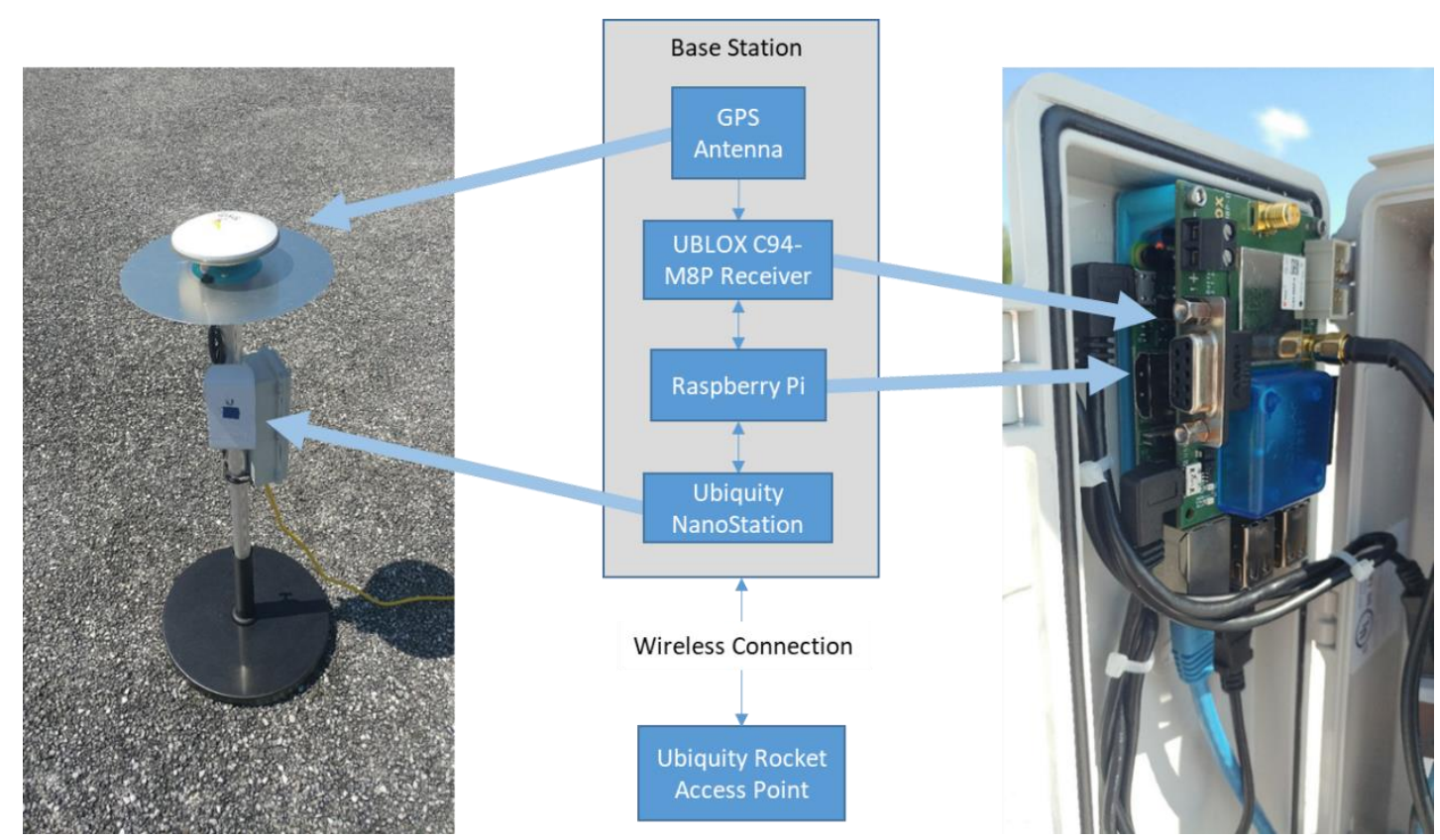

Figure 7. Base Station Components. 


\subsubsection{U-blox C94-M8P}

The U-blox C94-M8P is a low cost GNSS receiver designed with the ability to generate and transmit RTK corrections over its integrated radio link with an advertised centimeter level accuracy. The device is able to receive measurements from GPS L1, GLONASS, and BeiDou [25]. The U-blox receiver was configured to output raw GPS measurements and the logging of all other GNSS was disable. This receiver was configured to output both raw code and carrier measurements at $1 \mathrm{~Hz}$ to match the update rate of the tablet.

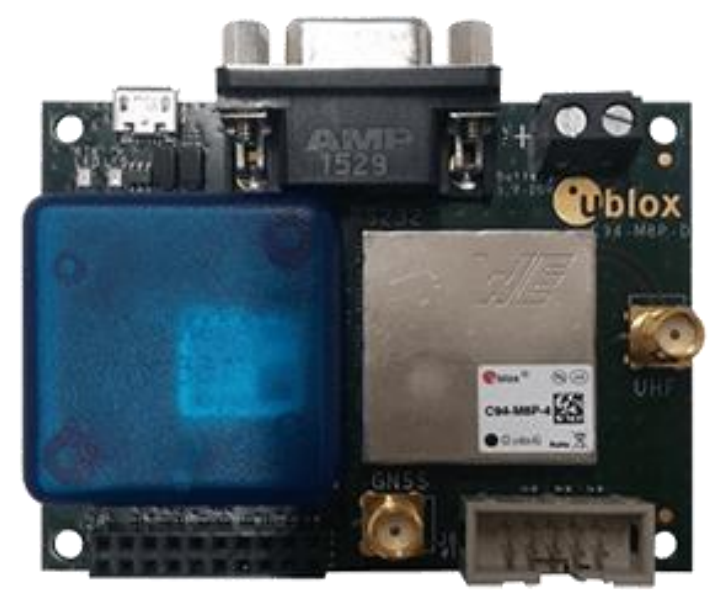

Figure 8. U-blox C94-M8P [26].

\subsubsection{Swift Nav GPS500}

The Swift Nav GPS500 mini survey antenna is designed for GPS L1/L2, GLONASS L1/L2, BeiDou B1/B2/B3. It has built in Multi-path rejection, is water and dust proof, and is designed to have a consistent phase center regardless of azimuth and elevation of the received signal [27]. The antenna can be operated for GPS only or multiconstellation applications. In this case, only L1 signals measured by the receiver and while 
this allows for additional noise on the measured signals, this had an insignificant impact on the measurements of the base stations.
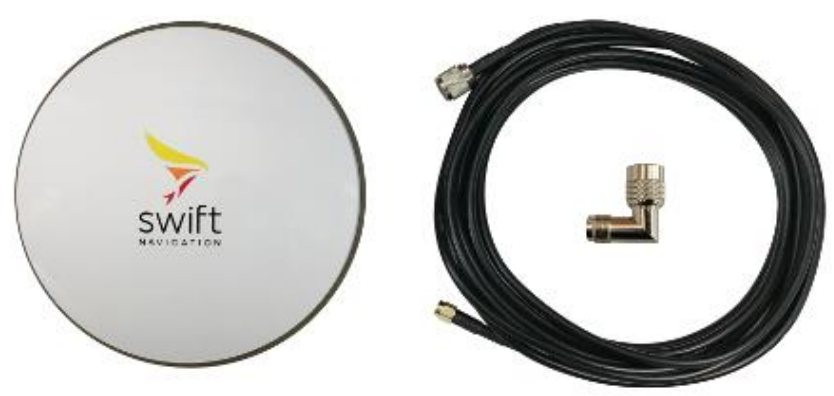

Figure 9. Swift Nav GPS500 [28].

\subsubsection{Raspberry Pi 3 B}

The Raspberry Pi 3 model B is a small, low cost embedded ARM single board computer. The device has a 64-bit ARM CPU with 4 cores clocked at $1.2 \mathrm{GHz}$ along with 1GB of ram. The device houses many peripheral connections for its small size including 1 Ethernet port, 4 USB 2.0 ports, a full-size HDMI port, and a micro SD card slot port. Additionally, the device includes integrated Wi-Fi and Bluetooth Low Energy (BLE) connectivity [29]. The pi was used to power the U-blox receiver and the open-source software, RTKLIB, was used to parse and convert the incoming GPS measurement in RINEX format. These files were then made available over the network through SFTP. 


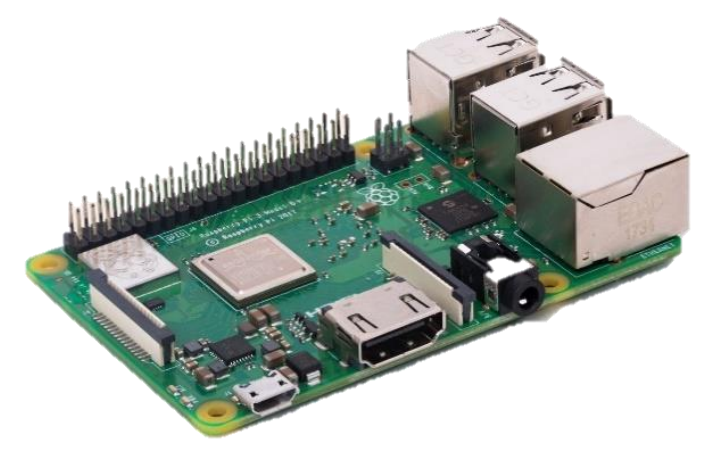

Figure 10. Raspberry Pi 3 B [30].

\subsubsection{Ubiquity Nanostation LocoM5}

The Ubiquity Nanostation LocoM5 is a directional 5Ghz wireless node capable of connecting to networks separated by $10 \mathrm{~km}$ or more. The device is waterproof and is powered over its Ethernet connection [31]. Two of the three base stations were equipped with a Nanostation focused on the centralized rocket M5 networking each of the base station raspberry pi and allowing access to the GPS measurements being made by each station. 


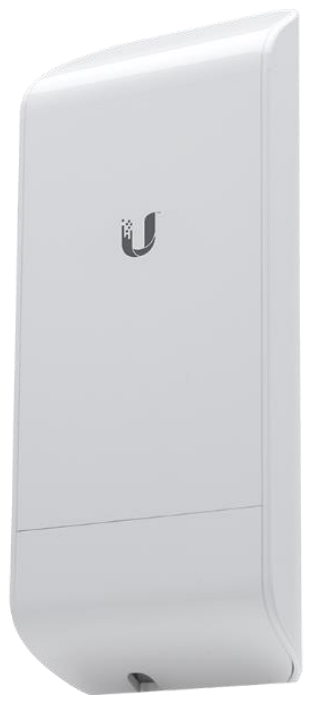

Figure 11. Ubiquity Nanostation LocoM5 [32].

\subsubsection{Ubiquity Rocket M5}

The Ubiquity Rocket M5 is a flexible $5 \mathrm{Ghz}$ wireless base station capable of creating a point to point or point to multi-point network. It has a single Ethernet port that is used for power as well as data transmission and reception [33]. It is capable of networking devices separated by large distances. The Rocket M5 was used as the centralized access point for the 3 base stations. It was directly connected to a base station over Ethernet and wirelessly connected to the other base stations via their Nanostations. 


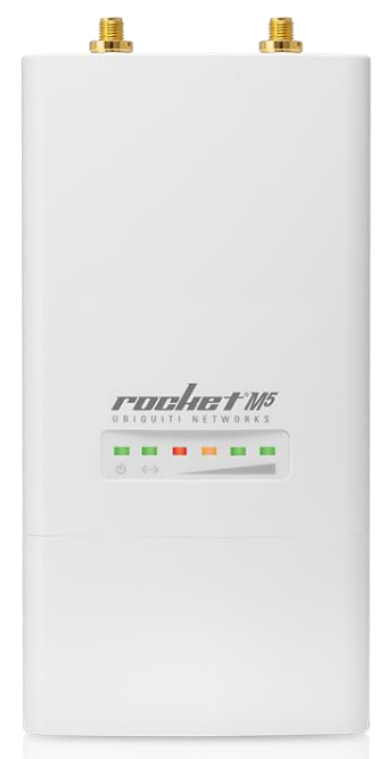

Figure 12. Ubiquity Rocket M5 [34].

\subsubsection{Experiment Locations}

For the stationary experiments, base stations were placed on the rooftops of several buildings on the LaRC Campus in Hampton, Virginia and the rover was placed at 6 positions around LaRC. The locations of the base stations are shown in blue and the 
location of the rover survey points are in red as in Figure 13 (Location 6 is not shown due to the large distance from the site).

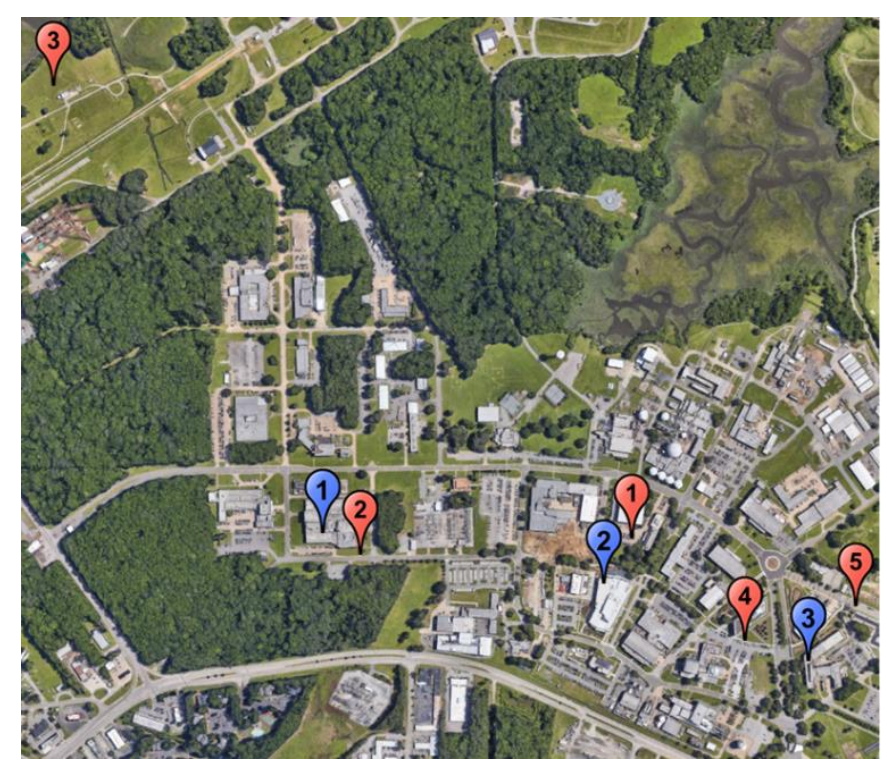

Figure 13. Map of Base Station and Rover Survey Locations.

The base stations were placed on the rooftops of the building to maximize sky visibility and reduce potential multipath. The environment around the base stations can be seen in Figure 14 - Figure 16. 


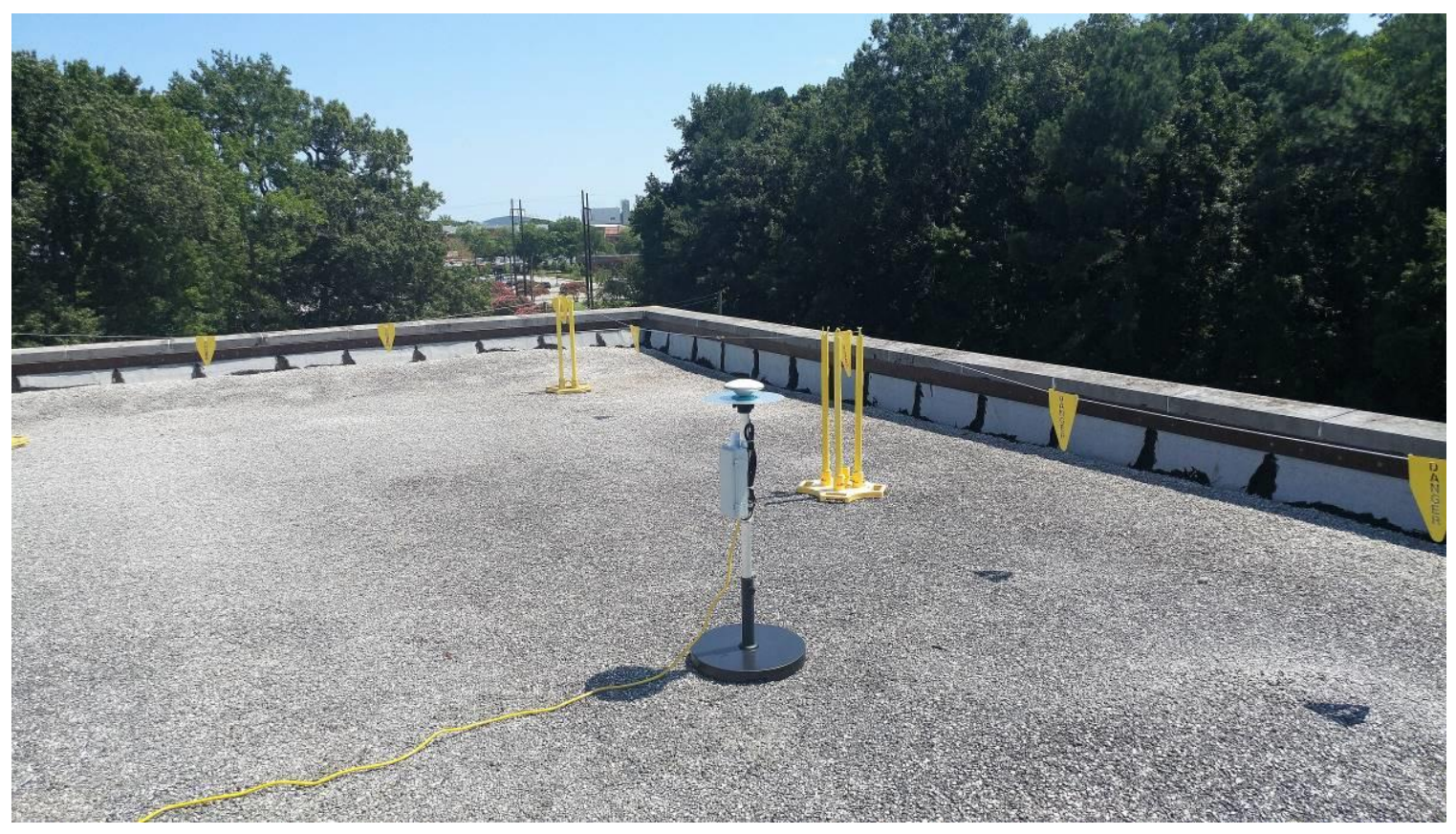

Figure 14. Photo of Base Station 1.

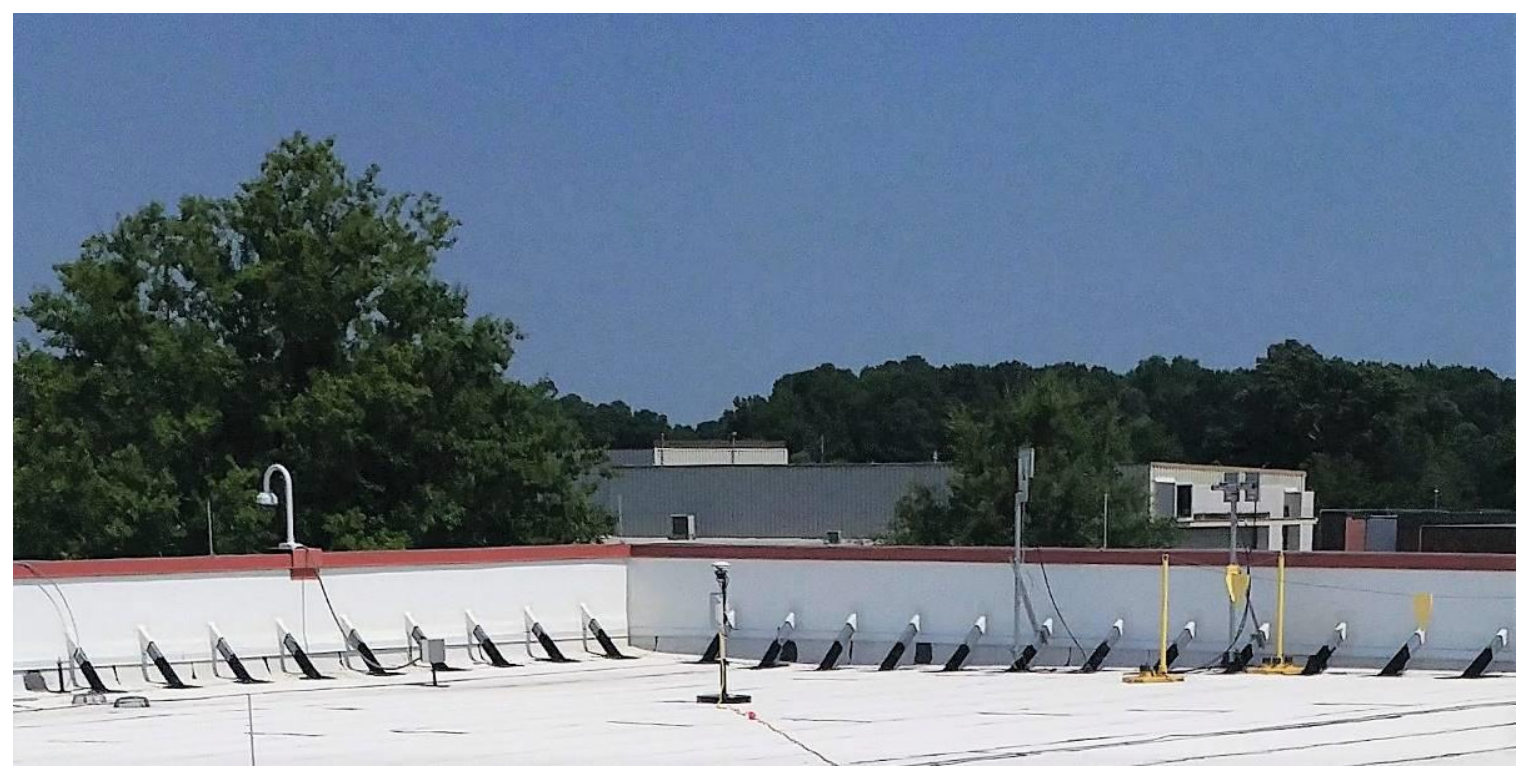

Figure 15. Photo of Base Station 2. 


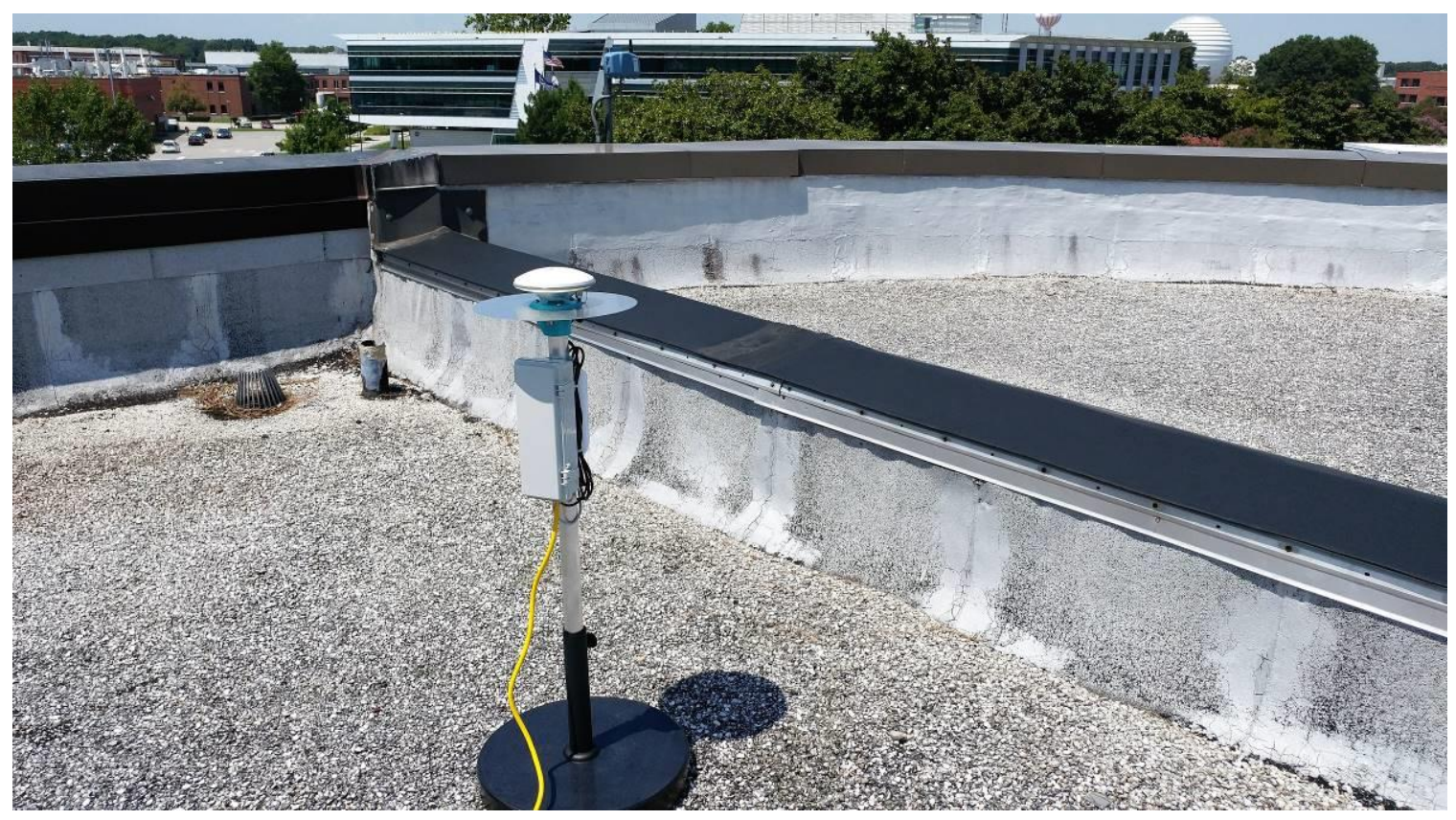

Figure 16. Photo of Base Station 3.

The rover locations were chosen to evaluate conditions that may be seen in a UAS package delivery scenario where a user would use their mobile device to specify the package delivery location. For this experiment, the user is considered to be operating in either an urban, suburban, or rural location where an urban location is around large buildings and/or foliage, a suburban location is around smaller buildings and/or foliage, and a rural area is surrounded by minimal buildings and/or foliage. These locations are shown in Table 1 and several locations are depicted in Figure 17 - Figure 19. 
Table 1. List of Rover Survey Locations.

\begin{tabular}{|c|c|c|c|}
\hline $\begin{array}{c}\text { Location } \\
\text { Number }\end{array}$ & Category & Sky Coverage & $\begin{array}{c}\text { Approximate } \\
\text { Distance to } \\
\text { Closest Base } \\
\text { Station }\end{array}$ \\
\hline $\mathbf{1}$ & Urban & Partial sky obstruction by building and foliage & $0.102 \mathrm{~km}$ \\
\hline $\mathbf{2}$ & Suburban & Partial sky obstruction by building and foliage & $0.022 \mathrm{~km}$ \\
\hline $\mathbf{3}$ & Rural & Unobstructed sky visibility & $1.128 \mathrm{~km}$ \\
\hline $\mathbf{4}$ & Urban & Partial sky obstruction by building & $0.132 \mathrm{~km}$ \\
\hline $\mathbf{5}$ & Rural & Minimal sky obstruction by foliage & $0.165 \mathrm{~km}$ \\
\hline $\mathbf{6}$ & Suburban & Partial sky obstruction by building and foliage & $4.000 \mathrm{~km}$ \\
\hline
\end{tabular}

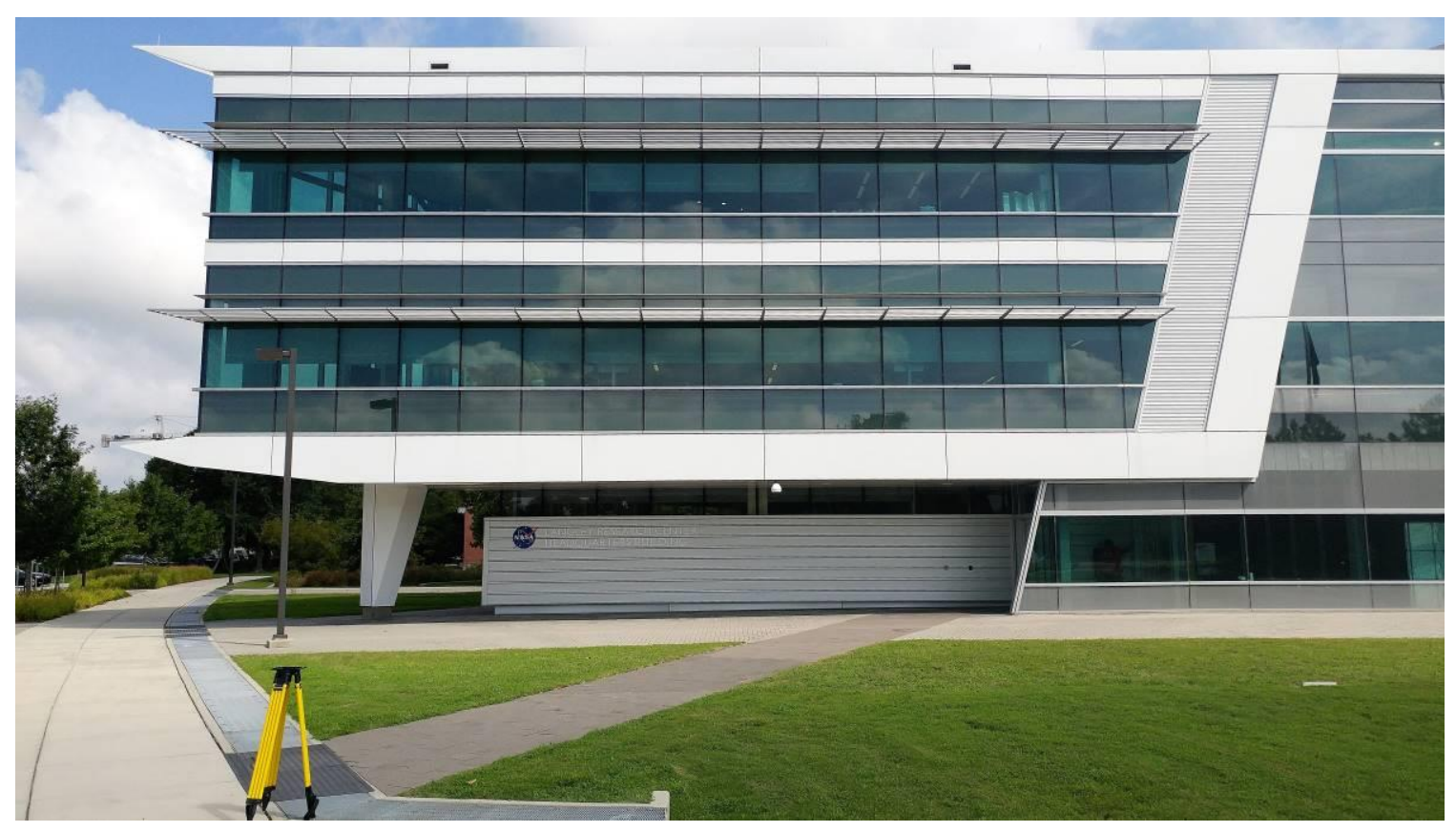

Figure 17. Photo of Location 4 (Urban). 


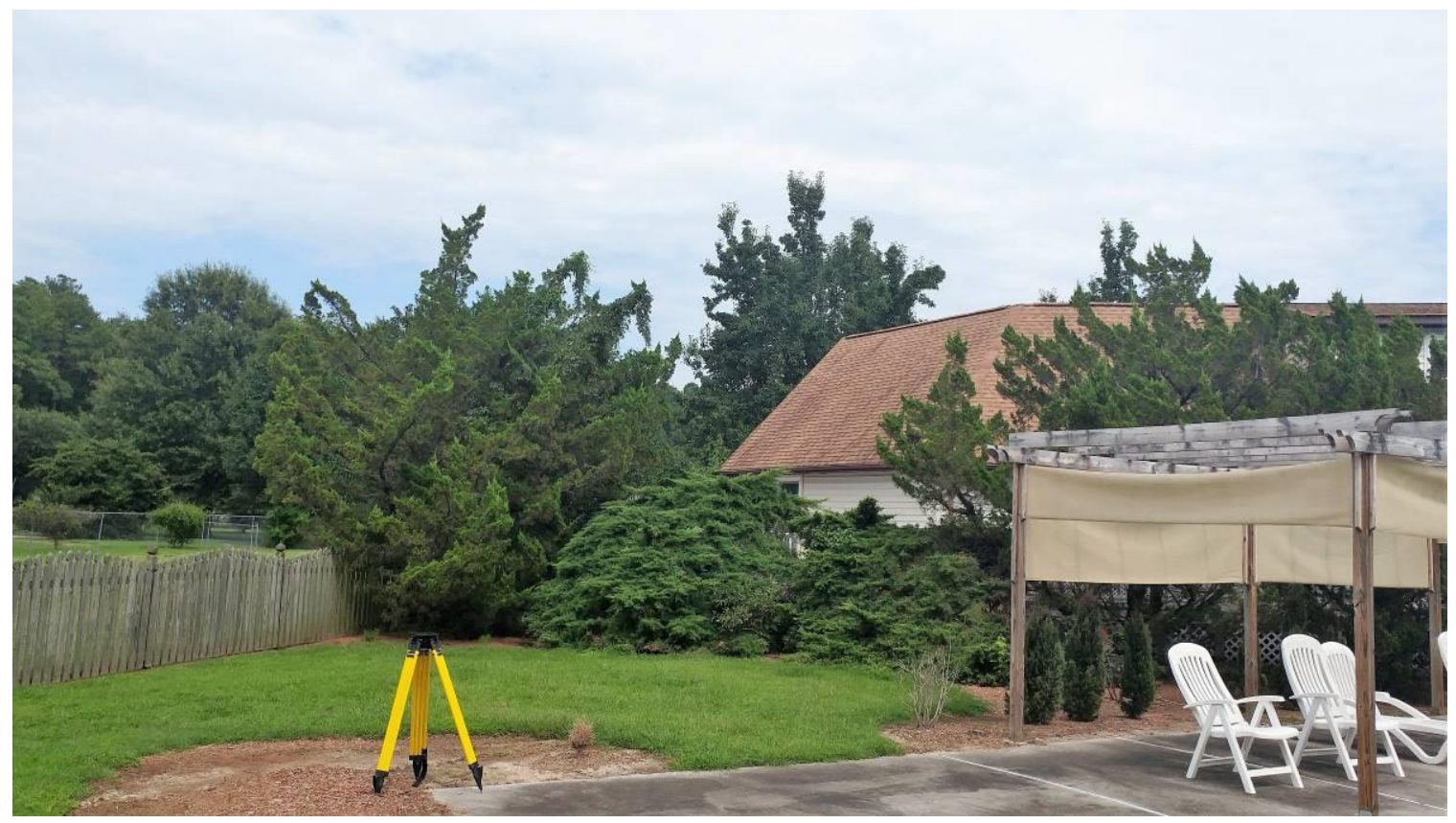

Figure 18. Photo of Location 6 (Suburban).

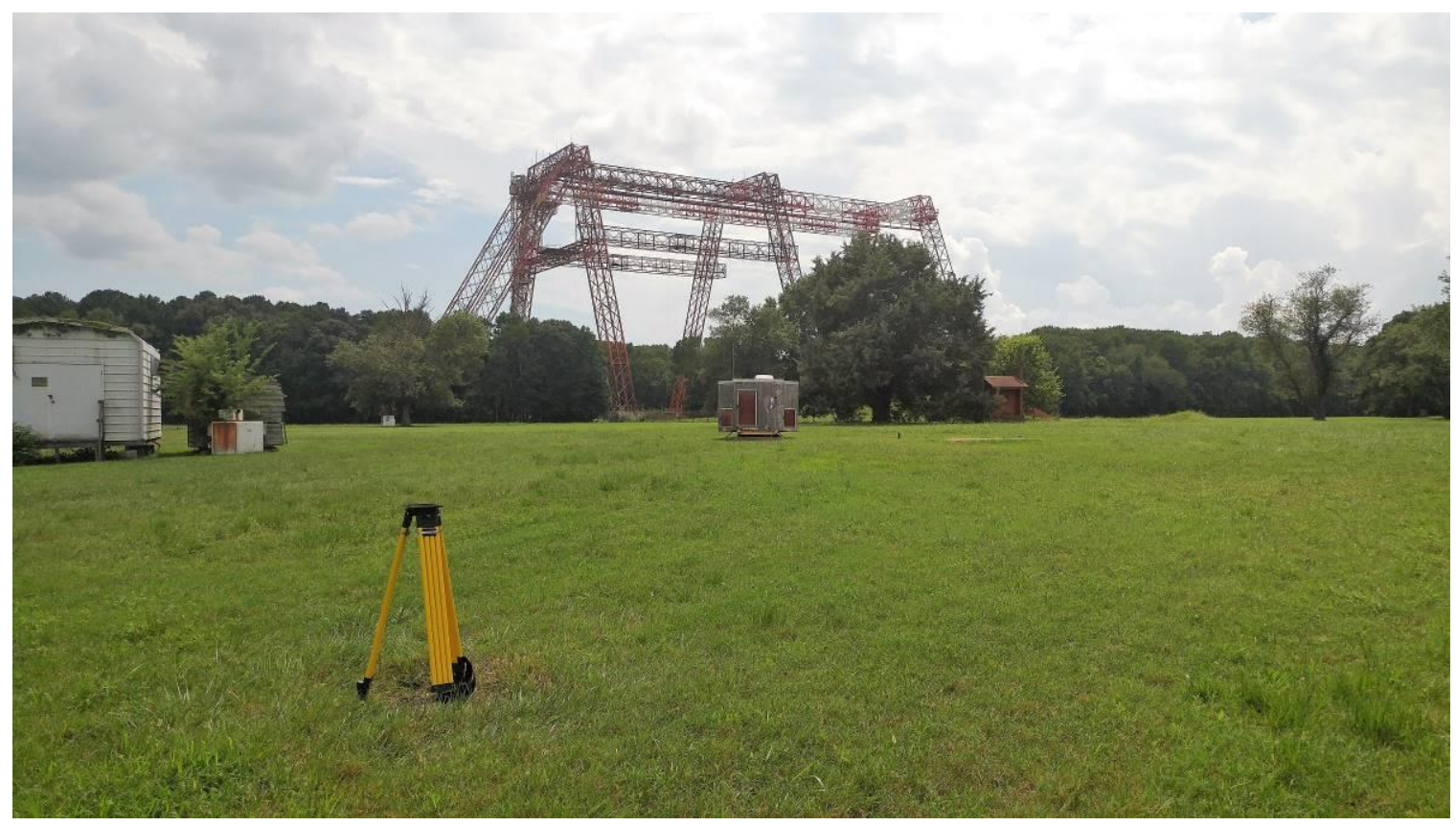

Figure 19. Photo of Location 3 (Rural). 


\subsubsection{Experiment Procedure}

The base stations were configured to continuously measure and store raw measurements of all observable satellites. The rover was then placed at each survey location for approximately 15 minutes and set to log the raw measurements. The data was offloaded from the both the base stations and rover for processing. The ephemeris data was provided by the NASA CDDIS GPS archive [35].

\subsection{Mobile Experiments (OU)}

\subsubsection{Base Stations}

For the mobile experiments, only a single base station was used. It simply consisted of a single U-blox M8P-C94 receiver connected to a NovAtel GPS-702-GGL antenna mounted on the rooftop of the Stocker Engineering Building at OU. The device was configured with the same settings as the stationary base stations. However, a laptop was used to log and convert the recorded raw measurements from the receiver as opposed to a dedicated embedded computer.

\subsubsection{NovAtel GPS-702-GGL}

The NovAtel GPS-702-GGL is a dual frequency GPS, GLONAAS, Galileo, and BeiDuo antenna capable of receiver L1, L2 signals. However, the antenna can be used for GPS only or multi-constellation applications. Its designed with multipath rejection and has choke ring level performance. The antenna's phase center remains constant regardless of the azimuth and elevation of the incoming signals [35]. 


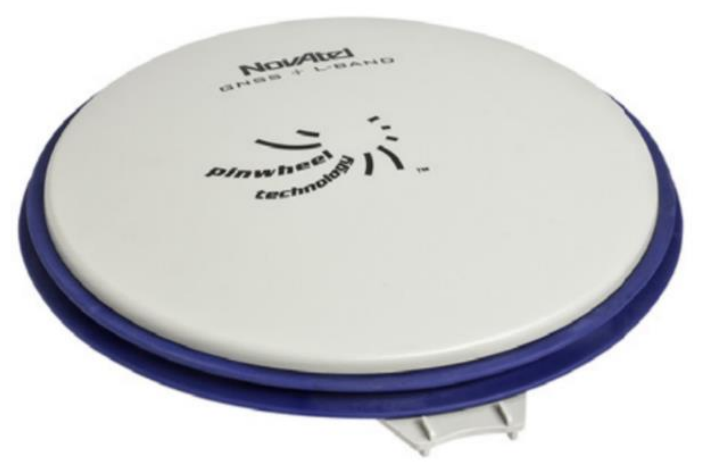

Figure 20. NovAtel GPS-702-GGL [35].

\subsubsection{UAS}

The rover was mounted on a 3DR X8 Octocopter UAS along with a NovAtel OEM 615 GNSS receiver and a small Tallysman GPS antenna shown in Figure 21. The UAS was flown while raw measurements were collected from both the rover, NovAtel OEM 615 , and the base station receivers. The UAS payload is described in detail below. 


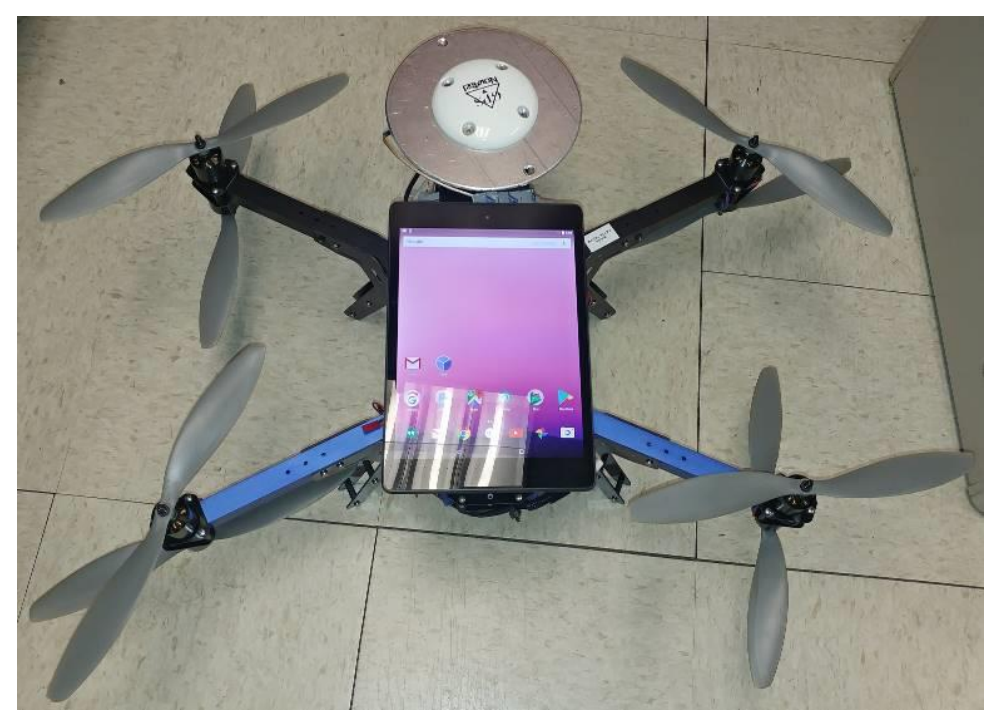

Figure 21. Photo of UAS Showing Android Tablet and GPS Antenna (The Tallysman 33-3870 antenna used in the experiment is not shown here).

\subsubsection{NovAtel OEM 615}

The NovAtel OEM 615, shown in Figure 22, is a GPS receiver capable of measuring L1, L2, L2C, B1, and E1 signals. It features low power consumption, software upgradability, and an API for software integration. The receiver is capable of measuring both code and carrier measurements and has built in RTK functionality [37]. The measurements produced by this receiver were used as the truth reference to compare the rover's solution against. 


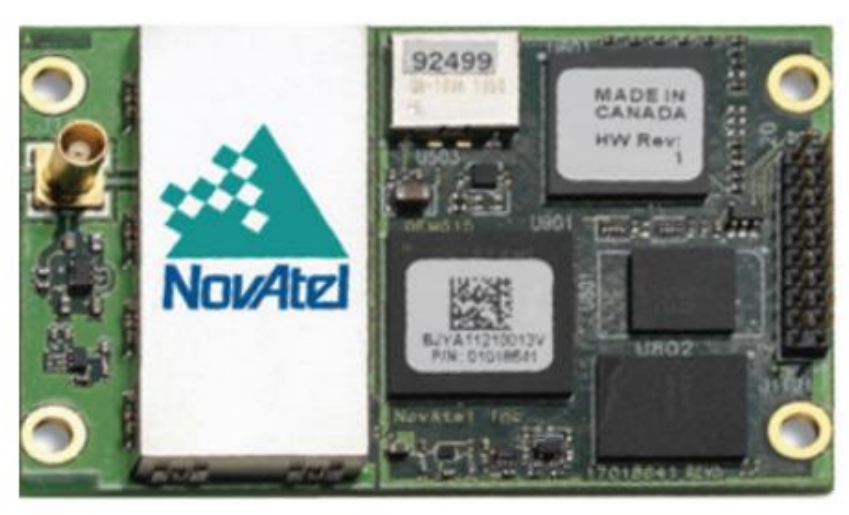

Figure 22. NovAtel OEM 615 [37].

\subsubsection{Tallysman 33-3870}

The Tallysman 33-3870, shown in Figure 23, is a compact multi-constellation GNSS receiver antenna that is capable of receiving GPS L1 and L2 signals. The antenna has a built-in LNA with $35 \mathrm{~dB}$ gain, built-in multipath rejection and is IP 67 rated [38]. This antenna was mounted on the UAS and connected to the NovAtel OEM 615 receiver.

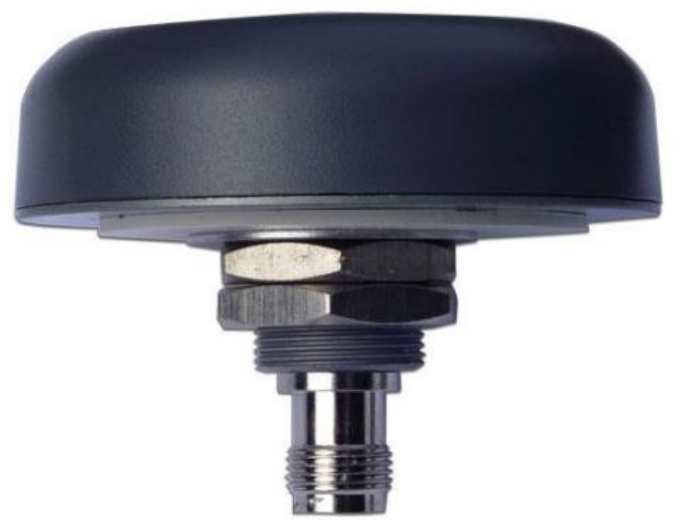

Figure 23. Tallysman 33-3870 [38]. 


\subsubsection{Experiment Locations}

The UAS was flown in 2 locations at in the OU campus with the base station antenna mounted to the rooftop of the Stocker Engineering Building on the OU campus as depicted in Figure 13.

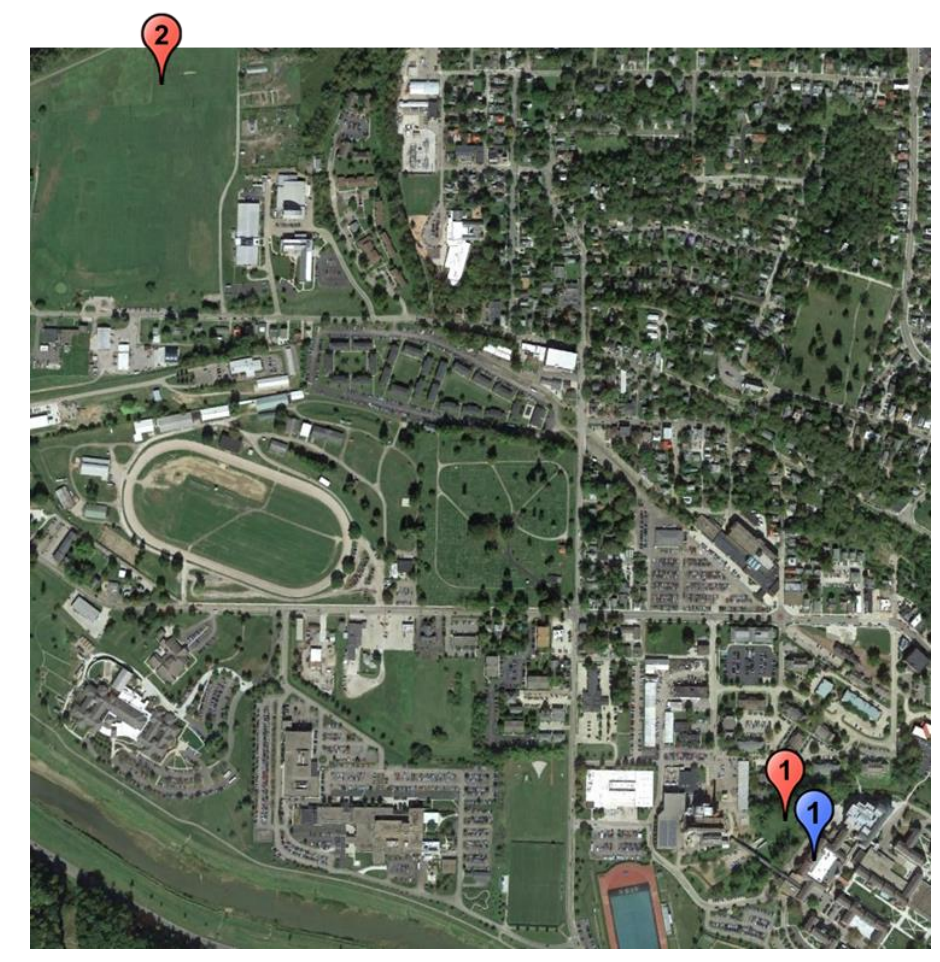

Figure 24. Map of Base Station and Rover Survey Locations.

The base station antenna's survey coordinates were produced by submitting raw receiver measurements to the Canadian Spatial Reference System (CSRS) PPP postprocessing service [39]. This solution was found to be within $2 \mathrm{~cm}$ of the solution produced using OPUS, another post-processing service. The antenna was placed on the rooftop of this building to maximize sky visibility and reduce potential multipath. The antenna can be seen in Figure 25. 


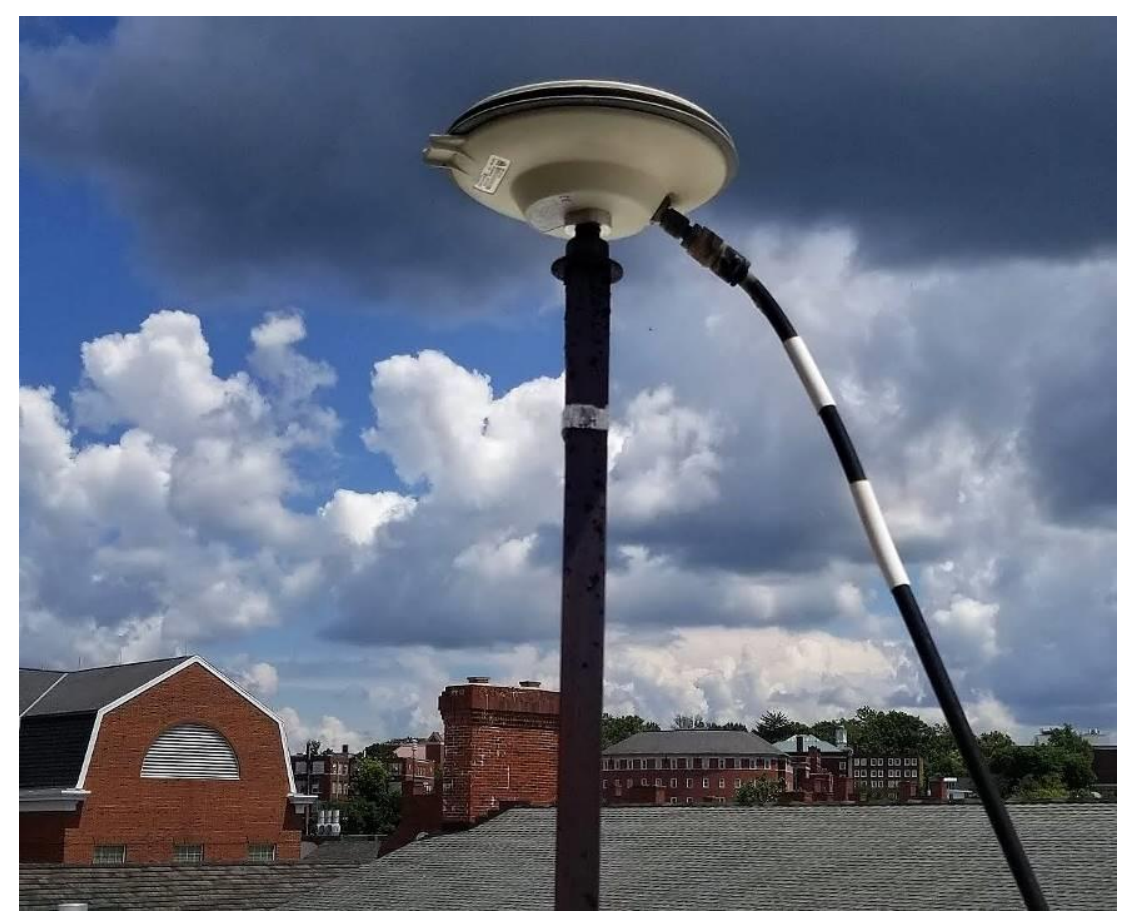

Figure 25. Photo of Base Station Antenna.

The rover locations were chosen to evaluate conditions that may be seen in a UAS package delivery scenario where a receiver would act as part of the navigation system on a UAS. The rover locations were divided in to only 2 categories, rural, and suburban. Rover location 1 is a short distance from the base station but is located close to a building and is surrounded by large trees and foliage. Location 2 is located further from the base station but is in an open field with little obstruction of the sky as described in Table 2 and shown in Figure 26 and Figure 27. 
Table 2. List of Rover Survey Locations.

\begin{tabular}{|c|c|c|c|}
\hline $\begin{array}{c}\text { Location } \\
\text { Number }\end{array}$ & Category & Sky Coverage & $\begin{array}{c}\text { Approximate } \\
\text { Distance to Closest } \\
\text { Base Station }\end{array}$ \\
\hline $\mathbf{1}$ & Urban & Partial sky obstruction caused by building and foliage & $0.060 \mathrm{~km}$ \\
\hline $\mathbf{2}$ & Rural & Unobstructed sky visibility & $1.503 \mathrm{~km}$ \\
\hline
\end{tabular}

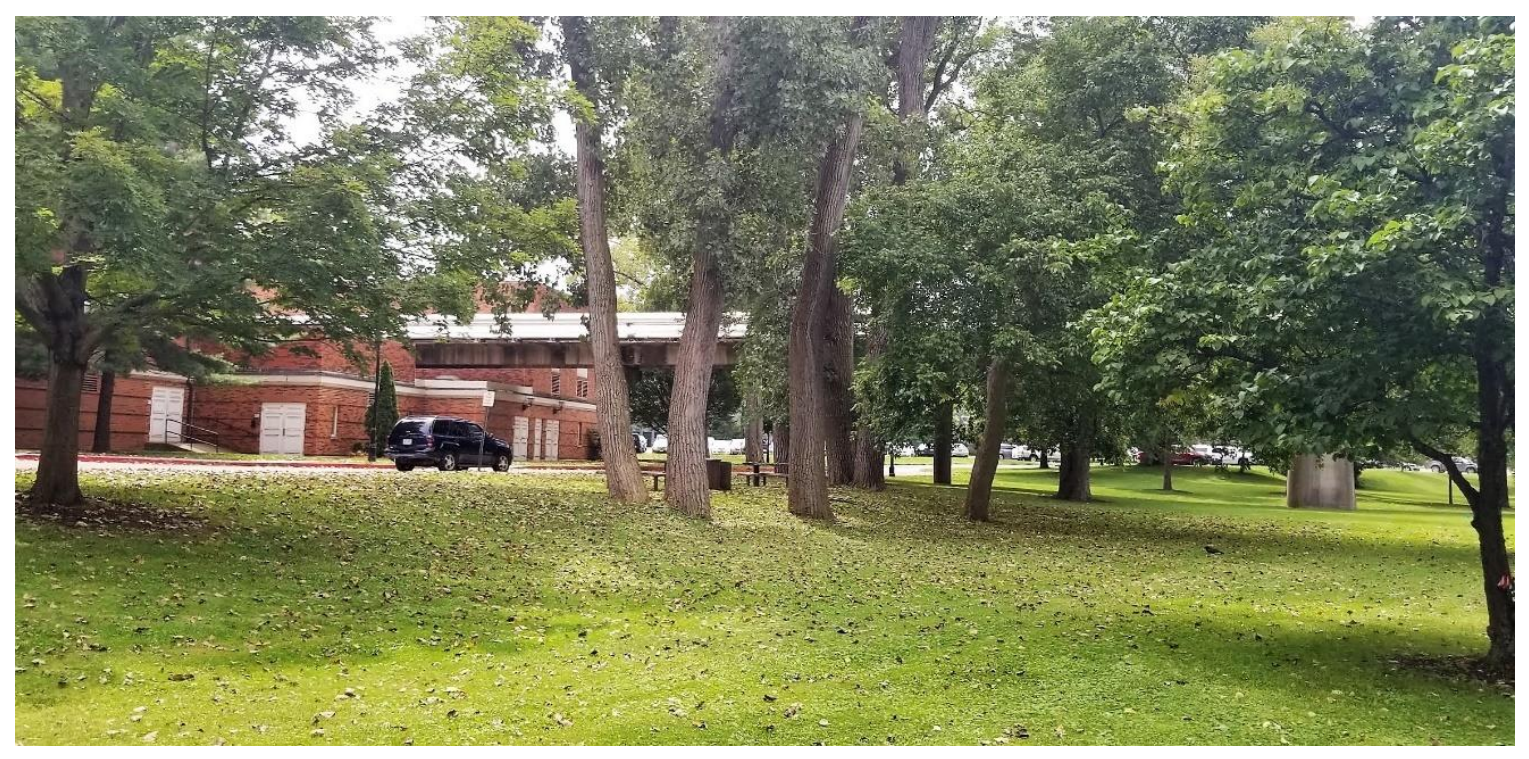

Figure 26. Photo of Location 1 (Urban). 


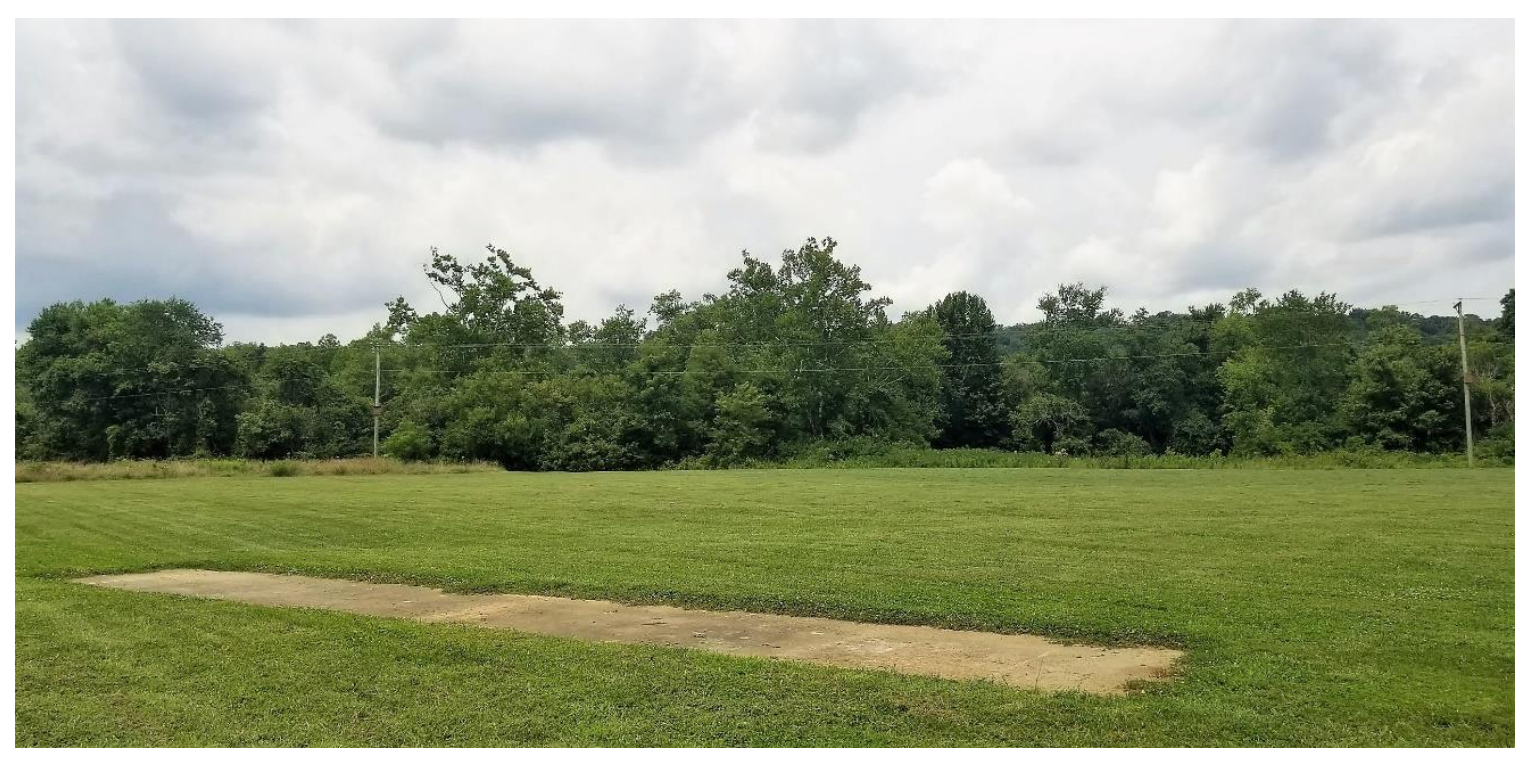

Figure 27. Photo of Location 1 (Rural).

\subsubsection{Experimental Procedure}

The procedure for the mobile experiments is similar to that of the stationary experiments. The base station was configured to continuously measure and store raw measurements of all observable satellites while that rover and NovAtel receivers were flown aboard the UAS. During the flights, the 2 receivers were configured to make raw GPS measurements. The data was off-loaded from both the base stations, the rover, and the NovAtel receiver for processing. The NovAtel data was processed through CSRS and used as the truth reference for the rover. The ephemeris data was provided by the NASA CDDIS GPS archive [35]. 


\section{CHAPTER 5: RESULTS}

The results in this chapter are divided into 2 sections corresponding to the 2 operational scenarios. The first section shows the results for the stationary experiments and the second section will show the mobile experiment results. For each location, the results are displayed in a tabular format showing the average lateral error and standard deviation for both the corrected and uncorrected position solutions. The sum of the standard deviation of the CMC residuals is shown for each base station along with the tabular data. The results are also compared against the solution reported to the device but the receiver chipset. Finally, the results for the smoothed and corrected solution will be shown using corrections from the base station with the lowest sum of the standard deviation of the CMC residuals. All of the errors are calculated relative to the precise survey location. 


\subsection{Stationary Results}

\subsubsection{Location 1}

For location 1, the application of the satellite filter removes several satellites that were inconsistently tracked. While this has little effect on the average lateral error of the solution, the standard deviation is reduced. The resulting error ellipse appears to have an elongated shape due to the geometry of the satellites used as well as possible scattering from nearby buildings and foliage. The north and east DOP values can be seen in Figure 28. It can be seen that while the application of the satellite filter increases both the north and east DOP values, there is a much larger increase in the east direction than the north direction.

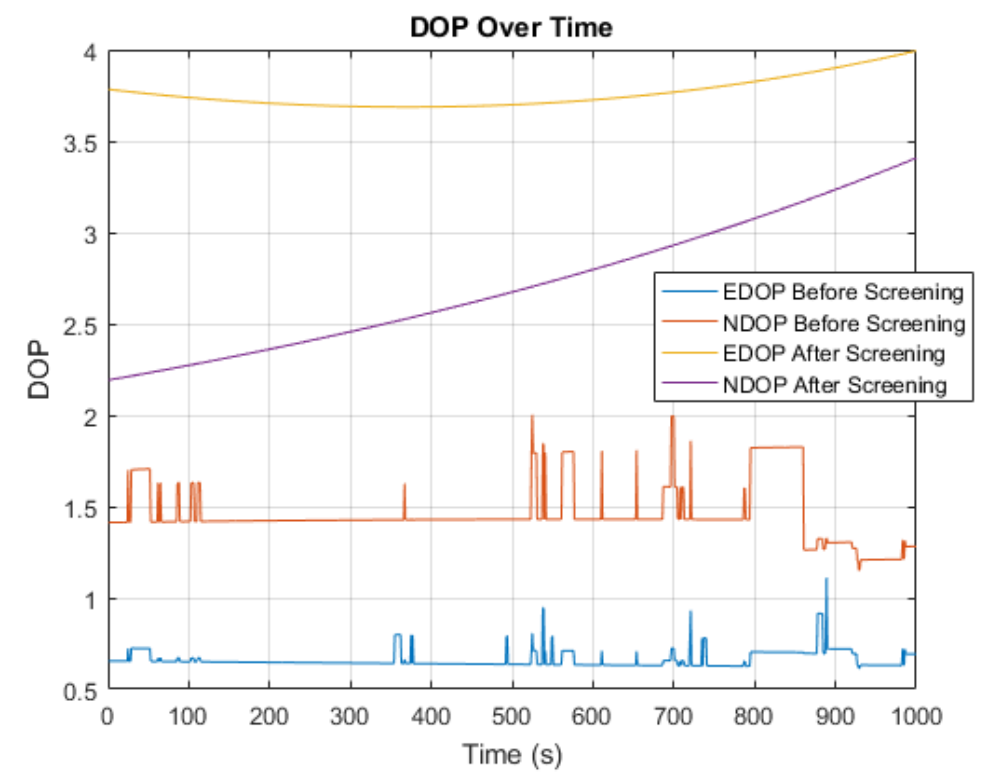

Figure 28. North and East DOP Values for Location 1.

The application of carrier smoothing, while having little effect on the average lateral error, significantly reduces the standard deviation of the solution due to the lower 
impact of multipath and receiver error present in the carrier measurement as depicted in Figure 29.
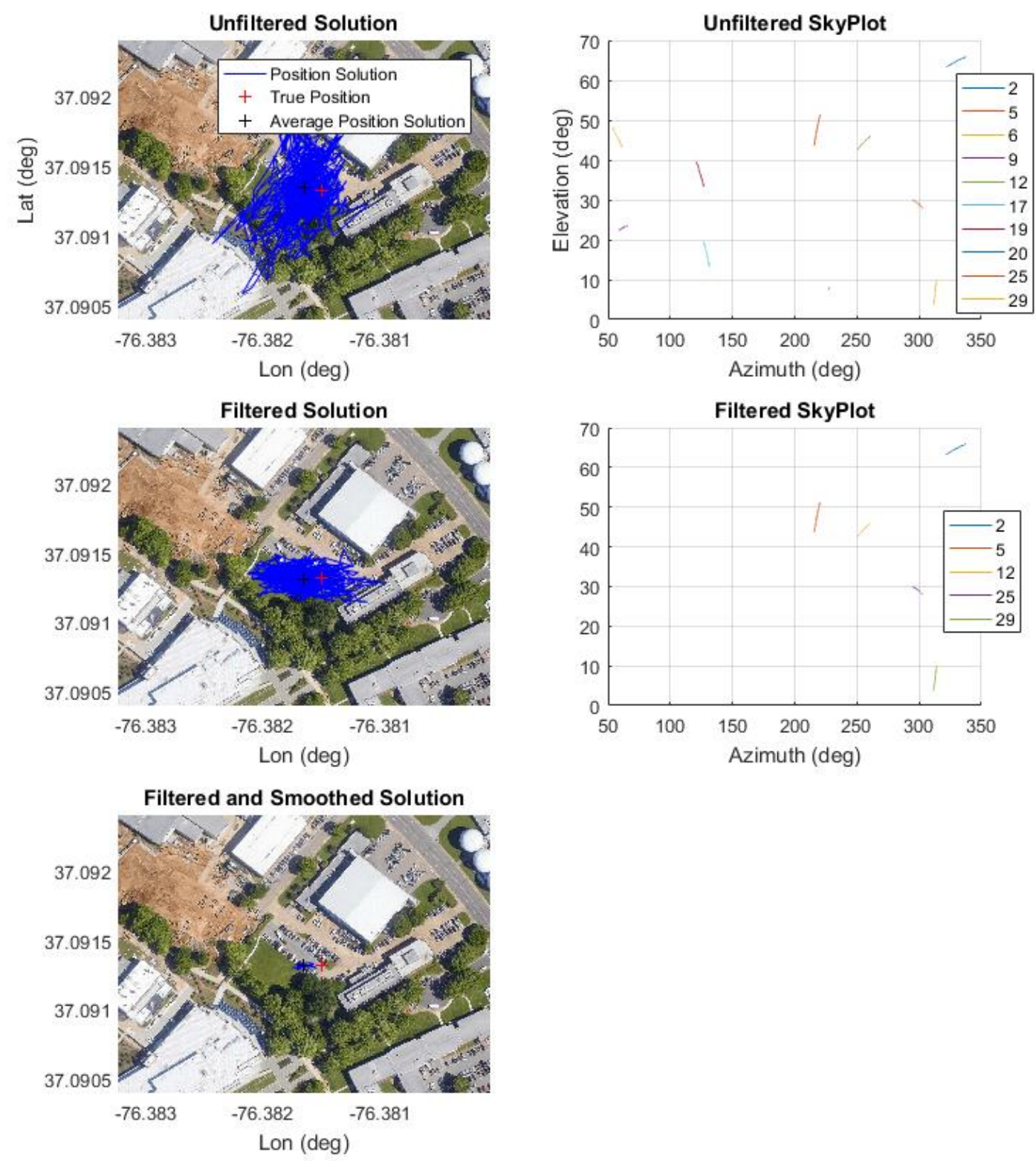

Figure 29. Graphs Depicting Solutions and Skyplots for Location 1. 
The results of Figure 29 are summarized in Table 3 where it can be seen that, while there is little change in the average lateral error of the solution between the unfiltered and filtered solution, the standard deviation of the solution is greatly reduced on the filtered solution. Additionally, when comparing the filtered solution with the filtered and smoothed solution, while there is again little change to the average lateral error, the standard deviation is reduced further as expected.

Table 3. Average Lateral Error and Standard Deviation of Solutions for Location 1.

\begin{tabular}{|c|c|c|c|c|c|}
\hline \multicolumn{2}{|c|}{ Unfiltered Solution } & \multicolumn{2}{c|}{ Filtered Solution } & \multicolumn{2}{c|}{$\begin{array}{c}\text { Filtered and } \\
\text { Smoothed Solution }\end{array}$} \\
\hline $\begin{array}{c}\text { Average } \\
\text { Lateral } \\
\text { Error }\end{array}$ & $\begin{array}{c}\text { Standard } \\
\text { Deviation }\end{array}$ & $\begin{array}{c}\text { Average } \\
\text { Lateral } \\
\text { Error }\end{array}$ & $\begin{array}{c}\text { Standard } \\
\text { Deviation }\end{array}$ & $\begin{array}{c}\text { Average } \\
\text { Lateral } \\
\text { Error }\end{array}$ & $\begin{array}{c}\text { Standard } \\
\text { Deviation }\end{array}$ \\
\hline & North: & & North: & & $\begin{array}{c}\text { North: } \\
13.368 \mathrm{~m}\end{array}$ \\
& $24.047 \mathrm{~m}$ & \multirow{2}{*}{$13.881 \mathrm{~m}$} & $6.867 \mathrm{~m}$ & $13.827 \mathrm{~m}$ & $1.099 \mathrm{~m}$ \\
& East: & East: & & \\
& $15.056 \mathrm{~m}$ & & $16.917 \mathrm{~m}$ & & $3.660 \mathrm{~m}$ \\
\hline
\end{tabular}

Figure 30 shows the solutions produced using corrections from the three base stations as well as their CMC residuals. It can be observed that the measurements from base station 3 have the lowest CMC residuals and, as a result, the utilization of corrections based on these measurements produces a solution with the lowest average lateral error. 

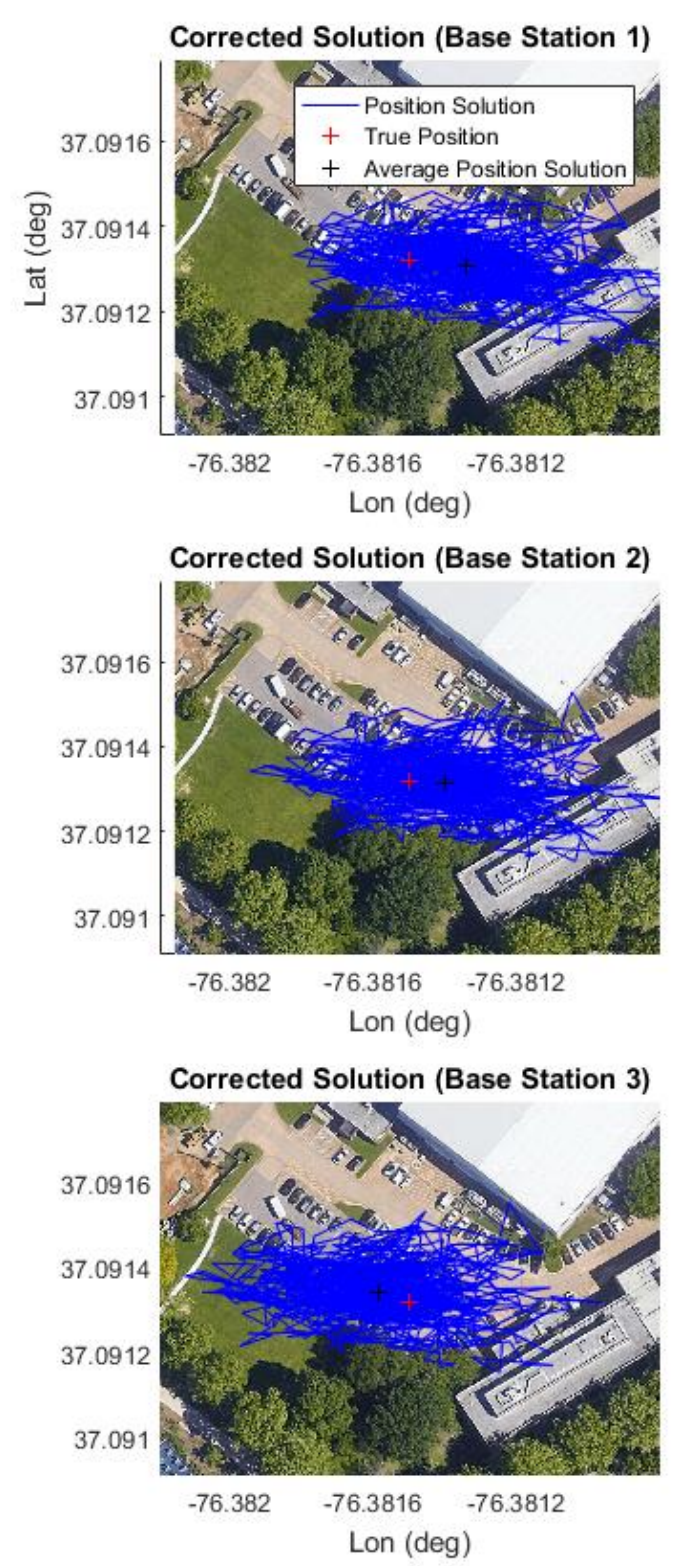
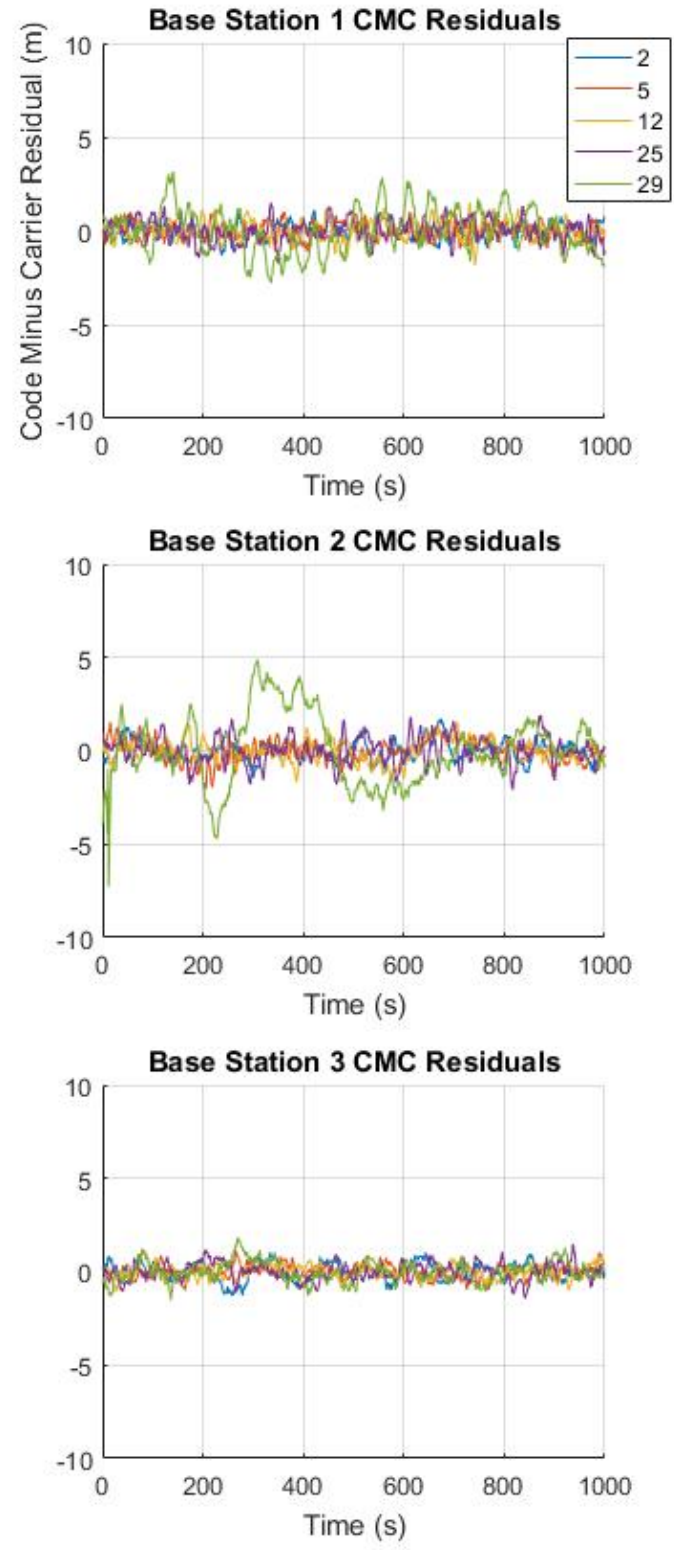

Figure 30. Solutions Produced Using Corrections for Location 1.

These results are summarized in Table 4 where it can be seen that the base station with the lowest sum of CMC residuals produces corrections that result in the lowest 
average lateral error. It is also shown that there is little variation in the standard deviation between the base station results.

Table 4. Base Station Correction Results for Location 1.

\begin{tabular}{|c|c|c|c|}
\hline & \multicolumn{3}{|c|}{ Corrected Solutions } \\
\hline & $\begin{array}{c}\text { Average } \\
\text { Lateral } \\
\text { Error }\end{array}$ & $\begin{array}{l}\text { Standard } \\
\text { Deviation }\end{array}$ & $\begin{array}{c}\text { Sum of } \\
\text { STD } \\
\text { CMC } \\
\text { Residuals }\end{array}$ \\
\hline $\begin{array}{c}\text { Station } \\
1\end{array}$ & $14.371 \mathrm{~m}$ & $\begin{array}{c}\text { North: } \\
6.949 \mathrm{~m} \\
\text { East: } \\
16.970 \mathrm{~m}\end{array}$ & $3.084 \mathrm{~m}$ \\
\hline $\begin{array}{c}\text { Station } \\
2\end{array}$ & $8.963 \mathrm{~m}$ & $\begin{array}{c}\text { North: } \\
6.931 \mathrm{~m} \\
\text { East: } \\
16.827 \mathrm{~m}\end{array}$ & $4.303 \mathrm{~m}$ \\
\hline $\begin{array}{c}\text { Station } \\
\mathbf{3}\end{array}$ & $8.344 \mathrm{~m}$ & $\begin{array}{c}\text { North: } \\
6.931 \mathrm{~m} \\
\text { East: } \\
16.828 \mathrm{~m}\end{array}$ & $2.197 \mathrm{~m}$ \\
\hline
\end{tabular}

The results of the rover solution produced using corrections from the base station with the lowest CMC residuals is compared to the filtered but uncorrected solution as well as the solution produced by the device in Figure 31 . 


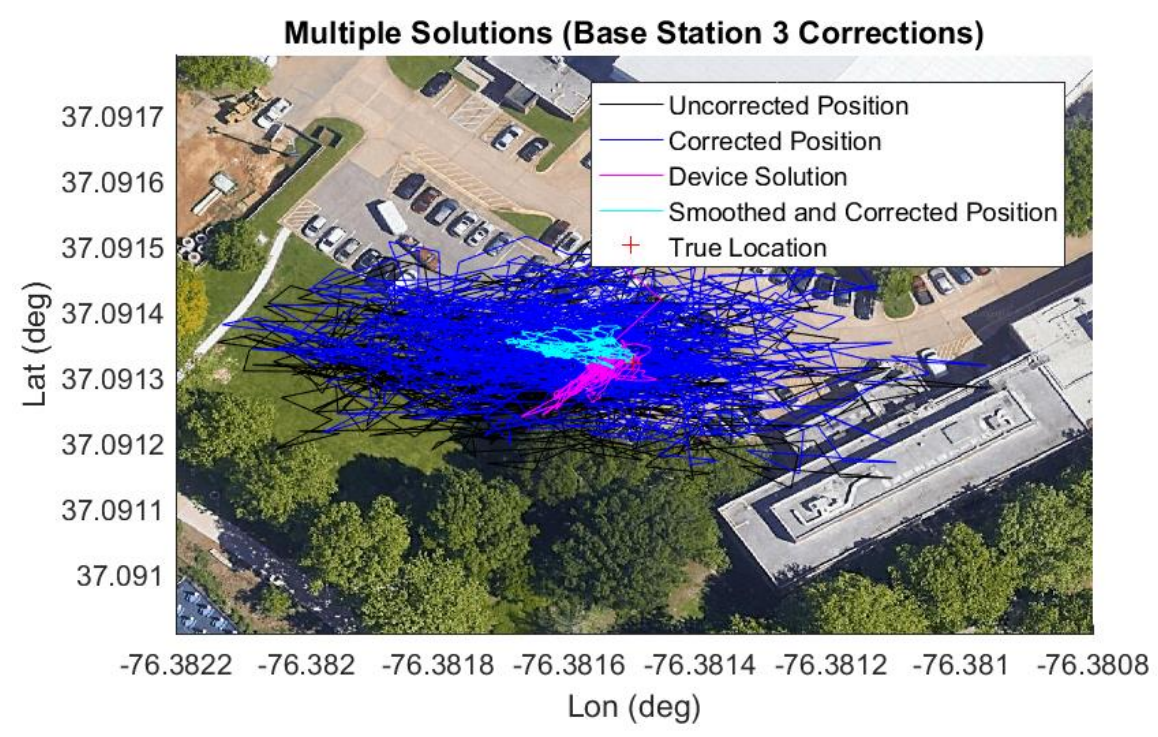

Figure 31. Graph of Solutions for Location 1.

The smoothed and corrected solution maintains the reduced lateral error from the corrections while obtaining a reduction in the standard deviation through the application of the carrier smoothing. However, while the final smoothed and corrected solution has a lower lateral error and standard deviation relative to the corrected solution, the lateral error of the device solution is smaller by several meters. This is likely due to the poor visibility due to the nearby buildings and foliage and other supplemental techniques utilized by the device's receiver. These results are summarized in Table 5. 
Table 5. Summary of Results for Location 1.

\begin{tabular}{|c|c|c|c|c|c|c|c|}
\hline \multicolumn{2}{|c|}{ Uncorrected Solution } & \multicolumn{2}{|c|}{ Corrected Solution } & \multicolumn{2}{c|}{ Device Solution } & \multicolumn{2}{c|}{$\begin{array}{c}\text { Smoothed and } \\
\text { Corrected Solution }\end{array}$} \\
\hline $\begin{array}{c}\text { Average } \\
\text { Lateral } \\
\text { Error }\end{array}$ & $\begin{array}{c}\text { Standard } \\
\text { Deviation }\end{array}$ & $\begin{array}{c}\text { Average } \\
\text { Lateral } \\
\text { Error }\end{array}$ & $\begin{array}{c}\text { Standard } \\
\text { Deviation }\end{array}$ & $\begin{array}{c}\text { Average } \\
\text { Lateral } \\
\text { Error }\end{array}$ & $\begin{array}{c}\text { Standard } \\
\text { Deviation }\end{array}$ & $\begin{array}{c}\text { Average } \\
\text { Lateral } \\
\text { Error }\end{array}$ & $\begin{array}{c}\text { Standard } \\
\text { Deviation }\end{array}$ \\
\hline & North: & & North: & & North: & & North: \\
$13.881 \mathrm{~m}$ & $6.867 \mathrm{~m}$ \\
& East: & $8.344 \mathrm{~m}$ & $6.931 \mathrm{~m}$ \\
& $16.917 \mathrm{~m}$ & & East: & $4.961 \mathrm{~m}$ & $\begin{array}{c}3.205 \mathrm{~m} \\
\text { East: }\end{array}$ & $8.372 \mathrm{~m}$ & $\begin{array}{c}1.308 \mathrm{~m} \\
\text { East: }\end{array}$ \\
& & $16.828 \mathrm{~m}$ & & $3.082 \mathrm{~m}$ & & $4.014 \mathrm{~m}$ \\
\hline
\end{tabular}

\subsubsection{Location 2}

For location 2, the satellite filter removed the satellites that were not consistently tracked. In this case, the average lateral error as well as the standard deviation are reduced. After filtering, the error ellipse appears to be nearly circular in shape. The application of carrier smoothing greatly reduces the standard deviation of the solution while having minimal impact on the average lateral error as shown in Figure 32. 

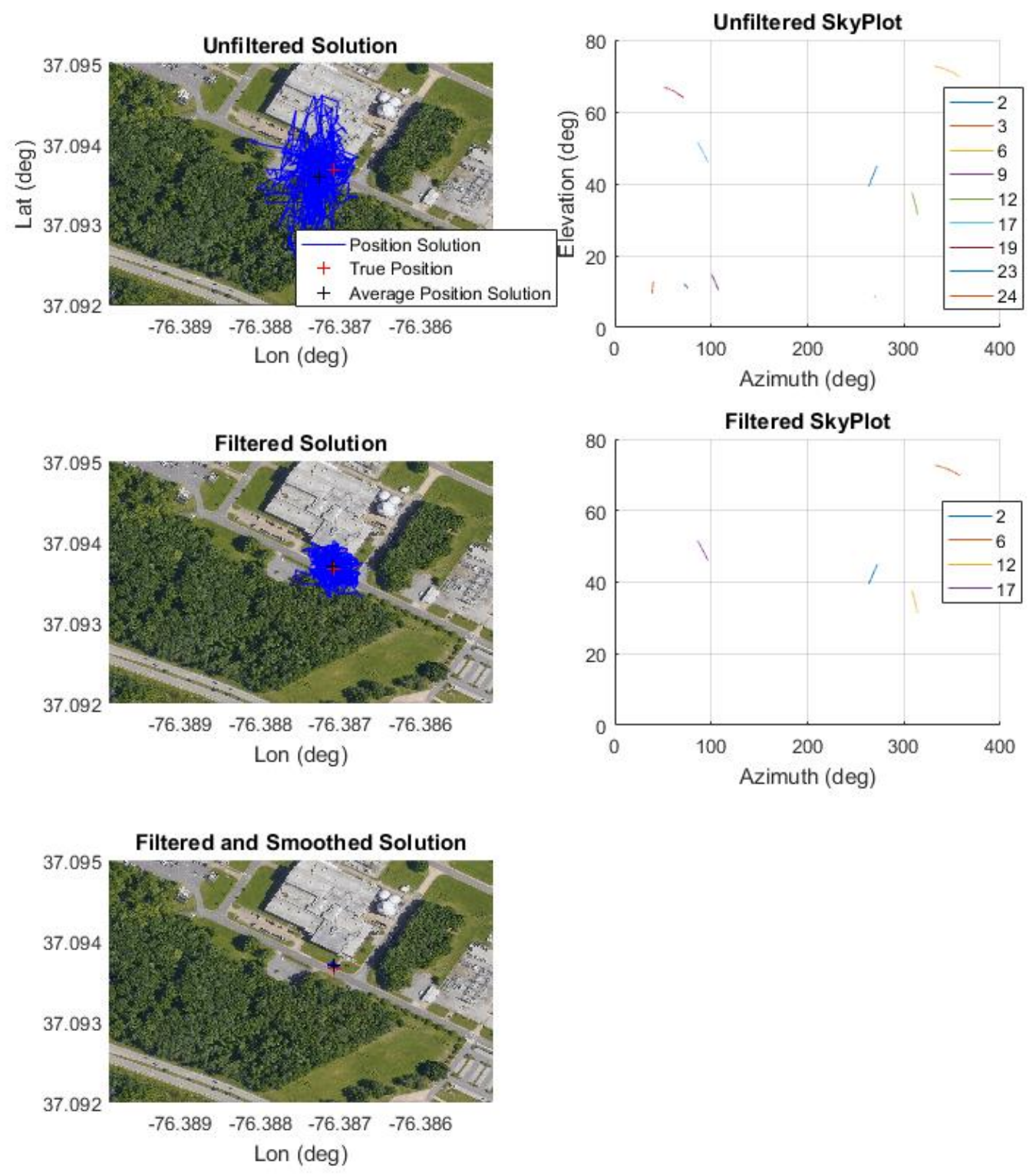

Figure 32. Graphs Depicting Solutions and Skyplots for Location 2.

These results are summarized in Table 6 where it is shown that is significant improvement of both the average lateral error and standard deviation between the unfiltered 
and filtered solutions. There is little difference in the average lateral error between the filtered and smoothed solutions. However, there is a large reduction in the standard deviation of the solution between the two.

Table 6. Average Lateral Error and Standard Deviation of Solutions for Location 2.

\begin{tabular}{|c|c|c|c|c|c|}
\hline \multicolumn{2}{|c|}{ Unfiltered Solution } & \multicolumn{2}{c|}{ Filtered Solution } & \multicolumn{2}{c|}{$\begin{array}{c}\text { Filtered and } \\
\text { Smoothed Solution }\end{array}$} \\
\hline $\begin{array}{c}\text { Average } \\
\text { Lateral } \\
\text { Error }\end{array}$ & $\begin{array}{c}\text { Standard } \\
\text { Deviation }\end{array}$ & $\begin{array}{c}\text { Average } \\
\text { Lateral } \\
\text { Error }\end{array}$ & $\begin{array}{c}\text { Standard } \\
\text { Deviation }\end{array}$ & $\begin{array}{c}\text { Average } \\
\text { Lateral } \\
\text { Error }\end{array}$ & $\begin{array}{c}\text { Standard } \\
\text { Deviation }\end{array}$ \\
\hline & North: & & North: & & $\begin{array}{c}\text { North: } \\
19.455 \mathrm{~m}\end{array}$ \\
$\begin{array}{c}35.463 \mathrm{~m} \\
\text { East: }\end{array}$ & $3.86 \mathrm{~m}$ & $\begin{array}{c}14.254 \mathrm{~m} \\
\text { East: }\end{array}$ & $3.332 \mathrm{~m}$ & $\begin{array}{c}2.489 \mathrm{~m} \\
\text { East: }\end{array}$ \\
& $16.276 \mathrm{~m}$ & & $12.373 \mathrm{~m}$ & & $2.514 \mathrm{~m}$ \\
\hline
\end{tabular}

Figure 33 depicts the solution produced when corrections from the three base stations are used to correct the measurements from the rover along with their CMC residuals. By visual inspection, it appears that measurements from base station 3 have the lowest CMC residuals during this time. Additionally, the solution produced using these corrections has the lowest average lateral error of the possible solutions. 

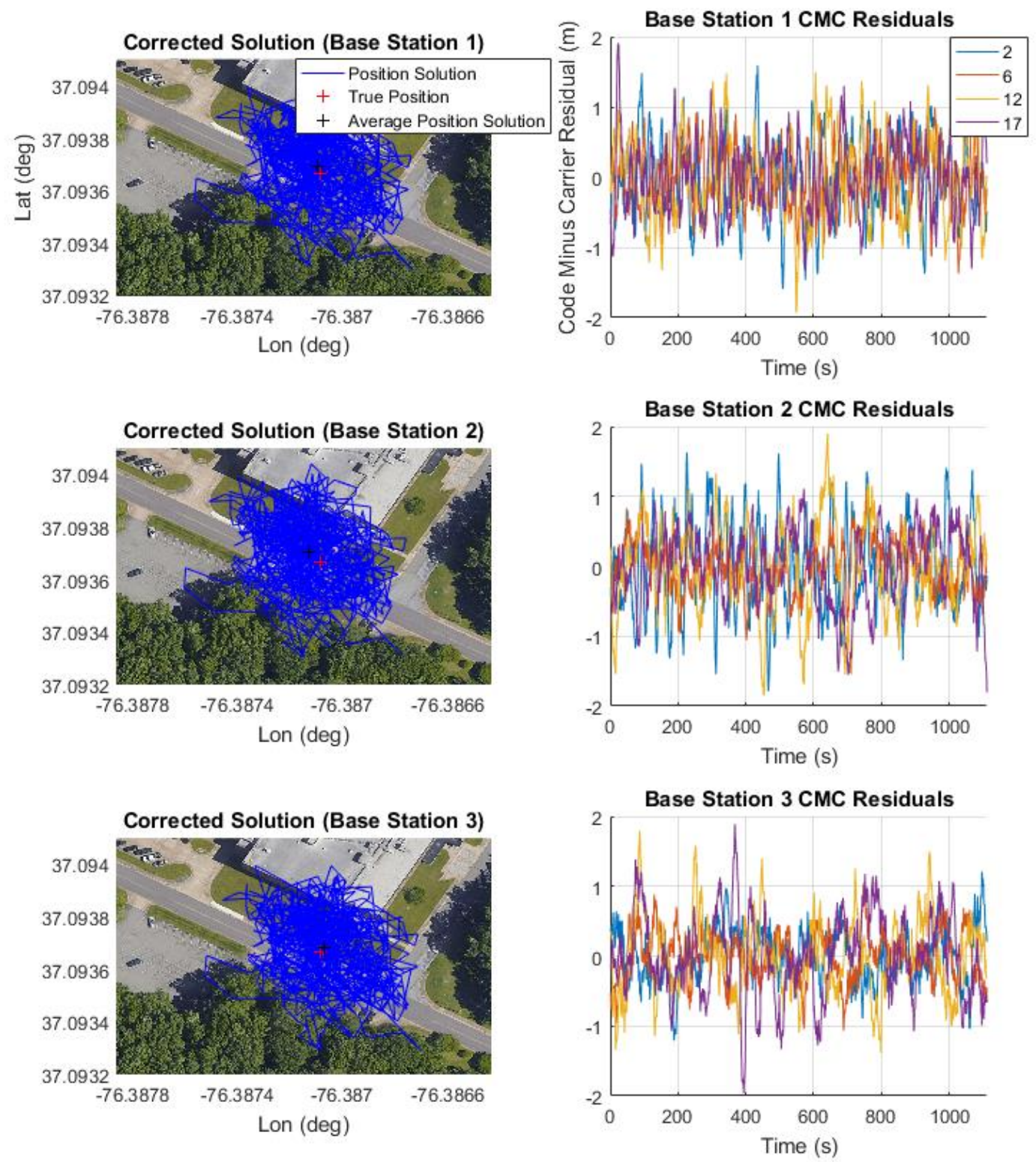

Figure 33. Solutions Produced Using Corrections for Location 2.

The results for this location are summarized in Table 7. It can be seen that the solution with the lowest average lateral error is produced using corrections from the base 
station with the lowest sum of the standard deviation of the CMC residuals. Additionally, as with the previous location, there is little variable in the standard deviation of the solution between the base stations.

\section{Table 7. Base Station Correction Results for Location 2.}

\begin{tabular}{|c|c|c|c|}
\hline & \multicolumn{3}{|c|}{ Corrected Solutions } \\
\hline & $\begin{array}{l}\text { Average } \\
\text { Lateral } \\
\text { Error }\end{array}$ & $\begin{array}{l}\text { Standard } \\
\text { Deviation }\end{array}$ & $\begin{array}{c}\text { Sum of } \\
\text { STD } \\
\text { CMC } \\
\text { Residuals }\end{array}$ \\
\hline $\begin{array}{c}\text { Station } \\
1\end{array}$ & $2.862 \mathrm{~m}$ & $\begin{array}{c}\text { North: } \\
14.303 \mathrm{~m} \\
\text { East: } \\
12.375 \mathrm{~m}\end{array}$ & $2.038 \mathrm{~m}$ \\
\hline $\begin{array}{c}\text { Station } \\
2\end{array}$ & $5.934 \mathrm{~m}$ & $\begin{array}{c}\text { North: } \\
14.484 \mathrm{~m} \\
\text { East: } \\
12.417 \mathrm{~m}\end{array}$ & $2.116 \mathrm{~m}$ \\
\hline $\begin{array}{c}\text { Station } \\
\mathbf{3}\end{array}$ & $2.192 \mathrm{~m}$ & $\begin{array}{c}\text { North: } \\
14.175 \mathrm{~m} \\
\text { East: } \\
12.394 \mathrm{~m}\end{array}$ & $1.840 \mathrm{~m}$ \\
\hline
\end{tabular}

The rover solution using the uncorrected, corrected, device solution, as well as the smoothed and corrected solution are shown in Figure 34 along with the true surveyed location. The results of the rover solution produced using corrections from the base station with the lowest $\mathrm{CMC}$ residuals is compared to the filtered but uncorrected solution as well as the solution produced by the device in Figure 31 . 


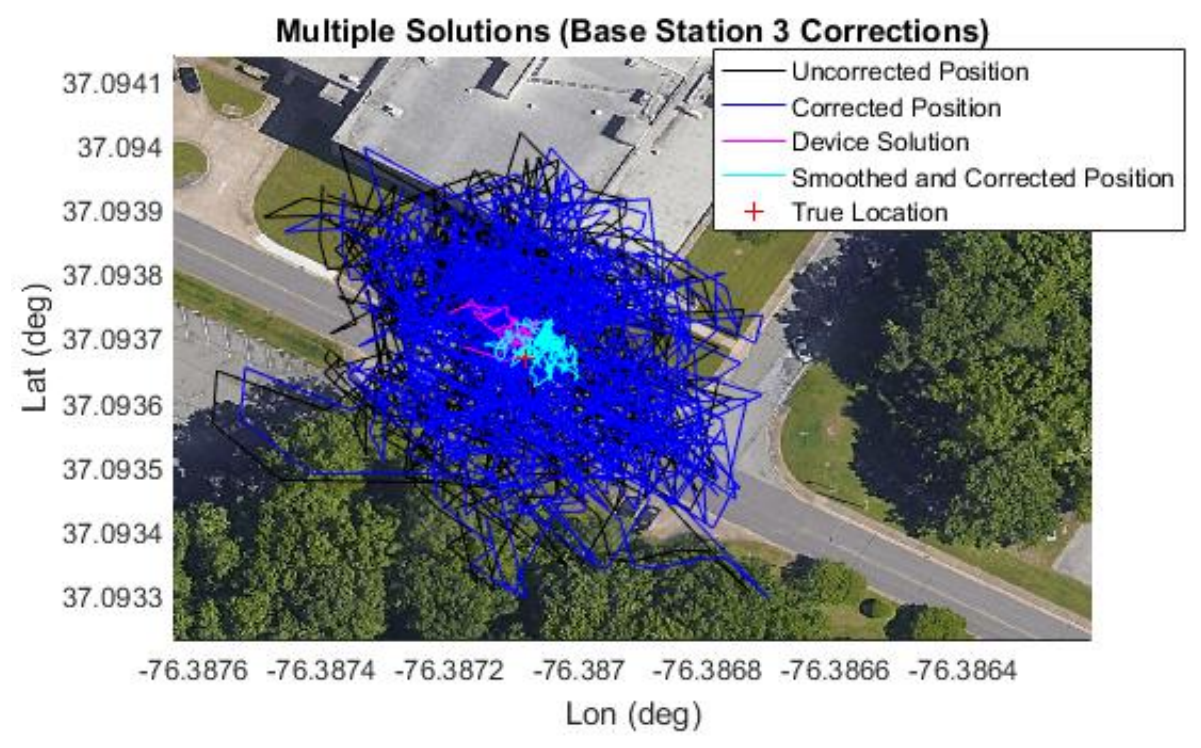

Figure 34. Graph of Solutions for Location 2.

The smoothed and corrected solution has a similar average lateral error as the corrected solution. However, the standard deviation is greatly reduced. When compared to the device solution, the smoothed and corrected solution has a lower average lateral error by about a meter and a similar standard deviation. These results are summarized in Table 8.

Table 8. Summary of Results for Location 2.

\begin{tabular}{|c|c|c|c|c|c|c|c|}
\hline \multicolumn{2}{|c|}{ Uncorrected Solution } & \multicolumn{2}{c|}{ Corrected Solution } & \multicolumn{2}{c|}{ Device Solution } & \multicolumn{2}{c|}{$\begin{array}{c}\text { Smoothed and } \\
\text { Corrected Solution }\end{array}$} \\
\hline $\begin{array}{c}\text { Average } \\
\text { Lateral } \\
\text { Error }\end{array}$ & $\begin{array}{c}\text { Standard } \\
\text { Deviation }\end{array}$ & $\begin{array}{c}\text { Average } \\
\text { Lateral } \\
\text { Error }\end{array}$ & $\begin{array}{c}\text { Standard } \\
\text { Deviation }\end{array}$ & $\begin{array}{c}\text { Average } \\
\text { Lateral } \\
\text { Error }\end{array}$ & $\begin{array}{c}\text { Standard } \\
\text { Deviation }\end{array}$ & $\begin{array}{c}\text { Average } \\
\text { Lateral } \\
\text { Error }\end{array}$ & $\begin{array}{c}\text { Standard } \\
\text { Deviation }\end{array}$ \\
\hline & North: & & North: & & North: & & North: \\
$3.863 \mathrm{~m}$ & $14.254 \mathrm{~m}$ & $2.192 \mathrm{~m}$ & $\begin{array}{c}14.175 \mathrm{~m} \\
\text { East: }\end{array}$ & $4.241 \mathrm{~m}$ & $\begin{array}{c}2.713 \mathrm{~m} \\
\text { East: }\end{array}$ & $3.00 \mathrm{~m}$ & $\begin{array}{c}2.348 \mathrm{~m} \\
\text { East: }\end{array}$ \\
& $12.373 \mathrm{~m}$ & & $\begin{array}{c}\text { East: } \\
12.394 \mathrm{~m}\end{array}$ & & $2.399 \mathrm{~m}$ & & $2.517 \mathrm{~m}$ \\
\hline
\end{tabular}




\subsubsection{Location 3}

For location 3, the application of the satellite filter removes only a few satellites that were not consistently tracked. However, this reduces the lateral average error as well as the standard deviation resulting in a circular error ellipse. The application of carrier smoothing significantly reduced the standard deviation of the solution while having a minimal impact on the average lateral error as seen in Figure 35. 

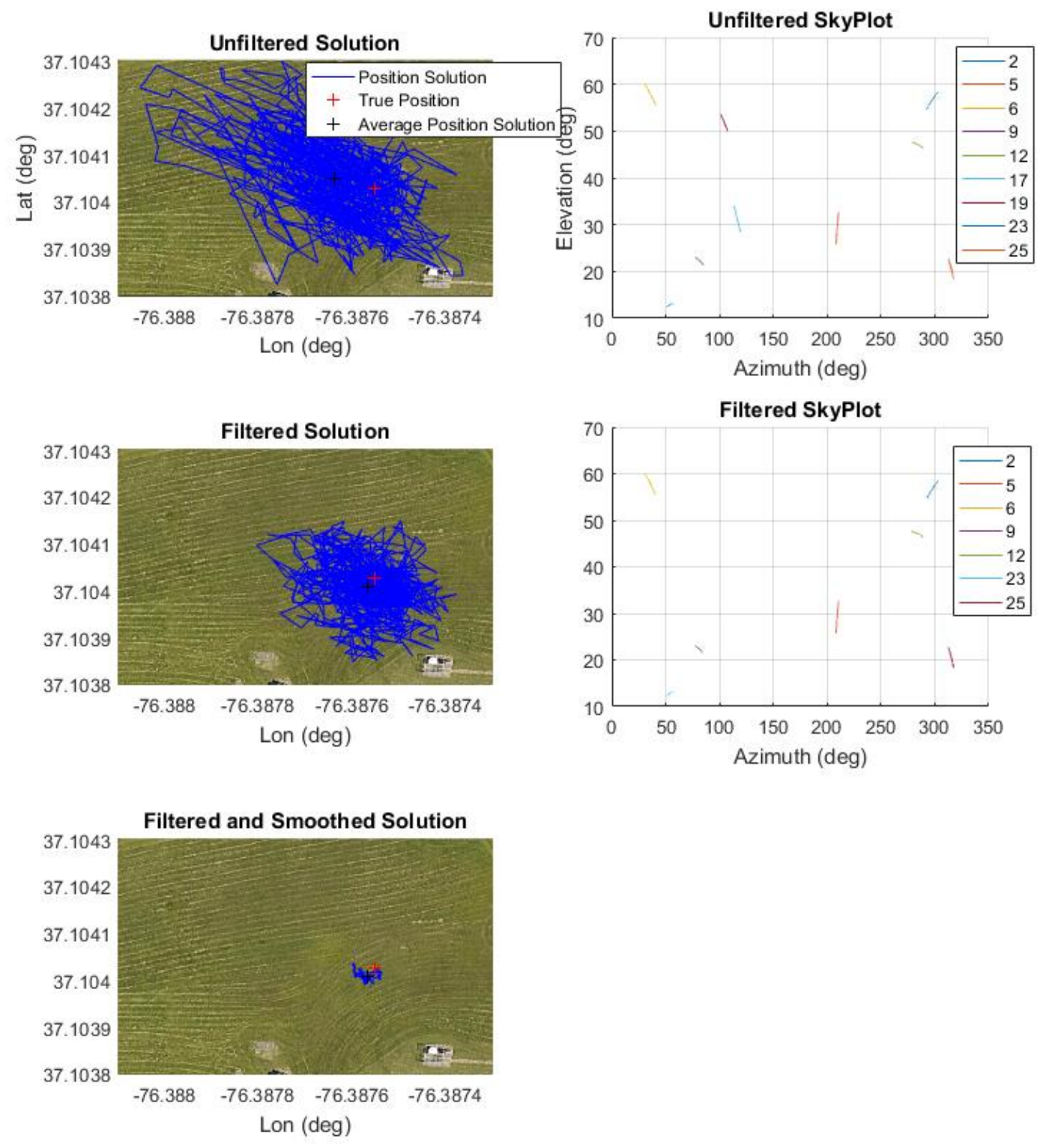

Figure 35. Graphs Depicting Solutions and Skyplots for Location 3.

The results of Figure 35 are summarized in Table 9. It can be seen that the filter reduces both the average lateral error as well as the standard deviation. As was seen in the 
previous locations, the carrier smoothing is shown to have minimal impact on the average lateral error while greatly reducing the standard deviation of the solution.

Table 9. Average Lateral Error and Standard Deviation of Solutions for Location 3.

\begin{tabular}{|c|c|c|c|c|c|}
\hline \multicolumn{2}{|c|}{ Unfiltered Solution } & \multicolumn{2}{|c|}{ Filtered Solution } & \multicolumn{2}{|c|}{$\begin{array}{c}\text { Filtered and } \\
\text { Smoothed Solution }\end{array}$} \\
\hline $\begin{array}{c}\text { Average } \\
\text { Lateral } \\
\text { Error }\end{array}$ & $\begin{array}{l}\text { Standard } \\
\text { Deviation }\end{array}$ & $\begin{array}{c}\text { Average } \\
\text { Lateral } \\
\text { Error }\end{array}$ & $\begin{array}{l}\text { Standard } \\
\text { Deviation }\end{array}$ & $\begin{array}{c}\text { Average } \\
\text { Lateral } \\
\text { Error }\end{array}$ & $\begin{array}{l}\text { Standard } \\
\text { Deviation }\end{array}$ \\
\hline $8.066 \mathrm{~m}$ & $\begin{array}{l}\text { North: } \\
9.035 \mathrm{~m} \\
\text { East: } \\
9.406 \mathrm{~m}\end{array}$ & $2.617 \mathrm{~m}$ & $\begin{array}{c}\text { North: } \\
5.965 \mathrm{~m} \\
\text { East: } \\
6.044 \mathrm{~m}\end{array}$ & $2.621 \mathrm{~m}$ & $\begin{array}{c}\text { North: } \\
0.868 \mathrm{~m} \\
\text { East: } \\
1.272 \mathrm{~m}\end{array}$ \\
\hline
\end{tabular}

Figure 36 shows the solutions produced using corrections from the three base stations as well as the $\mathrm{CMC}$ residuals of the base station receivers during this time. It can be seen that the measurements from base station 1 appear to have the lowest CMC residual values during this time period. Corrections from this base station also result in a solution with the lowest average lateral error. 

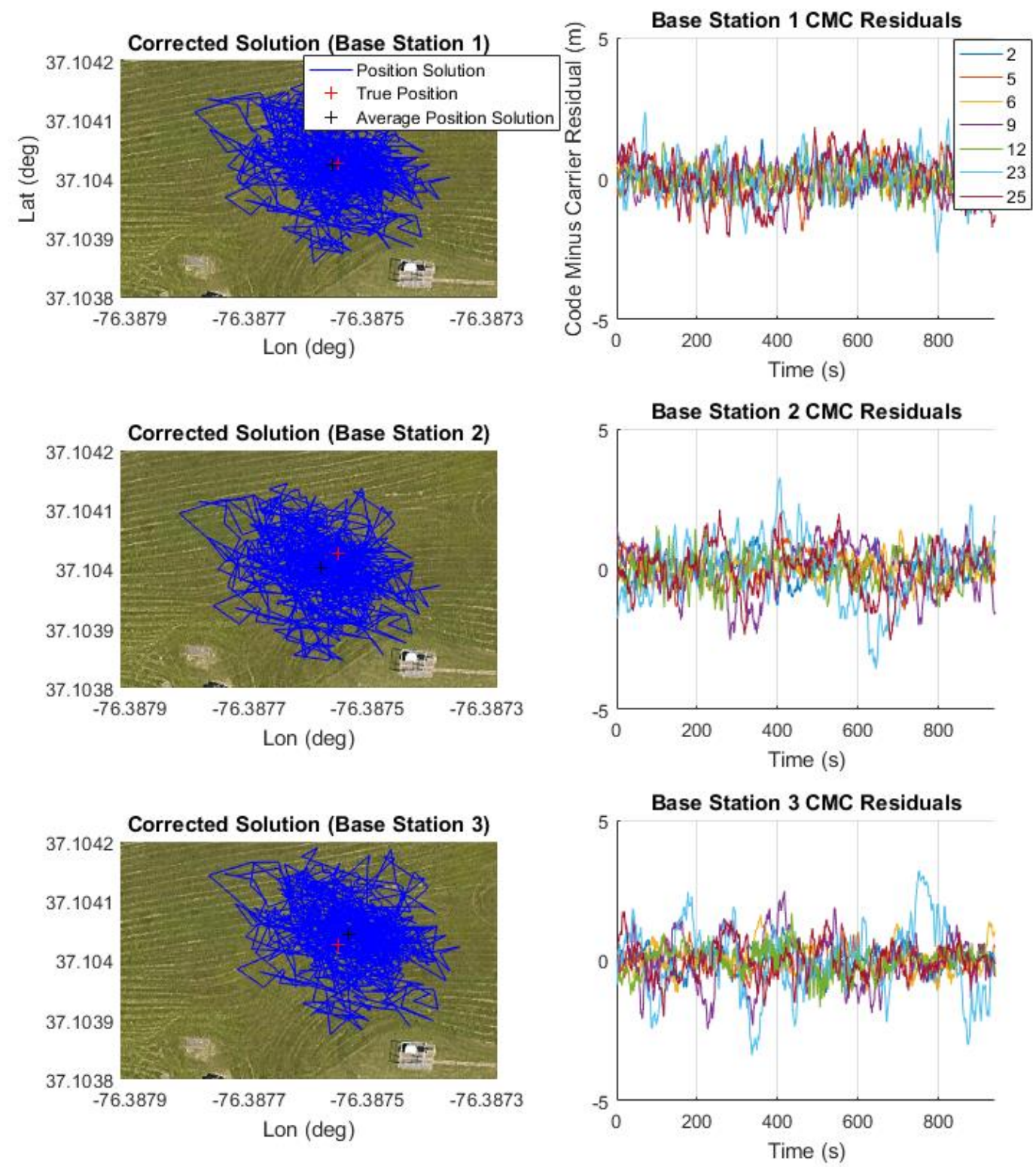

Figure 36. Solutions Produced Using Corrections for Location 3.

These results are summarized in Figure 36. As with the previous locations, it can be seen that there is little variation in the standard deviation of the solution produced using 
the three base stations. It can also be seen that the solution with the lowest average lateral error is produced using corrections from the base station with the lowest sum of the standard deviation CMC residuals.

Table 10. Base Station Correction Results for Location 3.

\begin{tabular}{|c|c|c|c|}
\hline & \multicolumn{3}{|c|}{ Corrected Solutions } \\
\hline & $\begin{array}{c}\text { Average } \\
\text { Lateral } \\
\text { Error }\end{array}$ & $\begin{array}{l}\text { Standard } \\
\text { Deviation }\end{array}$ & $\begin{array}{c}\text { Sum of } \\
\text { STD } \\
\text { CMC } \\
\text { Residuals }\end{array}$ \\
\hline $\begin{array}{c}\text { Station } \\
1\end{array}$ & $0.824 \mathrm{~m}$ & $\begin{array}{l}\text { North: } \\
6.020 \mathrm{~m} \\
\text { East: } \\
6.097 \mathrm{~m}\end{array}$ & $3.978 \mathrm{~m}$ \\
\hline $\begin{array}{c}\text { Station } \\
2\end{array}$ & $3.696 \mathrm{~m}$ & $\begin{array}{c}\text { North: } \\
6.060 \mathrm{~m} \\
\text { East: } \\
6.035 \mathrm{~m}\end{array}$ & $4.721 \mathrm{~m}$ \\
\hline $\begin{array}{c}\text { Station } \\
\mathbf{3}\end{array}$ & $2.514 \mathrm{~m}$ & $\begin{array}{l}\text { North: } \\
6.041 \mathrm{~m} \\
\text { East: } \\
6.056 \mathrm{~m}\end{array}$ & $4.526 \mathrm{~m}$ \\
\hline
\end{tabular}

A plot comparing the uncorrected, corrected, device solution and the smoothed and corrected solution is shown in Figure 37 along with the true surveyed location. 


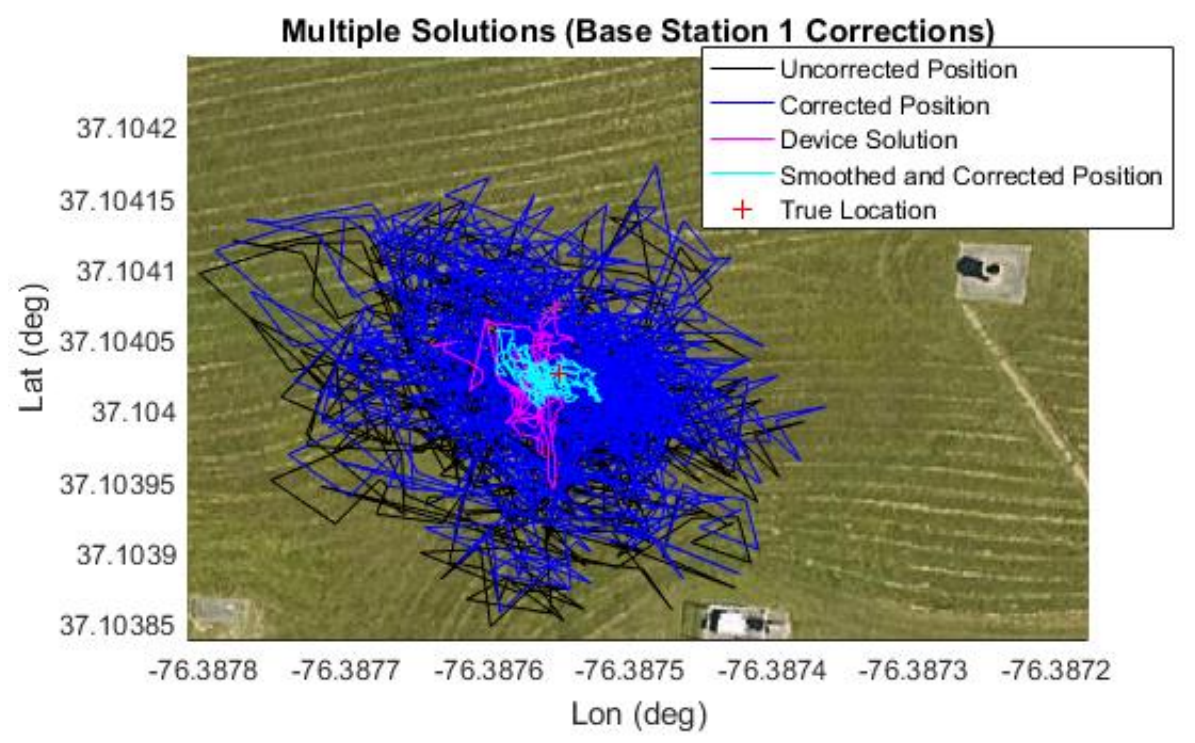

Figure 37. Graph of Solutions for Location 3.

As has been the case with previous solutions, the application of corrections reduces the average lateral error while having little impact on the standard deviation of the solution. The application of carrier smoothing has little impact on the average lateral error while further reducing the standard deviation of the solution. This can be seen in Table 11.

Table 11. Summary of Results for Location 3.

\begin{tabular}{|c|c|c|c|c|c|c|c|}
\hline \multicolumn{2}{|c|}{ Uncorrected Solution } & \multicolumn{2}{|c|}{ Corrected Solution } & \multicolumn{2}{|c|}{ Device Solution } & \multicolumn{2}{|c|}{$\begin{array}{c}\text { Smoothed and } \\
\text { Corrected Solution }\end{array}$} \\
\hline $\begin{array}{c}\text { Average } \\
\text { Lateral } \\
\text { Error } \\
\end{array}$ & $\begin{array}{l}\text { Standard } \\
\text { Deviation }\end{array}$ & $\begin{array}{c}\text { Average } \\
\text { Lateral } \\
\text { Error } \\
\end{array}$ & $\begin{array}{l}\text { Standard } \\
\text { Deviation }\end{array}$ & $\begin{array}{c}\text { Average } \\
\text { Lateral } \\
\text { Error } \\
\end{array}$ & $\begin{array}{l}\text { Standard } \\
\text { Deviation }\end{array}$ & $\begin{array}{c}\text { Average } \\
\text { Lateral } \\
\text { Error } \\
\end{array}$ & $\begin{array}{l}\text { Standard } \\
\text { Deviation }\end{array}$ \\
\hline $2.617 \mathrm{~m}$ & $\begin{array}{l}\text { North: } \\
5.965 \mathrm{~m} \\
\text { East: } \\
6.044 \mathrm{~m}\end{array}$ & $0.824 \mathrm{~m}$ & $\begin{array}{l}\text { North: } \\
6.020 \mathrm{~m} \\
\text { East: } \\
6.097 \mathrm{~m}\end{array}$ & $2.149 \mathrm{~m}$ & $\begin{array}{l}\text { North: } \\
3.146 \mathrm{~m} \\
\text { East: } \\
1.702 \mathrm{~m}\end{array}$ & $0.830 \mathrm{~m}$ & $\begin{array}{l}\text { North: } \\
1.099 \mathrm{~m} \\
\text { East: } \\
1.525 \mathrm{~m}\end{array}$ \\
\hline
\end{tabular}




\subsubsection{Location 4}

At this location, the satellite filter removes several satellites that were not consistently tracked during the observation. This appears to have reduced the average lateral error as well as the standard deviation of the solution. As is seen with previous location, the application of carrier smoothing greatly reduces the standard deviation of the solution while having little impact on the average lateral error. This can be seen in Figure 38. 

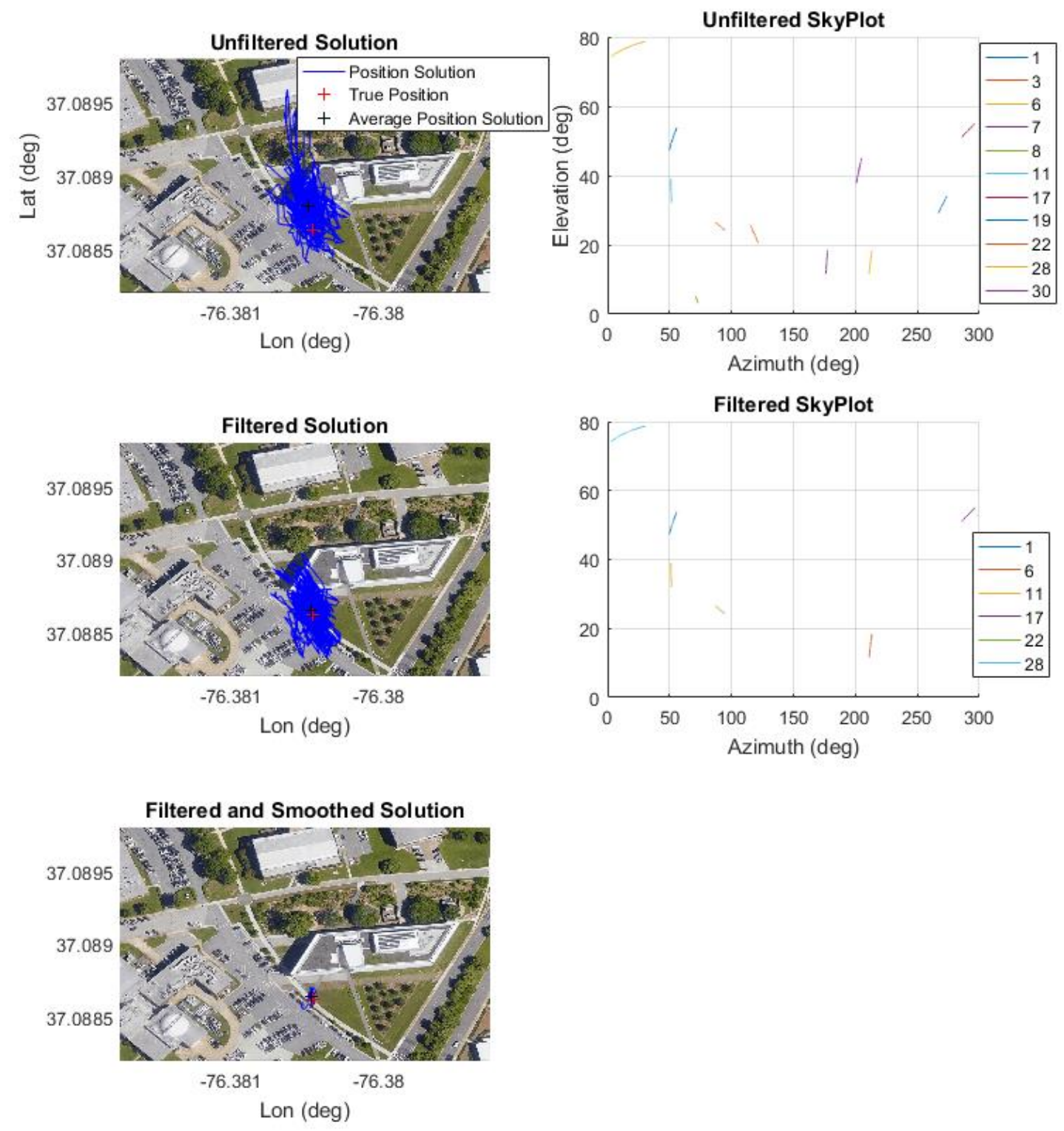

Figure 38. Graphs Depicting Solutions and Skyplots for Location 4.

These results are shown in Table 12 where it can be seen that the application of the filter reduces both the average lateral error as well as the standard deviation of the solution. 
The carrier smoothing has little impact on the average lateral error while further reducing the standard deviation of the solution.

Table 12. Average Lateral Error and Standard Deviation of Solutions for Location 4.

\begin{tabular}{|c|c|c|c|c|c|}
\hline \multicolumn{2}{|c|}{ Unfiltered Solution } & \multicolumn{2}{|c|}{ Filtered Solution } & \multicolumn{2}{|c|}{$\begin{array}{c}\text { Filtered and } \\
\text { Smoothed Solution }\end{array}$} \\
\hline $\begin{array}{c}\text { Average } \\
\text { Lateral } \\
\text { Error }\end{array}$ & $\begin{array}{l}\text { Standard } \\
\text { Deviation }\end{array}$ & $\begin{array}{c}\text { Average } \\
\text { Lateral } \\
\text { Error }\end{array}$ & $\begin{array}{l}\text { Standard } \\
\text { Deviation }\end{array}$ & $\begin{array}{c}\text { Average } \\
\text { Lateral } \\
\text { Error }\end{array}$ & $\begin{array}{l}\text { Standard } \\
\text { Deviation }\end{array}$ \\
\hline $18.760 \mathrm{~m}$ & $\begin{array}{c}\text { North: } \\
16.897 \mathrm{~m} \\
\text { East: } \\
7.054 \mathrm{~m}\end{array}$ & $2.617 \mathrm{~m}$ & $\begin{array}{c}\text { North: } \\
5.965 \mathrm{~m} \\
\text { East: } \\
6.044 \mathrm{~m}\end{array}$ & $2.589 \mathrm{~m}$ & $\begin{array}{c}\text { North: } \\
3.730 \mathrm{~m} \\
\text { East: } \\
1.394 \mathrm{~m}\end{array}$ \\
\hline
\end{tabular}

The solutions produced using corrections from the three ground stations are shown in Figure 39. It can be seen that the solution with the lowest average lateral error is produced using corrections from the base station with the lowest CMC residual values. 

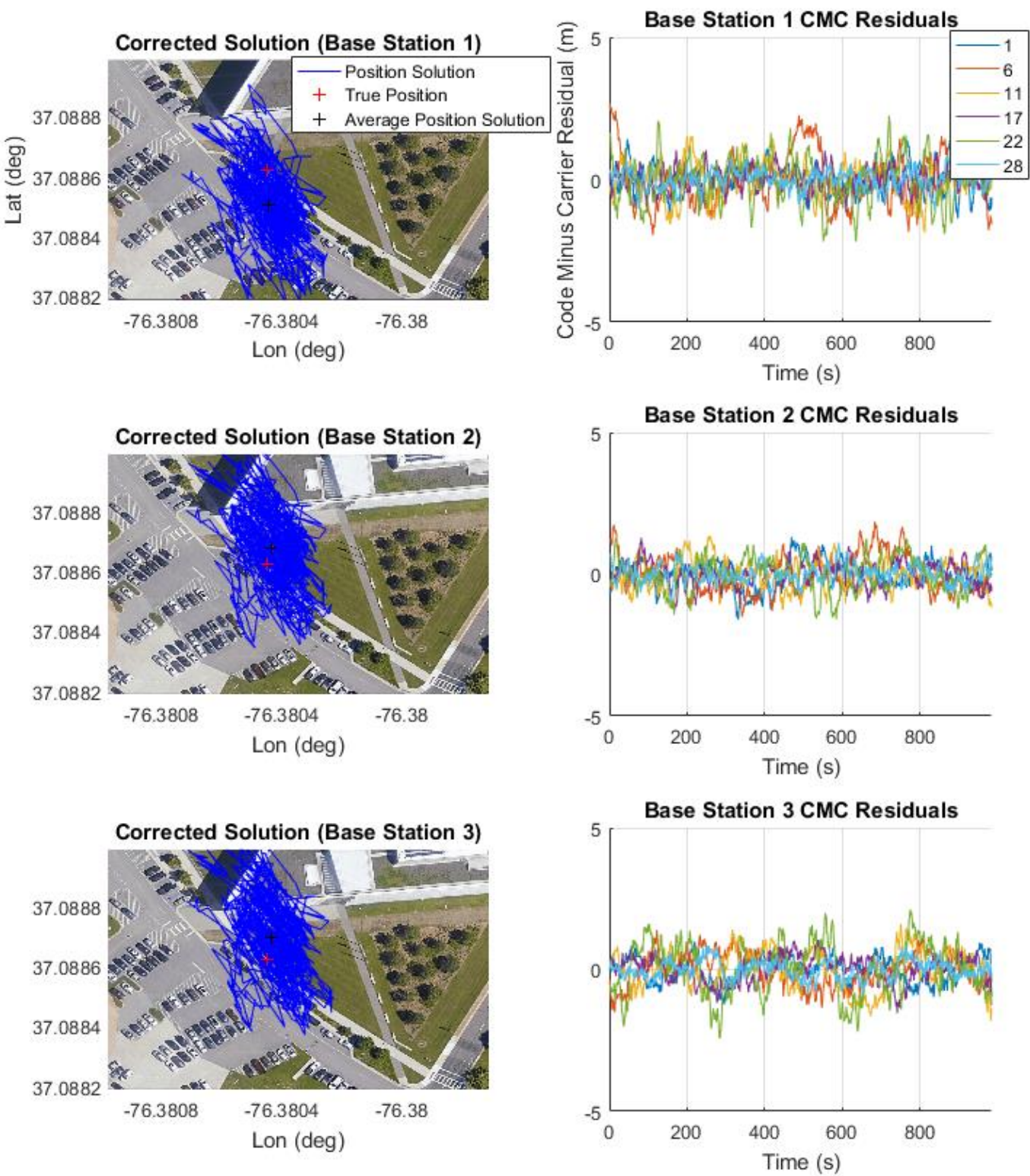

Figure 39. Solutions Produced Using Corrections for Location 4.

This is confirmed in Table 13 where it is shown that the solution with the lowest average lateral error is produced by the base station measurements with the lowest sum of 
standard deviation CMC residuals value. There is also little variation in the standard deviation of the solutions produced using the three sets of corrections.

Table 13. Base Station Correction Results for Location 4.

\begin{tabular}{|c|c|c|c|}
\hline & \multicolumn{3}{|c|}{ Corrected Solutions } \\
\hline & $\begin{array}{c}\text { Average } \\
\text { Lateral } \\
\text { Error }\end{array}$ & $\begin{array}{l}\text { Standard } \\
\text { Deviation }\end{array}$ & $\begin{array}{c}\text { Sum of } \\
\text { STD } \\
\text { CMC } \\
\text { Residuals }\end{array}$ \\
\hline $\begin{array}{c}\text { Station } \\
1\end{array}$ & $13.039 \mathrm{~m}$ & $\begin{array}{c}\text { North: } \\
13.837 \mathrm{~m} \\
\text { East: } \\
6.984 \mathrm{~m}\end{array}$ & $3.601 \mathrm{~m}$ \\
\hline $\begin{array}{c}\text { Station } \\
2\end{array}$ & $6.390 \mathrm{~m}$ & $\begin{array}{c}\text { North: } \\
14.176 \mathrm{~m} \\
\text { East: } \\
6.968 \mathrm{~m}\end{array}$ & $2.972 \mathrm{~m}$ \\
\hline $\begin{array}{c}\text { Station } \\
3\end{array}$ & $8.480 \mathrm{~m}$ & $\begin{array}{c}\text { North: } \\
14.130 \mathrm{~m} \\
\text { East: } \\
7.009 \mathrm{~m}\end{array}$ & $3.418 \mathrm{~m}$ \\
\hline
\end{tabular}

The solutions produced using the uncorrected, corrected, and smoothed and corrected measurements are compared to the device solution and the true surveyed location in Figure 40. 


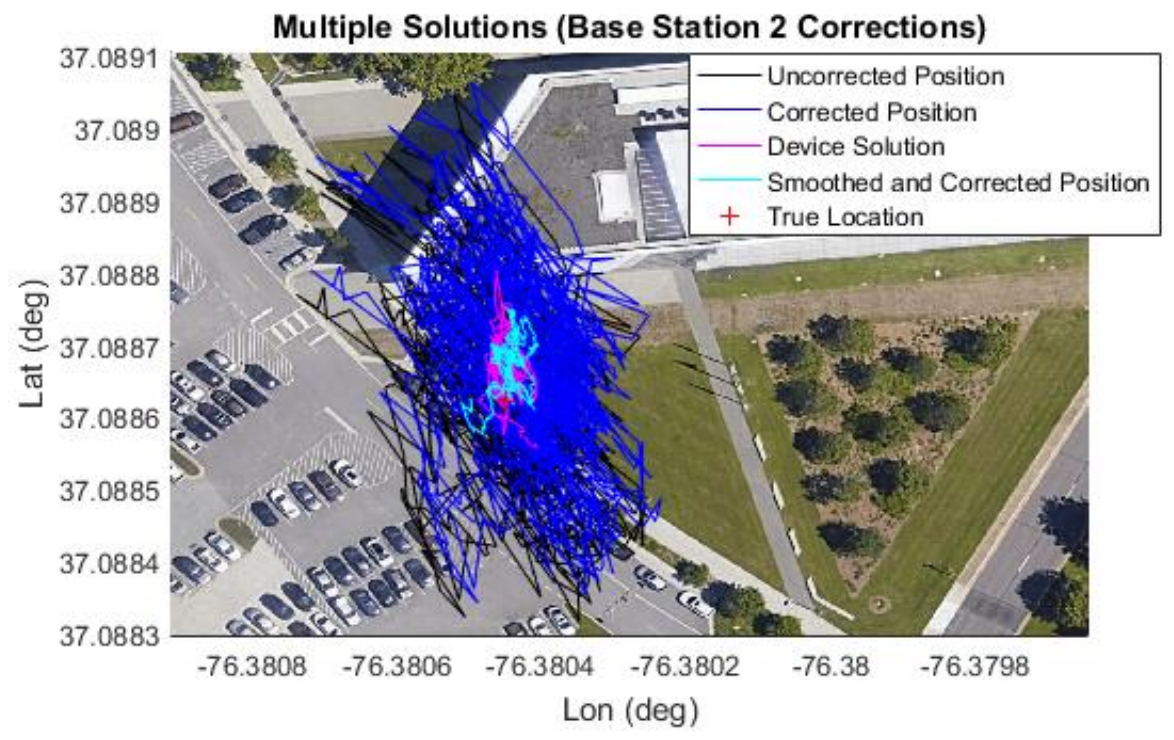

Figure 40. Graph of Solutions for Location 4.

These results are summarized in Table 14 where it can be seen that the corrections from the base station with the lowest sum of standard deviation of the CMC residuals appears to increase the average lateral error while slightly reducing the standard deviation. The application of the carrier smoothing further reduces the average lateral error as well as the standard deviation. The average lateral error of the final smoothed and corrected solution is about a meter larger than the device solution. The error introduced by the corrections may be due multipath on the measurements of the rover that are not contained within the corrections. 
Table 14. Summary of Results for Location 4.

\begin{tabular}{|c|c|c|c|c|c|c|c|}
\hline \multicolumn{2}{|c|}{ Uncorrected Solution } & \multicolumn{2}{|c|}{ Corrected Solution } & \multicolumn{2}{|c|}{ Device Solution } & \multicolumn{2}{|c|}{$\begin{array}{c}\text { Smoothed and } \\
\text { Corrected Solution }\end{array}$} \\
\hline $\begin{array}{c}\text { Average } \\
\text { Lateral } \\
\text { Error } \\
\end{array}$ & $\begin{array}{l}\text { Standard } \\
\text { Deviation }\end{array}$ & $\begin{array}{c}\text { Average } \\
\text { Lateral } \\
\text { Error }\end{array}$ & $\begin{array}{l}\text { Standard } \\
\text { Deviation }\end{array}$ & $\begin{array}{c}\text { Average } \\
\text { Lateral } \\
\text { Error }\end{array}$ & $\begin{array}{l}\text { Standard } \\
\text { Deviation }\end{array}$ & $\begin{array}{c}\text { Average } \\
\text { Lateral } \\
\text { Error }\end{array}$ & $\begin{array}{l}\text { Standard } \\
\text { Deviation }\end{array}$ \\
\hline $2.826 \mathrm{~m}$ & $\begin{array}{c}\text { North: } \\
16.897 \mathrm{~m} \\
\text { East: } \\
7.054 \mathrm{~m}\end{array}$ & $6.390 \mathrm{~m}$ & $\begin{array}{l}\text { North: } \\
14.176 \mathrm{~m} \\
\text { East: } \\
6.968 \mathrm{~m}\end{array}$ & $4.848 \mathrm{~m}$ & $\begin{array}{l}\text { North: } \\
5.355 \mathrm{~m} \\
\text { East: } \\
1.212 \mathrm{~m}\end{array}$ & $5.871 \mathrm{~m}$ & $\begin{array}{l}\text { North: } \\
3.903 \mathrm{~m} \\
\text { East: } \\
1.599 \mathrm{~m}\end{array}$ \\
\hline
\end{tabular}

\subsubsection{Location 5}

For this location, the application of the satellite filter removes several satellites from the solution. In this case, the filter appears to be particularly successful at reducing a large bias that is caused by the inconsistently tracked satellites. The application of carrier smoothing, as is true of the other locations, further reduces the standard deviation of the solution. 

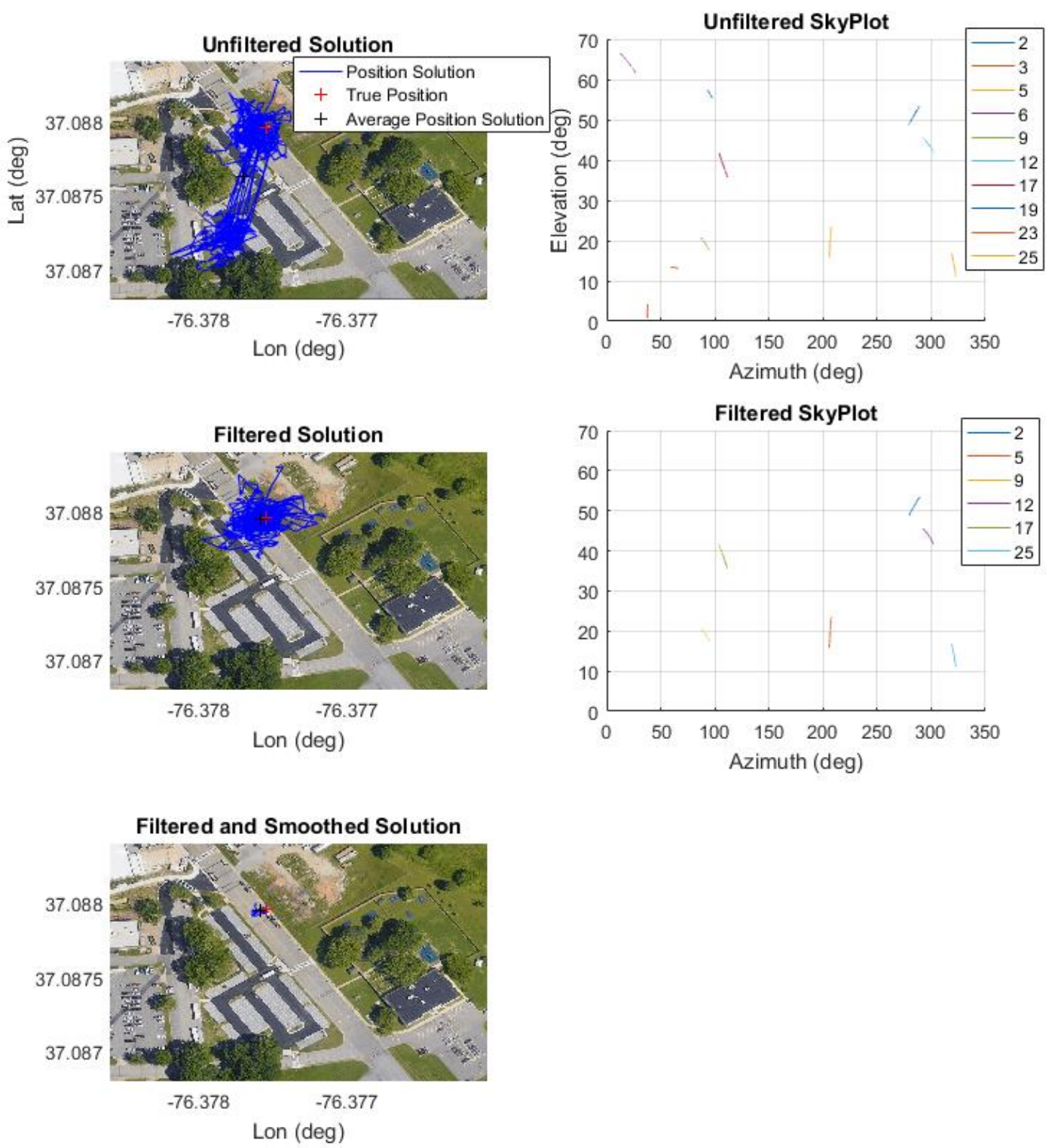

Figure 41. Graphs Depicting Solutions and Skyplots for Location 5.

For this location, the solution converges around two location. This occurs as measurements from satellite 3 come in and out of the solution as the satellite travels beyond 
the horizon. These results are shown in Table 15 where it can be seen that both the standard deviation and average lateral error are significantly reduced by the application of the filter which included the removal of measurements from satellite 3. Additionally, it is shown that smoothing of the solution has only a minor impact on the average lateral error of the solution but further reduces the standard deviation.

Table 15. Average Lateral Error and Standard Deviation of Solutions for Location 5.

\begin{tabular}{|c|c|c|c|c|c|}
\hline \multicolumn{2}{|c|}{ Unfiltered Solution } & \multicolumn{2}{|c|}{ Filtered Solution } & \multicolumn{2}{|c|}{$\begin{array}{c}\text { Filtered and } \\
\text { Smoothed Solution }\end{array}$} \\
\hline $\begin{array}{c}\text { Average } \\
\text { Lateral } \\
\text { Error }\end{array}$ & $\begin{array}{l}\text { Standard } \\
\text { Deviation }\end{array}$ & $\begin{array}{c}\text { Average } \\
\text { Lateral } \\
\text { Error } \\
\end{array}$ & $\begin{array}{l}\text { Standard } \\
\text { Deviation }\end{array}$ & $\begin{array}{c}\text { Average } \\
\text { Lateral } \\
\text { Error } \\
\end{array}$ & $\begin{array}{l}\text { Standard } \\
\text { Deviation }\end{array}$ \\
\hline $39.604 \mathrm{~m}$ & $\begin{array}{c}\text { North: } \\
40.082 \mathrm{~m} \\
\text { East: } \\
11.123 \mathrm{~m}\end{array}$ & $3.977 \mathrm{~m}$ & $\begin{array}{l}\text { North: } \\
7.900 \mathrm{~m} \\
\text { East: } \\
9.440 \mathrm{~m}\end{array}$ & $3.681 \mathrm{~m}$ & $\begin{array}{c}\text { North: } \\
1.494 \mathrm{~m} \\
\text { East: } \\
2.797 \mathrm{~m}\end{array}$ \\
\hline
\end{tabular}

Figure 42 shows the solutions produced using corrections from the base stations along with the $\mathrm{CMC}$ residual values of the base station measurements. As with the previous locations, it appears that the solution with the lowest average lateral error is produced with the base station with the lowest CMC residual values. 

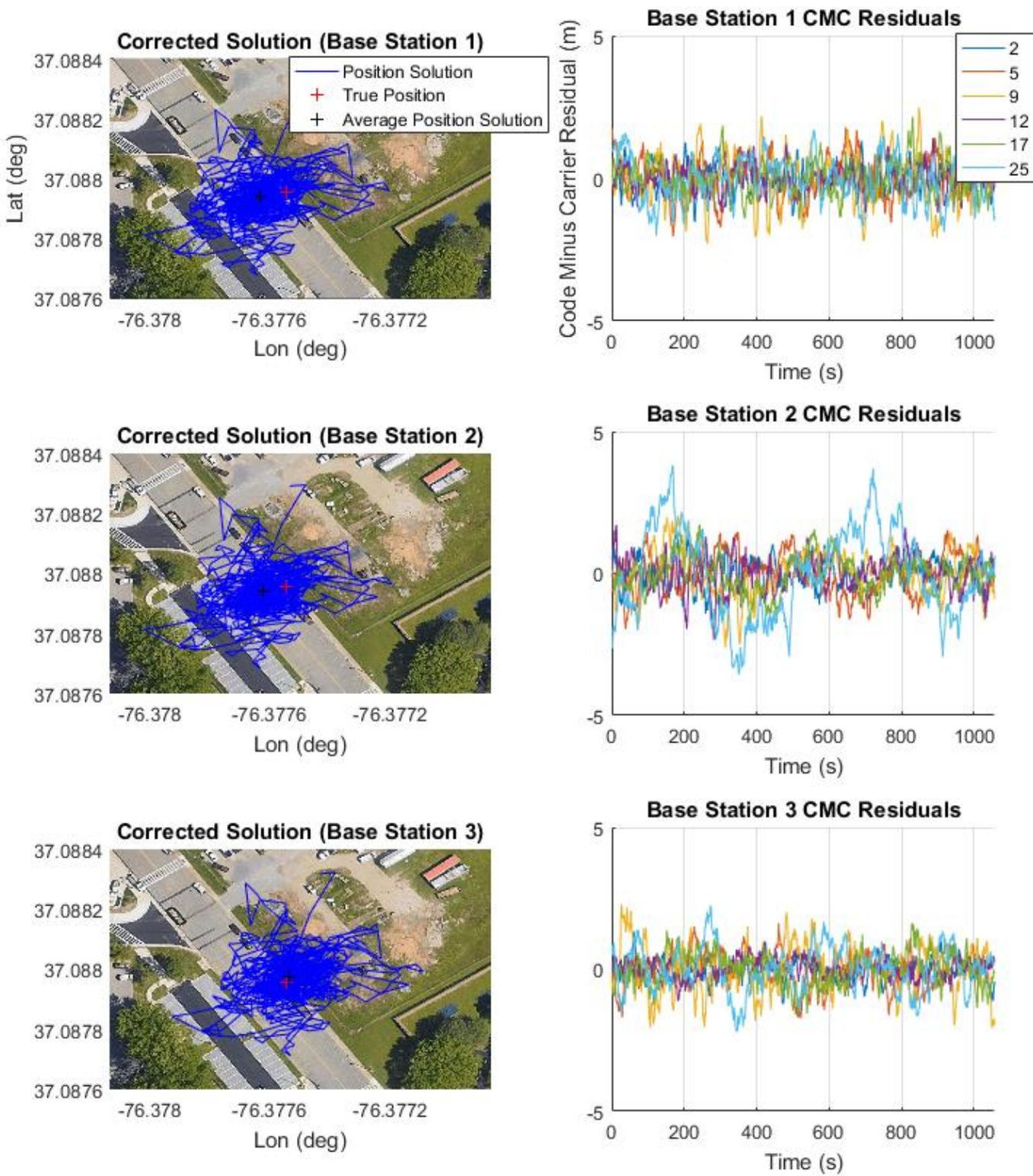

Figure 42. Solutions Produced Using Corrections for Location 5.

The results of this graph are summarized in Table 16. It is shown that while there is little variation in the standard deviation, the solution with the lowest average lateral error 
is produced using corrections from the base station with the lowest sum of the standard deviation CMC residuals.

Table 16. Base Station Correction Results for Location 5.

\begin{tabular}{|c|c|c|c|}
\hline & \multicolumn{3}{|c|}{ Corrected Solutions } \\
\hline & $\begin{array}{c}\text { Average } \\
\text { Lateral } \\
\text { Error }\end{array}$ & $\begin{array}{l}\text { Standard } \\
\text { Deviation }\end{array}$ & $\begin{array}{c}\text { Sum of } \\
\text { STD } \\
\text { CMC } \\
\text { Residuals } \\
\end{array}$ \\
\hline $\begin{array}{l}\text { Station } \\
\quad 1\end{array}$ & $8.027 \mathrm{~m}$ & $\begin{array}{c}\text { North: } \\
7.888 \mathrm{~m} \\
\text { East: } \\
9.502 \mathrm{~m}\end{array}$ & $3.816 \mathrm{~m}$ \\
\hline $\begin{array}{c}\text { Station } \\
2\end{array}$ & $7.128 \mathrm{~m}$ & $\begin{array}{l}\text { North: } \\
8.006 \mathrm{~m} \\
\text { East: } \\
9.412 \mathrm{~m}\end{array}$ & $4.792 \mathrm{~m}$ \\
\hline $\begin{array}{c}\text { Station } \\
\mathbf{3}\end{array}$ & $2.339 \mathrm{~m}$ & $\begin{array}{l}\text { North: } \\
7.907 \mathrm{~m} \\
\text { East: } \\
9.460 \mathrm{~m}\end{array}$ & $3.469 \mathrm{~m}$ \\
\hline
\end{tabular}

The uncorrected, corrected, and smoothed and corrected solutions are compared to the device solution and the true surveyed location in Figure 43. 


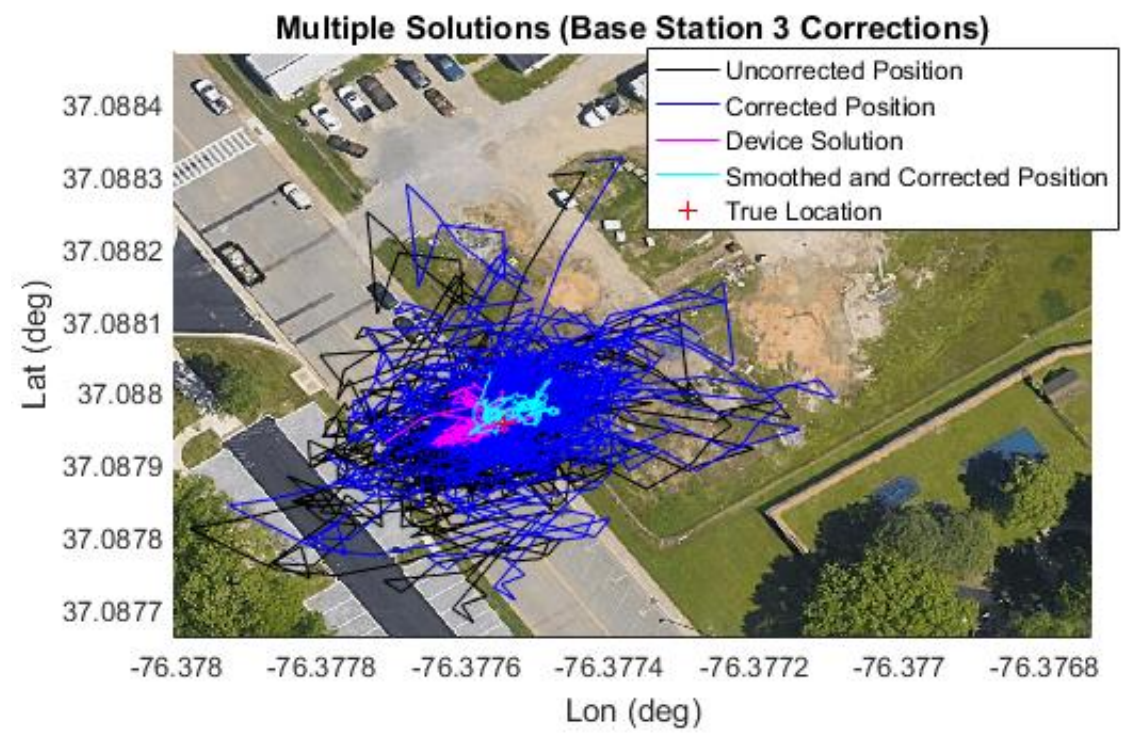

Figure 43. Graph of Solutions for Location 5.

These results are summarized in Table 17 where is can be seen that the corrections reduce the average lateral error while having little impact on the standard deviation. Both the average lateral error and standard deviation are further reduced by the application of carrier smoothing. The average lateral error of the final smoothed and corrected solution is improved by about a meter over the device solution with the standard deviation being comparable.

Table 17. Summary of Results for Location 5.

\begin{tabular}{|c|c|c|c|c|c|c|c|}
\hline \multicolumn{2}{|c|}{ Uncorrected Solution } & \multicolumn{2}{c|}{ Corrected Solution } & \multicolumn{2}{c|}{ Device Solution } & \multicolumn{2}{c|}{$\begin{array}{c}\text { Smoothed and } \\
\text { Corrected Solution }\end{array}$} \\
\hline $\begin{array}{c}\text { Average } \\
\text { Lateral } \\
\text { Error }\end{array}$ & $\begin{array}{c}\text { Standard } \\
\text { Deviation }\end{array}$ & $\begin{array}{c}\text { Average } \\
\text { Lateral } \\
\text { Error }\end{array}$ & $\begin{array}{c}\text { Standard } \\
\text { Deviation }\end{array}$ & $\begin{array}{c}\text { Average } \\
\text { Lateral } \\
\text { Error }\end{array}$ & $\begin{array}{c}\text { Standard } \\
\text { Deviation }\end{array}$ & $\begin{array}{c}\text { Average } \\
\text { Lateral } \\
\text { Error }\end{array}$ & $\begin{array}{c}\text { Standard } \\
\text { Deviation }\end{array}$ \\
\hline & North: & & North: & & North: & & North: \\
$3.976 \mathrm{~m}$ & $7.900 \mathrm{~m}$ & \multirow{2}{*}{$2.339 \mathrm{~m}$} & $7.907 \mathrm{~m}$ & $3.673 \mathrm{~m}$ & $\begin{array}{c}1.942 \mathrm{~m} \\
\text { East: }\end{array}$ & $2.640 \mathrm{~m}$ & $\begin{array}{c}1.504 \mathrm{~m} \\
\text { East: }\end{array}$ \\
& $\begin{array}{c}\text { East: } \\
9.440 \mathrm{~m}\end{array}$ & & $9.460 \mathrm{~m}$ & & $2.537 \mathrm{~m}$ & & $2.800 \mathrm{~m}$ \\
\hline
\end{tabular}




\subsubsection{Location 6}

The application of the satellite filter for location 6 removes several satellites that were not consistently tracked. This reduces the average lateral error while increasing the standard deviation in the north direction. The application of carrier smoothing for this location reduces the standard deviation while minimally impacting the average lateral error. These results can be seen in Figure 44. 

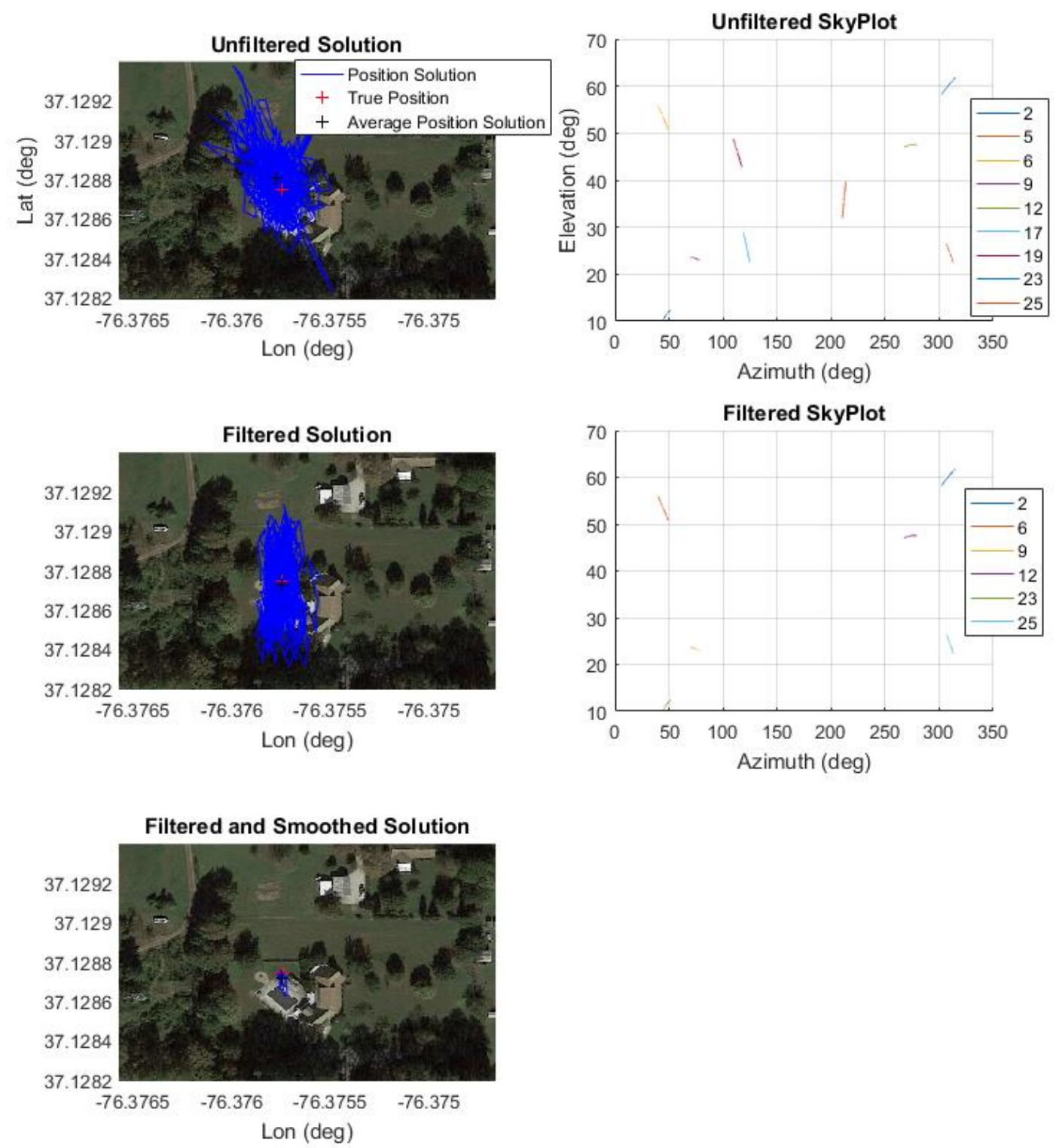

Figure 44. Graphs Depicting Solutions and Skyplots for Location 6.

In Table 18 it can be seen that the satellite filter reduces the average lateral error while decreasing the standard deviation in the east direction and increasing the standard 
deviation in the north direction. The application of carrier smoothing slightly increases the average lateral error while decreasing the standard deviation.

Table 18. Average Lateral Error and Standard Deviation of Solutions for Location 6.

\begin{tabular}{|c|c|c|c|c|c|}
\hline \multicolumn{2}{|c|}{ Unfiltered Solution } & \multicolumn{2}{|c|}{ Filtered Solution } & \multicolumn{2}{|c|}{$\begin{array}{c}\text { Filtered and } \\
\text { Smoothed Solution }\end{array}$} \\
\hline $\begin{array}{c}\text { Average } \\
\text { Lateral } \\
\text { Error }\end{array}$ & $\begin{array}{l}\text { Standard } \\
\text { Deviation }\end{array}$ & $\begin{array}{c}\text { Average } \\
\text { Lateral } \\
\text { Error }\end{array}$ & $\begin{array}{l}\text { Standard } \\
\text { Deviation }\end{array}$ & $\begin{array}{c}\text { Average } \\
\text { Lateral } \\
\text { Error }\end{array}$ & $\begin{array}{l}\text { Standard } \\
\text { Deviation }\end{array}$ \\
\hline $7.055 \mathrm{~m}$ & $\begin{array}{c}\text { North: } \\
14.347 \mathrm{~m} \\
\text { East: } \\
7.576 \mathrm{~m}\end{array}$ & $2.734 \mathrm{~m}$ & $\begin{array}{c}\text { North: } \\
16.370 \mathrm{~m} \\
\text { East: } \\
4.583 \mathrm{~m}\end{array}$ & $3.698 \mathrm{~m}$ & $\begin{array}{l}\text { North: } \\
3.274 \mathrm{~m} \\
\text { East: } \\
1.105 \mathrm{~m}\end{array}$ \\
\hline
\end{tabular}

Figure 45 depicts the solutions produced when corrections from the base stations are applied to the rover as well as their CMC residuals. The corrections from base station 1 result in the largest reduction in the average lateral error. 

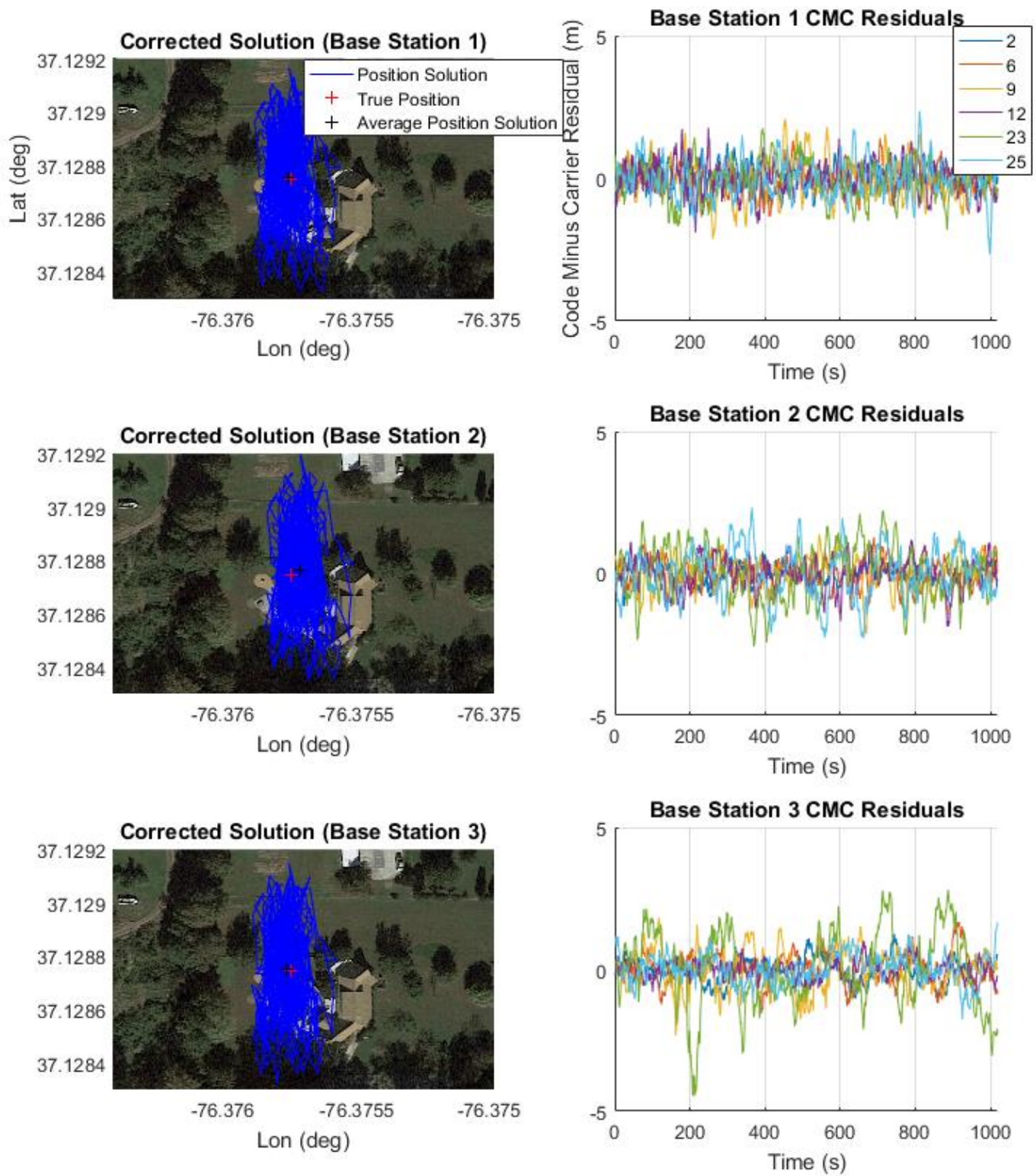

Figure 45. Solutions Produced Using Corrections for Location 6.

This is confirmed in Table 19 where is can be seen that base station 1 has the lowest sum of standard deviation of the CMC residuals during this time, resulting in the solution 
with the lowest average lateral error. The standard deviation produced using the three sets of corrections also has little variation.

Table 19. Base Station Correction Results for Location 6.

\begin{tabular}{|c|c|c|c|}
\hline & \multicolumn{3}{|c|}{ Corrected Solutions } \\
\hline & $\begin{array}{c}\text { Average } \\
\text { Lateral } \\
\text { Error }\end{array}$ & $\begin{array}{l}\text { Standard } \\
\text { Deviation }\end{array}$ & $\begin{array}{c}\text { Sum of } \\
\text { STD } \\
\text { CMC } \\
\text { Residuals } \\
\end{array}$ \\
\hline $\begin{array}{c}\text { Station } \\
1\end{array}$ & $1.577 \mathrm{~m}$ & $\begin{array}{c}\text { North: } \\
16.331 \mathrm{~m} \\
\text { East: } \\
4.640 \mathrm{~m}\end{array}$ & $3.379 \mathrm{~m}$ \\
\hline $\begin{array}{c}\text { Station } \\
2\end{array}$ & $3.080 \mathrm{~m}$ & $\begin{array}{c}\text { North: } \\
16.691 \mathrm{~m} \\
\text { East: } \\
4.654 \mathrm{~m}\end{array}$ & $3.742 \mathrm{~m}$ \\
\hline $\begin{array}{c}\text { Station } \\
\mathbf{3}\end{array}$ & $1.978 \mathrm{~m}$ & $\begin{array}{c}\text { North: } \\
16.356 \mathrm{~m} \\
\text { East: } \\
4.612 \mathrm{~m}\end{array}$ & $3.833 \mathrm{~m}$ \\
\hline
\end{tabular}

The uncorrected, corrected, and smoothed and corrected rover solutions are compared against the device solution and the true surveyed location in Figure 46. 


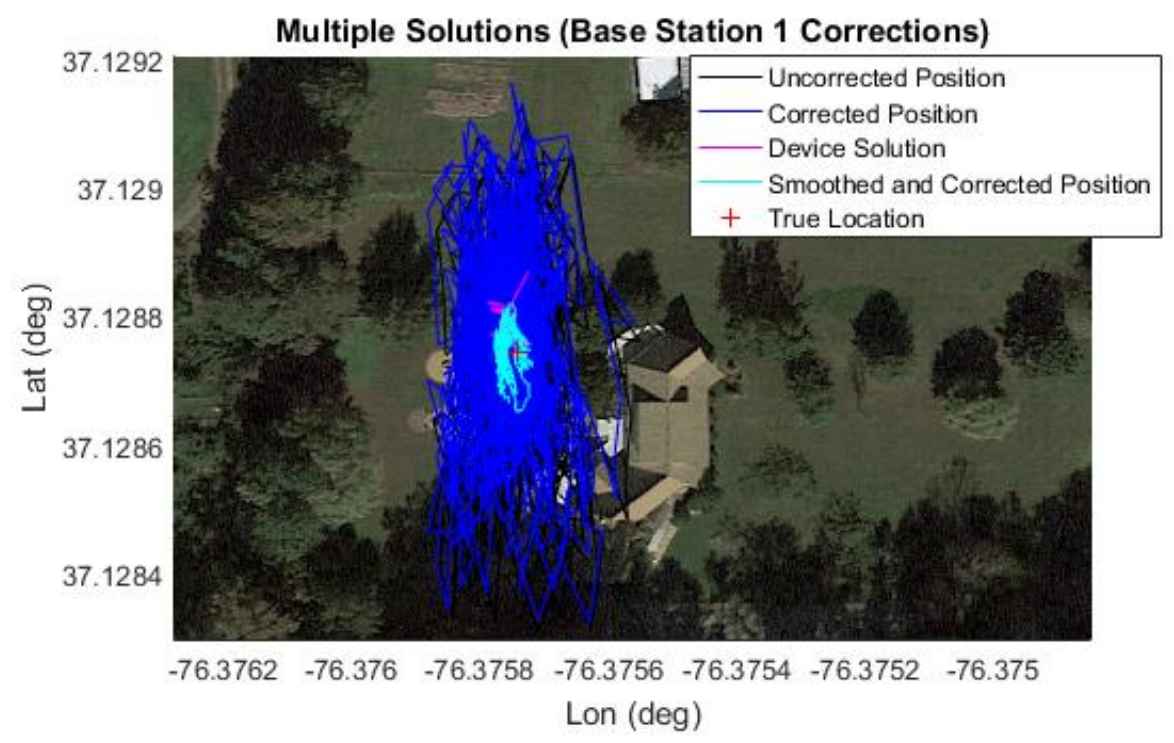

Figure 46. Graph of Solutions for Location 6.

These results are summarized in Table 20. It can be seen that the application of corrections from the base station with the lowest sum of standard deviation of the CMC residuals on its measurements reduces the average lateral error while having a minimal impact on the standard deviation. The application of carrier smoothing further reduces both the average lateral error and standard deviation of the solution. The average lateral error of the smoothed and corrected solution is lower than the device solution's by about 4 meters. 
Table 20. Summary of Results for Location 6.

\begin{tabular}{|c|c|c|c|c|c|c|c|}
\hline \multicolumn{2}{|c|}{ Uncorrected Solution } & \multicolumn{2}{|c|}{ Corrected Solution } & \multicolumn{2}{|c|}{ Device Solution } & \multicolumn{2}{|c|}{$\begin{array}{c}\text { Smoothed and } \\
\text { Corrected Solution }\end{array}$} \\
\hline $\begin{array}{c}\text { Average } \\
\text { Lateral } \\
\text { Error }\end{array}$ & $\begin{array}{l}\text { Standard } \\
\text { Deviation }\end{array}$ & $\begin{array}{c}\text { Average } \\
\text { Lateral } \\
\text { Error }\end{array}$ & $\begin{array}{l}\text { Standard } \\
\text { Deviation }\end{array}$ & $\begin{array}{c}\text { Average } \\
\text { Lateral } \\
\text { Error } \\
\end{array}$ & $\begin{array}{l}\text { Standard } \\
\text { Deviation }\end{array}$ & $\begin{array}{c}\text { Average } \\
\text { Lateral } \\
\text { Error }\end{array}$ & $\begin{array}{l}\text { Standard } \\
\text { Deviation }\end{array}$ \\
\hline $2.734 \mathrm{~m}$ & $\begin{array}{l}\text { North: } \\
16.370 \mathrm{~m} \\
\text { East: } \\
4.583 \mathrm{~m}\end{array}$ & $1.577 \mathrm{~m}$ & $\begin{array}{l}\text { North: } \\
16.331 \mathrm{~m} \\
\text { East: } \\
4.640 \mathrm{~m}\end{array}$ & $4.855 \mathrm{~m}$ & $\begin{array}{c}\text { North: } \\
3.064 \mathrm{~m} \\
\text { East: } \\
1.303 \mathrm{~m}\end{array}$ & $0.962 \mathrm{~m}$ & $\begin{array}{c}\text { North: } \\
3.622 \mathrm{~m} \\
\text { East: } \\
1.228 \mathrm{~m}\end{array}$ \\
\hline
\end{tabular}

\subsection{Mobile Results}

\subsubsection{Location 1}

For this location, no measurements were removed in the satellite filter as no inconsistencies in tracking were observed. The application of carrier smoothing greatly reduces the standard deviation of the solution while reducing the average lateral error as can be seen in Figure 47. 

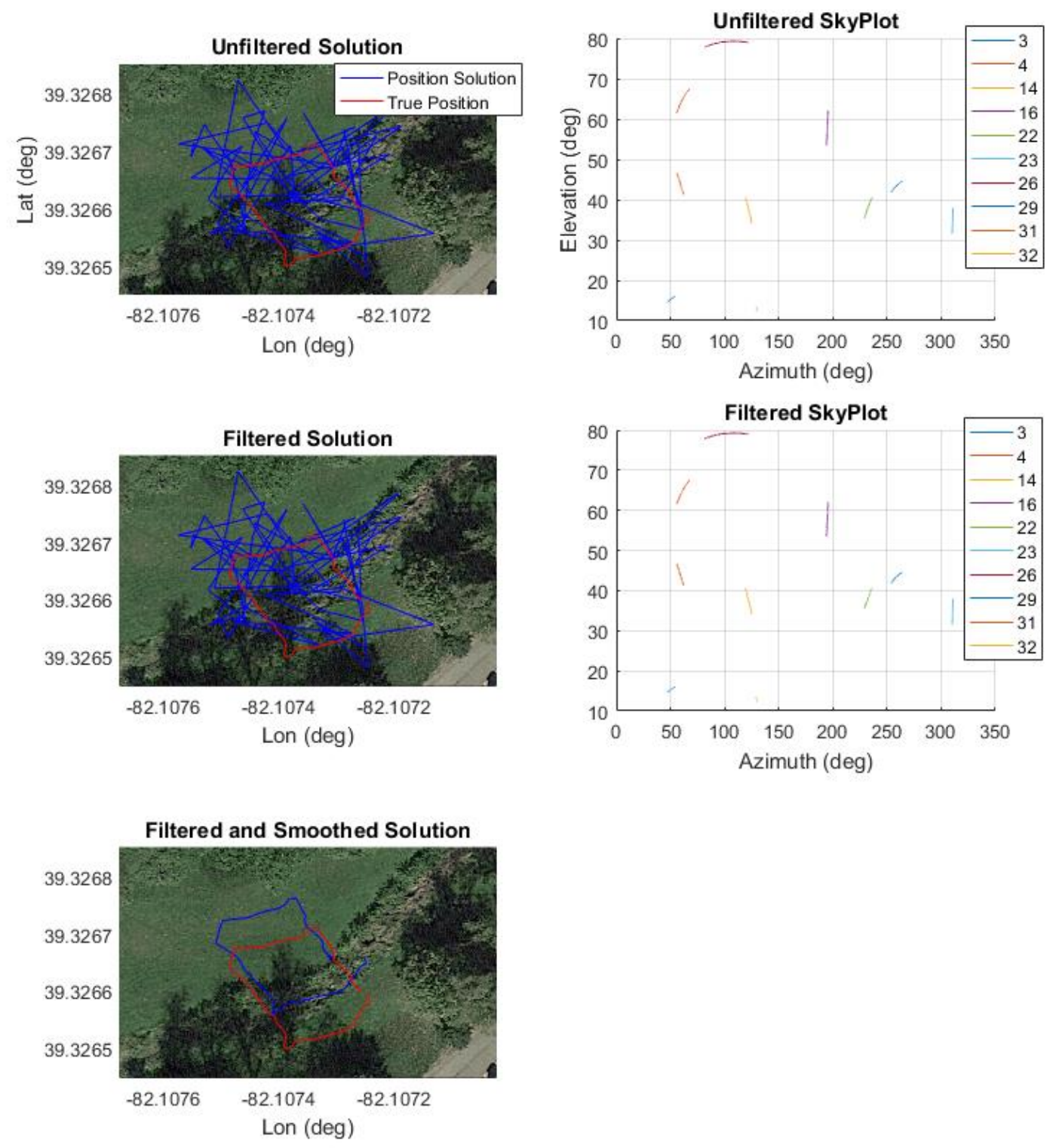

Figure 47. Graphs Depicting Solutions and Skyplots for Location 1.

These results are summarized in Table 21 where it can be seen that, that there is no change in the average lateral error and standard deviation between the filtered and 
unfiltered solutions as no satellite measurements were removed. The application of carrier smoothing reduces the average lateral error and greatly improves the standard deviation of the solution.

Table 21. Average Lateral Error and Standard Deviation of Solutions for Location 1.

\begin{tabular}{|c|c|c|c|c|c|}
\hline \multicolumn{2}{|c|}{ Unfiltered Solution } & \multicolumn{2}{c|}{ Filtered Solution } & \multicolumn{2}{c|}{$\begin{array}{c}\text { Filtered and } \\
\text { Smoothed Solution }\end{array}$} \\
\hline $\begin{array}{c}\text { Average } \\
\text { Lateral } \\
\text { Error }\end{array}$ & $\begin{array}{c}\text { Standard } \\
\text { Deviation }\end{array}$ & $\begin{array}{c}\text { Average } \\
\text { Lateral } \\
\text { Error }\end{array}$ & $\begin{array}{c}\text { Standard } \\
\text { Deviation }\end{array}$ & $\begin{array}{c}\text { Average } \\
\text { Lateral } \\
\text { Error }\end{array}$ & $\begin{array}{c}\text { Standard } \\
\text { Deviation }\end{array}$ \\
\hline & North: & & North: & & North: \\
$9.648 \mathrm{~m}$ & $7.605 \mathrm{~m}$ & $9.648 \mathrm{~m}$ & $7.605 \mathrm{~m}$ & $6.794 \mathrm{~m}$ & $0.652 \mathrm{~m}$ \\
& East: & & East: & & East: \\
& $6.154 \mathrm{~m}$ & & $6.154 \mathrm{~m}$ & & $1.039 \mathrm{~m}$ \\
\hline
\end{tabular}

The corrected solution and the CMC residuals for the base station can be seen in Figure 51 where the corrections result in an offset of the solution and the CMC residuals appear to be low relative to previous locations.
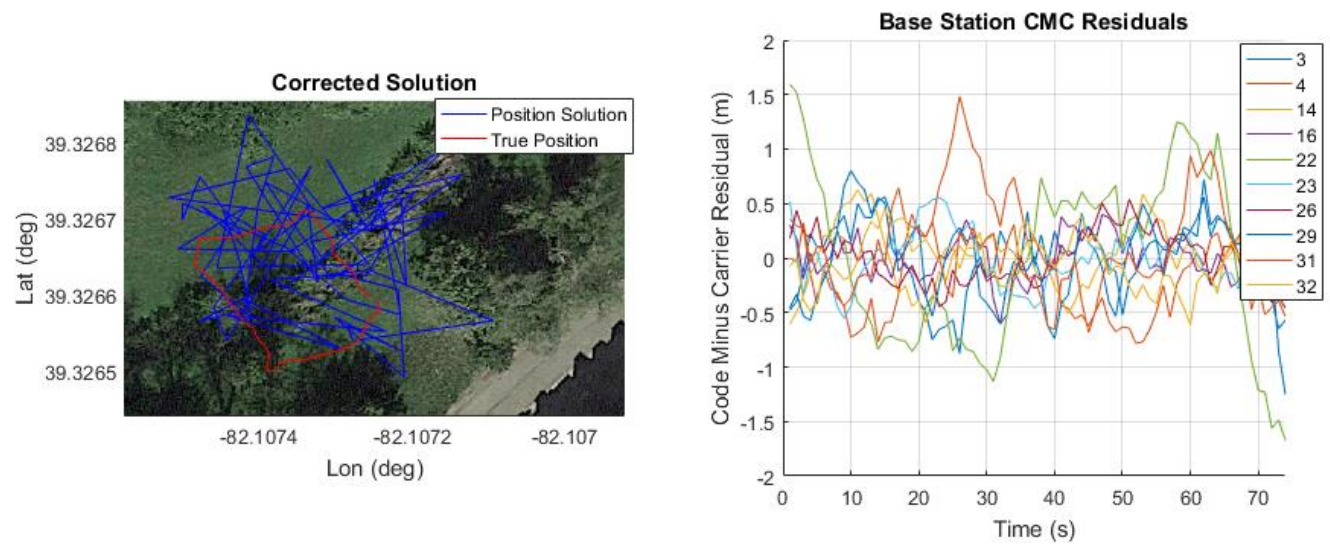

Figure 48. Solutions Produced Using Corrections for Location 1. 
These results are shown in Table 22 where it can be seen that the application of corrections results in an increase in the average lateral error. This is possibly due to the uncommon multipath on the measurements of the rover.

\section{Table 22. Base Station Correction Results for Location 1.}

\begin{tabular}{|c|c|c|}
\hline \multicolumn{3}{|c|}{ Corrected Solution } \\
\hline $\begin{array}{c}\text { Average } \\
\text { Lateral } \\
\text { Error }\end{array}$ & $\begin{array}{c}\text { Standard } \\
\text { Deviation }\end{array}$ & $\begin{array}{c}\text { Sum of } \\
\text { STD } \\
\text { CMC } \\
\text { Residuals }\end{array}$ \\
\hline & North: & \\
$10.190 \mathrm{~m}$ & $7.528 \mathrm{~m}$ & $3.688 \mathrm{~m}$ \\
& East: & \\
\hline & $6.343 \mathrm{~m}$ & \\
\hline
\end{tabular}

The solution produced using corrections from the base station is compared to the filtered but uncorrected solution as well as the solution produced by the device as shown in Figure 52.

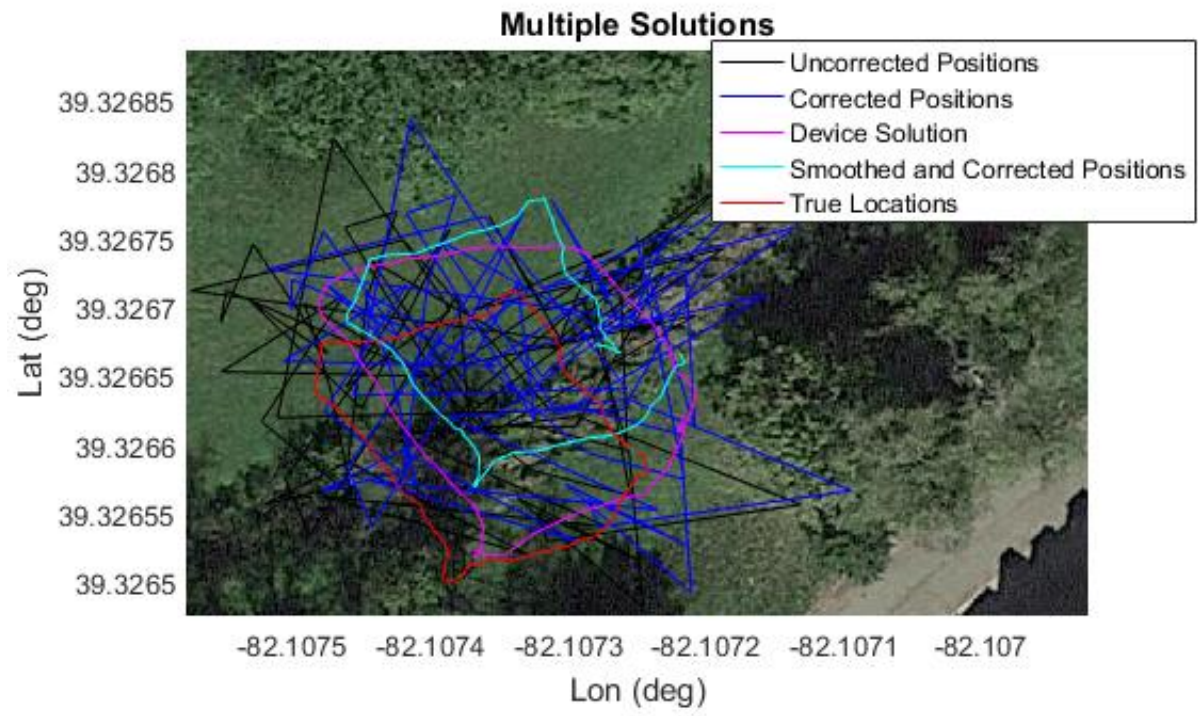

Figure 49. Graph of Solutions for Location 1. 
These results are summarized in Table 23 where it can be seen that the corrections introduce additional error on the average lateral error while having little impact on the standard deviation. The application of carrier smoothing reduces the average lateral error and standard deviation. The average lateral error of the smoothed and corrected solution is larger than that of the device solution by about 2.5 meters. However, the standard deviation of the smoothed and corrected solution is smaller than that of the device solution. This is likely due to multipath and signal scattering at the rover that is not common to the base stations as well as other techniques used by the device receiver.

Table 23. Summary of Results for Location 1.

\begin{tabular}{|c|c|c|c|c|c|c|c|}
\hline \multicolumn{2}{|c|}{ Uncorrected Solution } & \multicolumn{2}{|c|}{ Corrected Solution } & \multicolumn{2}{|c|}{ Device Solution } & \multicolumn{2}{|c|}{$\begin{array}{c}\text { Smoothed and } \\
\text { Corrected Solution }\end{array}$} \\
\hline $\begin{array}{c}\text { Average } \\
\text { Lateral } \\
\text { Error } \\
\end{array}$ & $\begin{array}{l}\text { Standard } \\
\text { Deviation }\end{array}$ & $\begin{array}{c}\text { Average } \\
\text { Lateral } \\
\text { Error }\end{array}$ & $\begin{array}{l}\text { Standard } \\
\text { Deviation }\end{array}$ & $\begin{array}{c}\text { Average } \\
\text { Lateral } \\
\text { Error }\end{array}$ & $\begin{array}{l}\text { Standard } \\
\text { Deviation }\end{array}$ & $\begin{array}{c}\text { Average } \\
\text { Lateral } \\
\text { Error }\end{array}$ & $\begin{array}{l}\text { Standard } \\
\text { Deviation }\end{array}$ \\
\hline $9.648 \mathrm{~m}$ & $\begin{array}{l}\text { North: } \\
7.605 \mathrm{~m} \\
\text { East: } \\
6.154 \mathrm{~m}\end{array}$ & $10.190 \mathrm{~m}$ & $\begin{array}{l}\text { North: } \\
7.528 \mathrm{~m} \\
\text { East: } \\
6.343 \mathrm{~m}\end{array}$ & $5.293 \mathrm{~m}$ & $\begin{array}{l}\text { North: } \\
2.799 \mathrm{~m} \\
\text { East: } \\
2.328 \mathrm{~m}\end{array}$ & $7.796 \mathrm{~m}$ & $\begin{array}{l}\text { North: } \\
0.638 \mathrm{~m} \\
\text { East: } \\
1.199 \mathrm{~m}\end{array}$ \\
\hline
\end{tabular}




\subsubsection{Location 2}

For this location, the application of the satellite filter removes several satellites that were not consistently tracked. This appears to result in a minor reduction of both the standard deviation and average lateral error of the solution. The application of carrier smoothing greatly reduces the standard deviation and produces a solution that closely resembles the ground track of the true solution. These results are shown in Figure 50. 

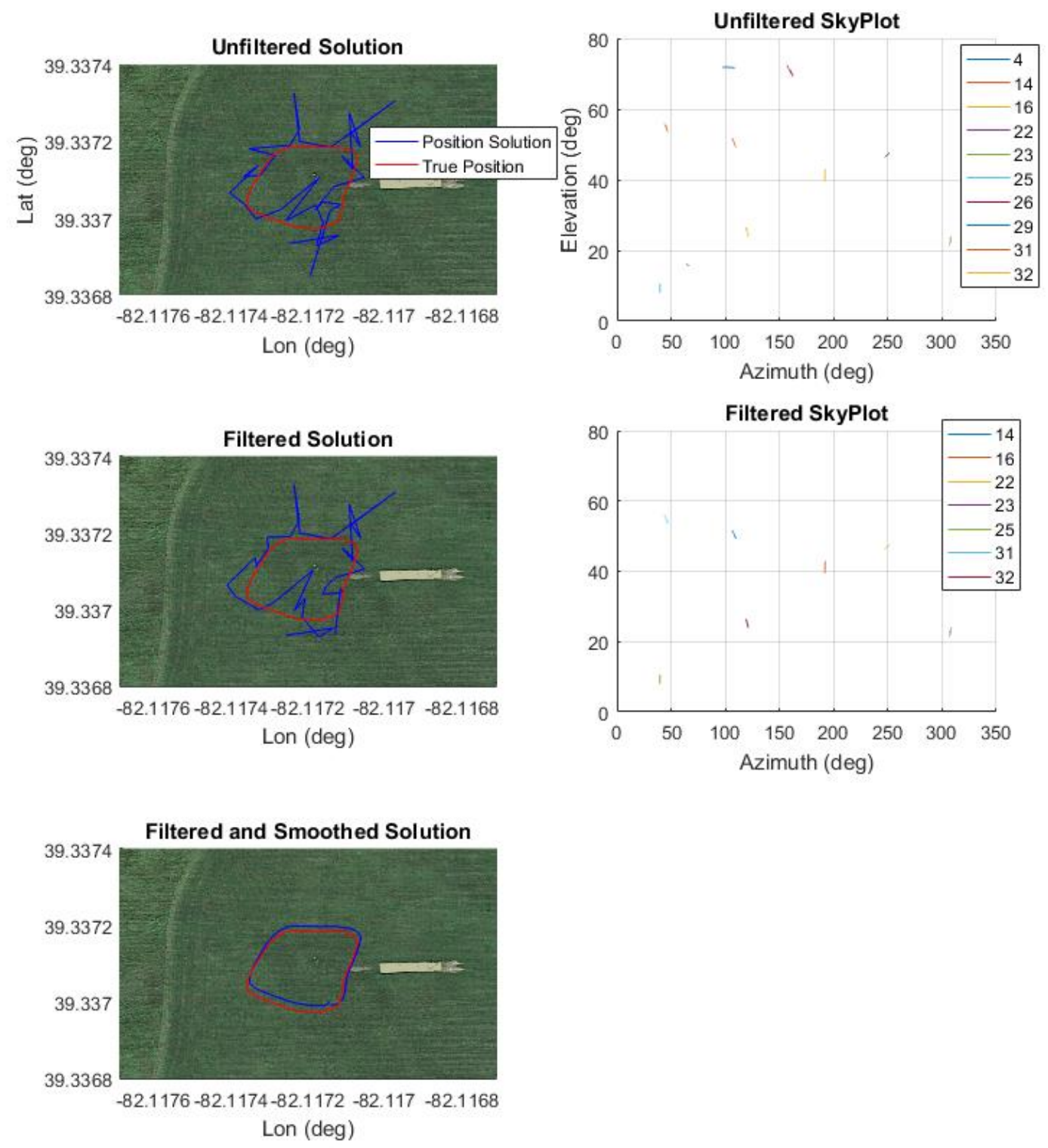

Figure 50. Graphs Depicting Solutions and Skyplots for Location 2.

These results are shown in Table 24 in where it can be seen that the satellite filter slightly reduces the average lateral error and standard deviation. The application of carrier 
smoothing greatly reduces the average lateral error and the standard deviation of the solution.

Table 24. Average Lateral Error and Standard Deviation of Solutions for Location 2.

\begin{tabular}{|c|c|c|c|c|c|}
\hline \multicolumn{2}{|c|}{ Unfiltered Solution } & \multicolumn{2}{c|}{ Filtered Solution } & \multicolumn{2}{c|}{$\begin{array}{c}\text { Filtered and } \\
\text { Smoothed Solution }\end{array}$} \\
\hline $\begin{array}{c}\text { Average } \\
\text { Lateral } \\
\text { Error }\end{array}$ & $\begin{array}{c}\text { Standard } \\
\text { Deviation }\end{array}$ & $\begin{array}{c}\text { Average } \\
\text { Lateral } \\
\text { Error }\end{array}$ & $\begin{array}{c}\text { Standard } \\
\text { Deviation }\end{array}$ & $\begin{array}{c}\text { Average } \\
\text { Lateral } \\
\text { Error }\end{array}$ & $\begin{array}{c}\text { Standard } \\
\text { Deviation }\end{array}$ \\
\hline & North: & & North: & & North: \\
& $5.838 \mathrm{~m}$ & $5.856 \mathrm{~m}$ & $5.140 \mathrm{~m}$ & $1.660 \mathrm{~m}$ & $0.345 \mathrm{~m}$ \\
East: & East: \\
& East: & & East: & & $0.169 \mathrm{~m}$ \\
\hline
\end{tabular}

The corrected solution along with the CMC residuals of the base station are shown in Figure 51. The application of the corrections results in an offset of the solution and the CMC residuals on the base station appear to be relatively low.
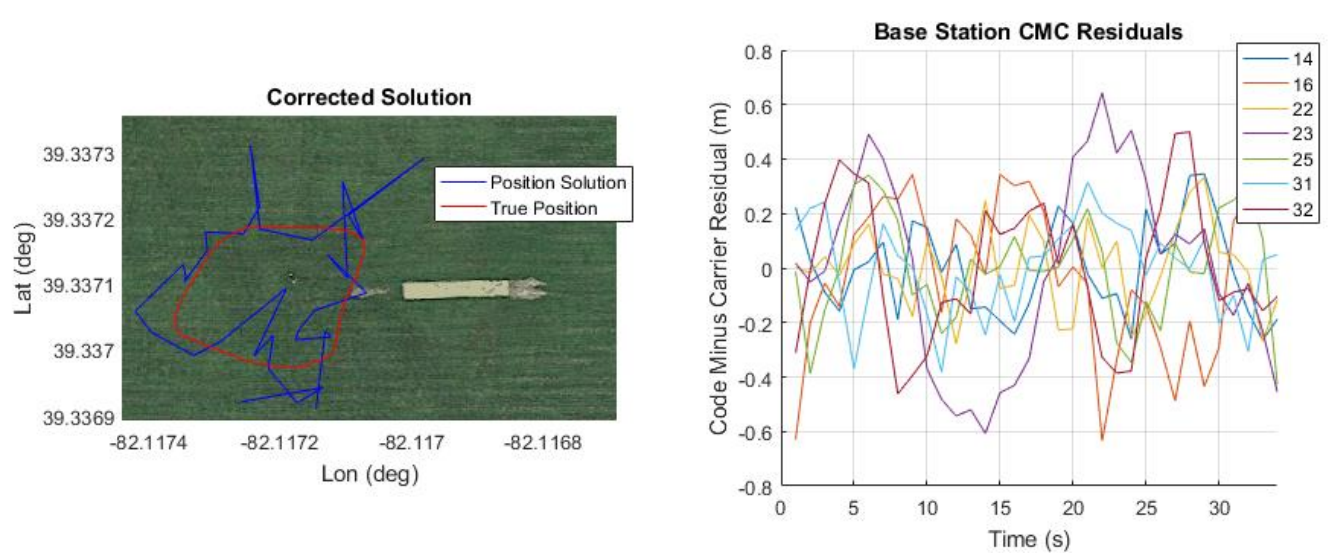

Figure 51. Solutions Produced Using Corrections Stations for Location 2.

Table 25 shows the summary of the results. There is a reduction in the average lateral error of the solution while there is little effect on the standard deviation. The sum of the standard deviation of the CMC residuals is low during this time. 
Table 25. Base Station Correction Results for Location 2.

\begin{tabular}{|c|c|c|}
\hline \multicolumn{3}{|c|}{ Corrected Solution } \\
\hline $\begin{array}{c}\text { Average } \\
\text { Lateral } \\
\text { Error }\end{array}$ & $\begin{array}{c}\text { Standard } \\
\text { Deviation }\end{array}$ & $\begin{array}{c}\text { Sum of } \\
\text { STD } \\
\text { CMC } \\
\text { Residuals }\end{array}$ \\
\hline & North: & \\
$5.306 \mathrm{~m}$ & $5.170 \mathrm{~m}$ & $1.621 \mathrm{~m}$ \\
& East: & $1.62 \mathrm{~m}$ \\
& $3.862 \mathrm{~m}$ \\
\hline
\end{tabular}

The results of the uncorrected, corrected, and smoothed and corrected rover solutions are compared against the device solution and the true surveyed location in Figure 52.

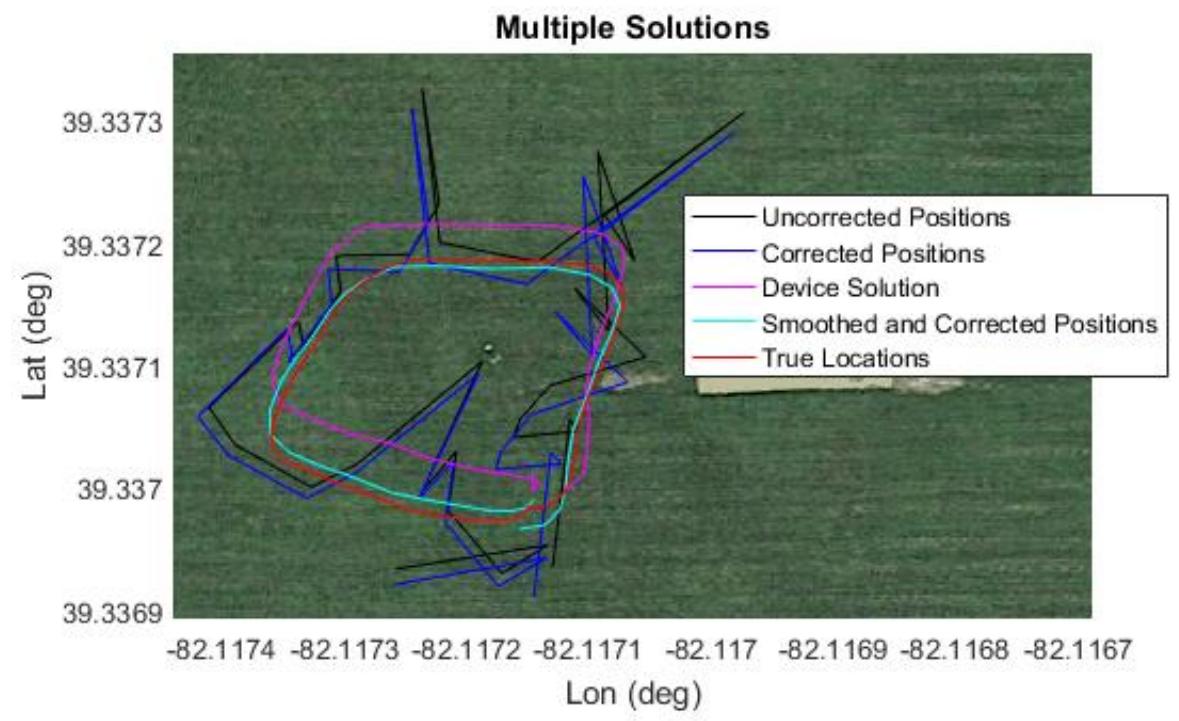

Figure 52. Graph of Solutions for Location 2.

Application of corrections results in a minor reduction of the average lateral error while there is little impact on the standard deviation. The application of carrier smoothing 
results in a further reduction of the standard deviation and the average lateral error. The average lateral error of the smoothed and corrected solution is about 4 meters less than that of the device solution's while the standard deviation of the two solutions is comparable.

These results are summarized in Table 26.

Table 26. Summary of Results for Location 2.

\begin{tabular}{|c|c|c|c|c|c|c|c|}
\hline \multicolumn{2}{|c|}{ Uncorrected Solution } & \multicolumn{2}{|c|}{ Corrected Solution } & \multicolumn{2}{|c|}{ Device Solution } & \multicolumn{2}{|c|}{$\begin{array}{c}\text { Smoothed and } \\
\text { Corrected Solution }\end{array}$} \\
\hline $\begin{array}{c}\text { Average } \\
\text { Lateral } \\
\text { Error }\end{array}$ & $\begin{array}{l}\text { Standard } \\
\text { Deviation }\end{array}$ & $\begin{array}{c}\text { Average } \\
\text { Lateral } \\
\text { Error } \\
\end{array}$ & $\begin{array}{l}\text { Standard } \\
\text { Deviation }\end{array}$ & $\begin{array}{c}\text { Average } \\
\text { Lateral } \\
\text { Error } \\
\end{array}$ & $\begin{array}{l}\text { Standard } \\
\text { Deviation }\end{array}$ & $\begin{array}{c}\text { Average } \\
\text { Lateral } \\
\text { Error } \\
\end{array}$ & $\begin{array}{l}\text { Standard } \\
\text { Deviation }\end{array}$ \\
\hline $5.856 \mathrm{~m}$ & $\begin{array}{l}\text { North: } \\
5.140 \mathrm{~m} \\
\text { East: } \\
3.846 \mathrm{~m}\end{array}$ & $5.306 \mathrm{~m}$ & $\begin{array}{l}\text { North: } \\
5.170 \mathrm{~m} \\
\text { East: } \\
3.862 \mathrm{~m}\end{array}$ & $4.220 \mathrm{~m}$ & $\begin{array}{c}\text { North: } \\
0.674 \mathrm{~m} \\
\text { East: } \\
2.090 \mathrm{~m}\end{array}$ & $1.042 \mathrm{~m}$ & $\begin{array}{l}\text { North: } \\
1.088 \mathrm{~m} \\
\text { East: } \\
0.321 \mathrm{~m}\end{array}$ \\
\hline
\end{tabular}




\section{CHAPTER 6: CONCLUSION}

For each of the stationary locations, it can be seen that when corrections are applied from the base station with the lowest sum of CMC residuals, a position with the lowest error among the three possibilities is produced. This solution also had an error lower than the uncorrected error for all but one of the locations. The application of differential corrections primarily results in a shifting of the solution with minimal impact on the standard deviation of the solution at each location. This is likely due to the high receiver noise on the pseudorange measurements that would not be present in the pseudorange corrections from the base stations. The implementation of carrier smoothing greatly reduced the standard deviation for all of the locations. The smoothed and corrected solution has a lower average lateral error when compared against the device solution for all but 2 of the locations tested. This solution had a comparable, and in some cases improved standard deviation when compared to the device solution.

For the mobile locations, a reduction in both the average lateral error and standard deviation were seen in the corrected and smoothed solution for location 2 and the resulting solution closely resembled the solution produced by the truth reference. However, for location 1 , while the standard deviation was reduced, the smoothed and corrected solution appeared to introduce some additional error into the solution. This is likely due to signal scattering and multipath at this location.

These results are summarized below in Table 27 showing the improvement of the smoothed in corrected solution over the device chipset solution for each of the locations tested. 
Table 27. Average Lateral Error Improvements.

\begin{tabular}{|c|c|c|c|c|c|c|c|c|}
\hline & \multicolumn{5}{|c|}{ Stationary Locations } & \multicolumn{2}{c|}{ Mobile Locations } \\
\cline { 2 - 9 } & $\begin{array}{c}\mathbf{1} \\
\text { (Urban) }\end{array}$ & $\begin{array}{c}\mathbf{2} \\
\text { (Suburban) }\end{array}$ & $\begin{array}{c}\mathbf{3} \\
\text { (Rural) }\end{array}$ & $\begin{array}{c}\mathbf{4} \\
\text { (Urban) }\end{array}$ & $\begin{array}{c}\mathbf{5} \\
\text { (Rural) }\end{array}$ & $\begin{array}{c}\mathbf{6} \\
\text { (Suburban) }\end{array}$ & $\begin{array}{c}\mathbf{1} \\
\text { (Urban) }\end{array}$ & $\begin{array}{c}\mathbf{2} \\
\text { (Rural) }\end{array}$ \\
\hline $\begin{array}{c}\text { Improvement } \\
\text { Over Device } \\
\text { Solution }\end{array}$ & $-3.411 \mathrm{~m}$ & $1.241 \mathrm{~m}$ & $1.319 \mathrm{~m}$ & $-1.023 \mathrm{~m}$ & $1.033 \mathrm{~m}$ & $3.893 \mathrm{~m}$ & $-2.502 \mathrm{~m}$ & $3.178 \mathrm{~m}$ \\
\hline
\end{tabular}

For the stationary experiments, there was an average improvement of $1.178 \mathrm{~m}$ for the rural areas, $2.567 \mathrm{~m}$ for the suburban areas, and $-2.217 \mathrm{~m}$ for the urban areas. For the mobile experiments, there was a $3.178 \mathrm{~m}$ improvement for the rural area and a -2.502 improvement for the urban area. From these results, it can be seen that while the application or smoothing and corrections appears to work well in open, minimally obstructive areas (rural and suburban areas), it fails to reach the same level of improvement in more obstructive environments (urban areas) when compared against the mobile device solution.

In general, these processing techniques, carrier smoothing and differential corrections, appear to improve the average lateral error and standard deviation of the position of the rover while operating in open and moderately open environments. The application of carrier smoothing is successful at reducing the standard deviation of the error in all cases tested. However, there appears to be degradation in the lateral average error when corrections are utilized while operating in highly obstructed areas. 


\section{CHAPTER 7: FUTURE WORK}

While this thesis focused on the effects of differential corrections on embedded GPS receivers in a post-processing manner, additional techniques could be applied as well. The carrier phase measurements captured on both the base station and the rover could be used to evaluate the performance of a Real-Time Kinematic technique either as a postprocessed or real time solution. Currently, while most embedded receivers do not have the capability of capturing the carrier phase measurements required for this technique, it is anticipated that newer generation devices will.

While the application of differential corrections was successful in reducing common errors between the receiver and base station, this solution had reduced efficacy in obstructive environments. The effects of removing satellites found to have highly variable CMC values will be investigated in an effort to further reduce error. Additionally, more work will be done to automate the selection of the base station and processing of the solution. Lastly, an analysis of integrity and performance issue, specifically the assessment and mitigation of errors due to operating in obstructive environments and reduced satellite availability, will be performed. 


\section{REFERENCES}

[1] M. Balaban, T. Mastaglio and C. Lynch, "Analysis of future UAS-based delivery", 2016 Winter Simulation Conference (WSC), 2016.

[2] L. Lee, M. Jones, G. Ridenour, S. Bennett, A. Majors, B. Melito and M. Wilson, "Comparison of Accuracy and Precision of GPS-Enabled Mobile Devices", 2016 IEEE International Conference on Computer and Information Technology (CIT), 2016.

[3] S. Banville and F. Diggelen, "Innovation: Precise positioning using raw GPS measurements from Android smartphones", Gpsworld.com, 2016. [Online]. Available: http://gpsworld.com/innovation-precise-positioning-using-raw-gpsmeasurements-from-android-smartphones/.

[4] M. Matosevic, Z. Salcic and S. Berber, "A Comparison of Accuracy Using a GPS and a Low-Cost DGPS", IEEE Transactions on Instrumentation and Measurement, vol. 55, no. 5, pp. 1677-1683, 2006.

[5] R. Gilabert, E. Dill and M. Uijt de Haag, "Location corrections through differential networks (LOCD-IN)", 2018 IEEE/ION Position, Location and Navigation Symposium (PLANS), 2018.

[6] P. Misra and P. Enge, Global Positioning System. Lincoln, Massachusetts: GangaJamuna Press, 2012.

[7] Gps.gov, 2018. [Online]. Available: https://www.gps.gov/multimedia/images/constellation.jpg.

[8] "GPS.gov: New Civil Signals", Gps.gov, 2018. [Online]. Available: https://www.gps.gov/systems/gps/modernization/civilsignals/.

[9] "GNSS-750 Wideband Choke Ring Antenna", Novatel.com. [Online]. Available: https://www.novatel.com/products/gnss-antennas/fixed-reference-gnssantennas/gnss-750/.

[10] M. Grewal, A. Andrews and C. Bartone, Global Navigation Satellite Systems, Inertial Navigation, and Integration, Third Edition. Hoboken, N.J.: John Wiley \& Sons, 2013.

[11] "Satellite Navigation - GPS - Policy - Selective Availability", Faa.gov, 2018. [Online]. Available:

https://www.faa.gov/about/office_org/headquarters_offices/ato/service_units/tech ops/navservices/gnss/gps/policy/availability/. 
[12] "GPS.gov: Augmentation Systems", Gps.gov, 2018. [Online]. Available: https://www.gps.gov/systems/augmentations/.

[13] "Satellite Navigation — Ground Based Augmentation System (GBAS)", Faa.gov, 2018. [Online]. Available:

https://www.faa.gov/about/office_org/headquarters_offices/ato/service_units/tech ops/navservices/gnss/laas/.

[14] "Satellite Navigation - Wide Area Augmentation System (WAAS)", Faa.gov, 2018. [Online]. Available:

https://www.faa.gov/about/office_org/headquarters_offices/ato/service_units/tech ops/navservices/gnss/waas/.

[15] "NDGPS General Information", Navcen.uscg.gov, 2018. [Online]. Available: https://www.navcen.uscg.gov/?pageName=dgpsMain.

[16] "OmniSTAR > Support > FAQs", Omnistar.com. [Online]. Available: http://www.omnistar.com/Support/FAQs.aspx.

[17] "Continuously Operating Reference Station (CORS) - National Geodetic Survey", Geodesy.noaa.gov, 2018. [Online]. Available: https://geodesy.noaa.gov/CORS/.

[18] S. Riley, H. Landau, V. Gomez, N. Mishukova, W. Lentz and A. Clare, "Positioning with Android: GNSS observables", Gpsworld.com, 2018. [Online]. Available: http://gpsworld.com/positioning-with-android-gnss-observables/.

[19] R. Hatch, "The synergism of GPS code and carrier measurements", in International Geodetic Symposium on Satellite Doppler Positioning, Las Cruces, 1983, pp. 1213-1231.

[20] J. Dickman, C. Bartone, Y. Zhang and B. Thornburg, "Characterization and Performance of a Prototype Wideband Airport Pseudolite Multipath Limiting Antenna for the Local Area Augmentation System", in Proceedings of the 2003 National Technical Meeting of The Institute of Navigation, Anaheim, CA, 2003, pp. 783 - 793.

[21] "Raw GNSS Measurements | Android Developers", Developer.android.com, 2018. [Online]. Available: https://developer.android.com/guide/topics/sensors/gnss.

[22] "Nexus 9 Teardown", Ifixit.com. [Online]. Available: https://www.ifixit.com/Teardown/Nexus+9+Teardown/31425.

[23] "Buy the Nexus 9", Htc.com, 2018. [Online]. Available: https://www.htc.com/us/go/buy-now-nexus-9/.

[24] "BCM4752", Broadcom.com, 2018. [Online]. Available: https://www.broadcom.com/products/wireless/gnss-gps-socs/bcm4752. 
[25] "C94-M8P", U-blox.com, 2018. [Online]. Available: https://www.ublox.com/en/product/c94-m8p.

[26] U-blox.com. [Online]. Available: https://www.ublox.com/sites/default/files/styles/product_full/public/products/C94-M8P-4CI.png?itok=HwDF9eG7.

[27] Swiftnav.com, 2018. [Online]. Available: https://www.swiftnav.com/resourcefiles/GNSS\%20Antenna/v1.0.1/Specification/SwiftNav\%20Mini\%20Survey\%20 Antenna\%20GPS500\%20Specifications\%20v1.0.1.pdf.

[28] "GNSS Antenna Pack", Swiftnav.com. [Online]. Available: https://www.swiftnav.com/store/accessories/gnss-antenna-pack.

[29] "Raspberry Pi 3 Model B - Raspberry Pi", Raspberrypi.org, 2018. [Online]. Available: https://www.raspberrypi.org/products/raspberry-pi-3-model-b/.

[30] Raspberrypi.org. [Online]. Available: https://www.raspberrypi.org/app/uploads/2018/03/770A5842-462x322.jpg.

[31] Dl.ubnt.com. [Online]. Available: https://dl.ubnt.com/datasheets/nanostationm/nsm_ds_web.pdf.

[32] "NanoStation Loco M5", Store.ubnt.com. [Online]. Available: https://store.ubnt.com/collections/wireless/products/nanolocom5.

[33] Dl.ubnt.com. [Online]. Available: https://dl.ubnt.com/datasheets/rocketm/RocketM_DS.pdf.

[34] "Rocket M5", Store.ubnt.com. [Online]. Available: https://store.ubnt.com/collections/wireless/products/rocket-m5.

[35] Cddis.nasa.gov. [Online]. Available: https://cddis.nasa.gov/Data_and_Derived_Products/GNSS/broadcast_ephemeris_ data.html.

[36] Novatel.com. [Online]. Available: https://www.novatel.com/assets/Documents/Papers/GPS-701_702-GGL.pdf.

[37] Novatel.com. [Online]. Available: https://www.novatel.com/assets/Documents/Papers/OEM615.pdf.

[38] Tallysman.com. [Online]. Available: http://www.tallysman.com/wpcontent/uploads/TW3870-TW3872_Datasheet_rev4_3.pdf.

[39] "Precise Point Positioning", Webapp.geod.nrcan.gc.ca. [Online]. Available: https://webapp.geod.nrcan.gc.ca/geod/tools-outils/ppp.php?locale=en. 


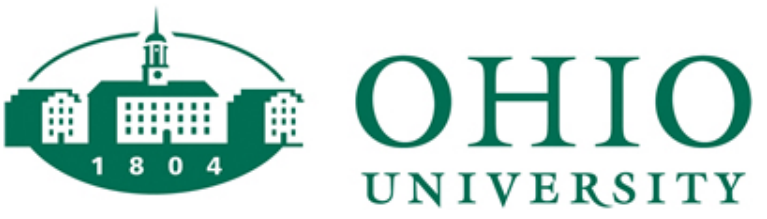

Thesis and Dissertation Services 